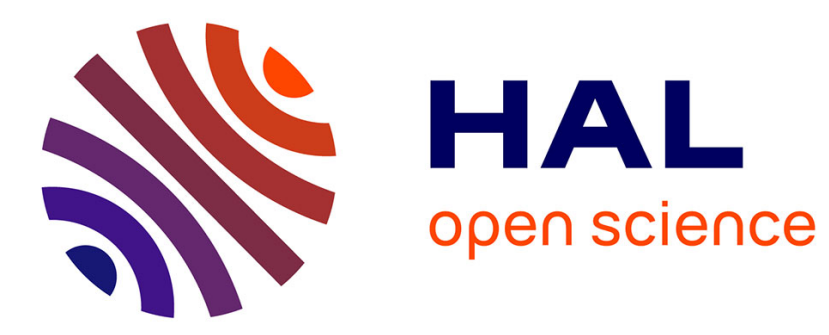

\title{
Les rites annuels de la maison et des communautés locales en transformation: intérieur et extérieur des lieux de vie communautaires
}

Anne Bouchy, Toshiko Ishikawa

\section{- To cite this version:}

Anne Bouchy, Toshiko Ishikawa. Les rites annuels de la maison et des communautés locales en transformation: intérieur et extérieur des lieux de vie communautaires. Cahiers d'Extrême-Asie, 2013, no. 22, p. 473-546. halshs-03134721

\section{HAL Id: halshs-03134721 \\ https://shs.hal.science/halshs-03134721}

Submitted on 8 Feb 2021

HAL is a multi-disciplinary open access archive for the deposit and dissemination of scientific research documents, whether they are published or not. The documents may come from teaching and research institutions in France or abroad, or from public or private research centers.
L'archive ouverte pluridisciplinaire HAL, est destinée au dépôt et à la diffusion de documents scientifiques de niveau recherche, publiés ou non, émanant des établissements d'enseignement et de recherche français ou étrangers, des laboratoires publics ou privés. 


\title{
Les rites annuels de la maison et des communautés locales en
} transformation : intérieur et extérieur des lieux de vie communautaires

\author{
Toshiko Ishikawa, Anne Bouchy
}

\begin{abstract}
The outside around the house (ie) is the local community (section, kumi, and area, ku), and the town of Sasaguri is composed of an aggregate of sections and areas. The present article studies the annual events of the town of Sasaguri, analyzing them according to three criteria that are places, actors and aims. Based on this analysis, the double dynamics between continuation and transformation in time, and inside and outside in space will be considered. There is also another outside in Sasaguri having impact on its inside, that is the pilgrims coming to visit its circuit of temples and oratories of the holy places of Shin-Shikoku (Shin-Shikoku reijō). The events inside houses are framed by the setting of special apparatus which convert their spaces from the everyday life (ke) to the festive (hare), and this setting tends to determine the events' actors and aims. Examining these particular moments of houses, it will be possible to shed light on the situation of contemporary families in this town. The participation of women has an important meaning in these annual events. On the other hand, events organized on the local community level have various relationships with regard to houses. Certain community events are held inside houses, imposing a big burden on women, so much so that the continuation of these events as well as that of the groups organizing them often depend on their availability. There are varying attempts being made in order to continue these events as far as possible.
\end{abstract}

\section{Citer ce document / Cite this document :}

Ishikawa Toshiko, Bouchy Anne. Les rites annuels de la maison et des communautés locales en transformation : intérieur et extérieur des lieux de vie communautaires. In: Cahiers d'Extrême-Asie, vol. 22, 2013. Le vivre ensemble à Sasaguri, une communauté de Kyūshū. Dans l'entrelacs des dynamiques du dedans et du dehors. pp. 473-546;

doi : https://doi.org/10.3406/asie.2013.1424

https://www.persee.fr/doc/asie_0766-1177_2013_num_22_1_1424

Fichier pdf généré le 06/02/2019 


\title{
LES RITES ANNUELS DE LA MAISON \\ ET DES COMMUNAUTÉS LOCALES EN TRANSFORMATION : INTÉRIEUR ET EXTÉRIEUR DES LIEUX DE VIE COMMUNAUTAIRES
}

\author{
IsHIKAwA Toshiko 石川稔子
}

\begin{abstract}
The outside around the bouse (ie 家) is the local community (section, kumi 組, and area, ku 区), and the town of Sasaguri is composed of an aggregate of sections and areas. The present article studies the annual events of the town of Sasaguri, analyzing them according to three criteria that are places, actors and aims. Based on this analysis, the double dynamics between continuation and transformation in time, and inside and outside in space will be considered. There is also another outside in Sasaguri having impact on its inside, that is the pilgrims coming to visit its circuit of temples and oratories of the holy places of Shin-Shikoku (Shin-Shikoku reijo 新四国霊場). The events inside houses are framed by the setting of special apparatus which convert their spaces from the everyday life (ke ケ) to the festive (hare Mレ), and this setting tends to determine the events' actors and aims. Examining these particular moments of houses, it will be possible to shed light on the situation of contemporary families in this town. The participation of women has an important meaning in these annual events. On the other hand, events organized on the local community level have various relationships with regard to bouses. Certain community events are held inside houses, imposing a big burden on women, so much so that the continuation of these events as well as that of the groups organizing them often depend on their availability. There are varying attempts being made in order to continue these events as far as possible.
\end{abstract}

Le mariage, les funérailles et toutes les célébrations de la vie individuelle entrent dans la catégorie des rites de la maison (ie XI $^{1}{ }^{1}$, de même que les rites annuels ou encore les ritualités relatives à la construction des bâtiments. C'est aux rites annuels que s'intéresse cette contribution. La raison en est que cette forme rituelle est répétée le même jour chaque année, ou se trouve incluse dans un cycle annuel fixé par le calendrier, ce qui en assure la transmission régulière, et par là, plus que toute autre ritualité, c'est un objet d'étude permettant d'éclairer de façon privilégiée les liens entre rites, maison et famille.

I. Comme c'est l'usage dans les études d'ethnologie du Japon, afin de distinguer la maisonhabitation (ie 家) et la maison-famille c'est-à-dire la maisonnée (ie イI) en tant que groupe socioéconomique, deux réalités qu'on désigne couramment par le même vocable (ie) et qu'on différencie par deux graphies différentes, est utilisée ici la graphie en kana (ie イI) pour désigner le groupe familial, et en français, le terme maison mis en italique. - Sur la "société à maison" (house society) définie par Claude Lévi-Strauss, voir Claude Lévi-Strauss, Paroles données, 1984, p. 189-194 ; Claude Lévi-Strauss, The Way of the Masks, 1982 ; et Elizabeth Fleury, éd., " Habiter la maison ", Terrain $\mathrm{n}^{\circ} 9$, numéro spécial (peut être téléchargé à l'adresse <http://terrain.revues.org/214>). (N.D.T.) 
«Maison (ie イエ) : terme polysémique, désignant un bâtiment d'habitation, un groupe familial fixé en un logement et lié par des relations de vie commune, ainsi que l'unité sociale transgénérationnelle ayant la famille comme support réel. » Telle est la définition du terme «ie » donnée par le Grand dictionnaire d'ethnologie du Japon $^{2}$. On retiendra donc ici que la maison est l'unité sociale constituée par une famille dont les membres, depuis plusieurs générations, cohabitent et vivent dans une même habitation, où se déroulent éventuellement leurs activités de subsistance. $\mathrm{Si}$, originellement, " maison » et " groupe familial résidant dans une même habitation » étaient de sens à peu près équivalents, avec le développement du travail saisonnier à l'extérieur, de l'emploi impliquant l'éloignement temporaire de la famille, de l'entrée des enfants dans des universités lointaines et de leur accès à l'emploi, la notion de maison en est venue à n'être plus limitée au groupe familial centré sur la cohabitation. C'est pourquoi j'ai choisi la maison-habitation comme cadre de base pour appréhender la question des transformations de la famille.

Dans un premier temps, enquêter sur les rites annuels m'avait semblé une approche efficace pour mettre en lumière les caractéristiques des pratiques culturelles et religieuses d'une communauté micro-locale. En effet, en 2008, dans le contexte d'un travail collectif visant la publication de l'historiographie de la commune de Kami-Yahagi 上矢作町 (Ena, département de Gifu 岐阜県恵那郡), j'avais pu mener à bien une enquête ethnographique sur les rites annuels pour le volume consacré aux faits coutumiers ${ }^{3}$. À Kami-Yahagi, de nombreux rites n'étaient déjà plus présents que dans les mémoires; néanmoins il m'a été possible de recueillir des témoignages précis pour la période allant de 1912 à 1950 (des années Taishō 大正 au début de Shōwa 昭和) en vue de cet ouvrage. Aussi ai-je commencé le travail de terrain à Sasaguri en pensant qu'il en serait de même.

Or, après avoir tenté de recueillir ce type de données auprès d'une bonne quarantaine d'habitants, il m'est apparu qu'à Sasaguri, cette entreprise s'avérait difficile. Dans ce genre d'enquête, il est habituel de repérer un ensemble d'éléments partagés par les habitants d'une même localité et de les considérer comme constituant le corps de leurs pratiques coutumières. Mais à Sasaguri, les rites de chaque maison présentent de subtiles différences, de telle sorte que les données communes à toutes sont peu nombreuses. ${ }^{4}$. Ainsi, on m'avait dit que dans toute la commune, pour le

2. Fukuta Ajio 福田アジオ et al., éd., Nibon minzoku daijiten 日本民俗大辞典, 1999-2000, vol. I, p. 62.

3. Kami-Yahagi chōshi hensan iinkai 上矢作町史緛策委員会, éd., Kami-Yahagi chōshi. Minzokuben 上败作町史:民俗編, 2008, p. 509-545.

4. Selon Orikuchi Shinobu 折口信夫, “ Nenjū gyōji. Minkan gyōji denshō no kenkyū » 年中 行事一—民間行事伝承の研究, dans Orikucbi Sbinobu zenshū 折口信夫全集, vol. 17, 1996, p. 21-35 ( ${ }^{\text {re }}$ éd. 1930-1932), la différence existant entre les modalités rituelles des maisons et des régions viendrait de la diversité des dieux vénérés. Selon Kura.ishi Tadahiko 倉石忠彦, "Nenjū gyōji no kōsei » 年中行事の構成, dans Jikan no minzoku 時間の民俗, Kōza. Nibon no Minzokugaku. 講座: 日本の民俗学, vol. 6, 1998, p. 124, cette différence serait due à une double pluri-stratification, " la pluri-stratification de l'arrière-plan rituel et celle des rites eux-mêmes ", qui engendrerait la diversité dans le temps et dans l'espace des contenus et des formes de ritualités se déroulant le même jour dans des maisons et des régions différentes. 
Jour de l'an, on retrouvait partout, surmonté d'une mandarine, l'empilement des 《mochi-miroir 》(kagami-mocbi 鏡餅) ${ }^{5}$ avec des feuilles de yuzuriba ユズリ八 (Daphniphyllum macropodum) et d'urajiro ウラジロ (Quercus salicina), dit ici moromoki モロ $モ キ$, entouré de kakis et de feuilles de laminaires séchés. Mais selon I. O., habitant de Tsubakuro 津波黒, chez lui, on aligne douze piles de petits mochi devant un seul grand mocbi-miroir placé dans le tokonoma 床の間. Ou alors, il semblait certain qu'autrefois, lors de la célébration des morts (obon お盆), pour l'accueil des âmes des défunts le i3 août, et pour leur renvoi le is août, tout le monde faisait des offrandes de boulettes de riz. Mais chez S. N. d'Oto.inu 乙犬, le is août, on fait un mocbichapeau (kasa-mocbi 笠餅) ${ }^{7}$. On peut supposer qu'il s'agit là de pratiques anciennes, mais comme je n'ai pu les relever nulle part ailleurs dans la commune, il est difficile de savoir si ce sont originellement des éléments de Sasaguri ou des usages propres à ces deux familles ${ }^{8}$.

Aussi, après avoir essayé de recueillir des témoignages sur les pratiques anciennes, afin de mettre en évidence la façon dont se transmettent les rites à l'intérieur des maisons, je réalisai que cette approche ne déboucherait pas sur un résultat satisfaisant. En outre, comme dans presque toutes les maisons qui se perpétuent depuis plus de trois générations, enfants ou petits-enfants habitent ailleurs, ou bien les enfants de l'héritier sont encore mineurs, la question de la transmission n'est pas évidente. C'est pour ces raisons que j'ai choisi comme focale la localisation des rites annuels, autrement dit ce qui se passe à l'intérieur et à l'extérieur de la maison d'habitation. Chaque maison a de plus un entourage externe représenté par l'ensemble des maisons constituant la communauté locale. A Sasaguri, celles-ci sont réunies par groupes de voisinage dites « sections》(kumi 組 ou kumi.ai 組合)", qui sont elles-mêmes assemblées en quartiers $(k u 区)$, dont elles forment l'unité de base. C'est donc en analysant à lá fois les rapports entre maison et communautć localc tels qu'ils s'articulent autour du lieu, que nous tenterons de voir en quoi consistent les dynamiques et les fonctionnalités des rites annuels pour les maisons-familles. Cet angle d'approche permet de réfléchir à la question de la transmission et de l'extinction des ritualités, et donc aux manières d'être de la famille et de la communauté locale.

5. Kagami-mochi 鏡餅 : riz cuit à la vapeur, pilé au mortier puis façonné en forme de disque d'une épaisseur de plusieurs centimètres. Il est généralement utilisé comme offrande au moment de la fête du Nouvel An. Ici, il s'agit de deux disques empilés l'un sur l'autre, un plus petit sur un plus grand. (N.D.T.)

6. Le tokonoma est un espace, plus ou moins grand, délimité par une paroi latérale et un pilier au fond de la pièce, de réception d'une habitation, au plancher légèrement surélevé par rapport au reste de la pièce : on y suspend sur le mur du fond rouleaux peints ou calligraphiés, et l'on y expose des arrangements de fleurs, ou autres éléments décoratifs pour accueillir les hôtes. (N.D.T.)

7. Les mochi étaient disposés sur le dessus d'un chapeau en lattes de bambou (banshō-gasa 番匠笠).

8. Cet éventail de petites différences m'est aussi apparu lors de mon enquête à Kami-Yahagi. Voir la partie sur les rites annuels chez Ishikawa Toshiko, "Nenjū gyōji " 年中行事, dans Uno Yũsuke 鵜野鿆介, Ōhashi Waka 大橋和華 et Ishikawa Toshiko 石川稔子, éd., Higashi Mino no minwa, uta, asobi to nenjū gyōji 東美泱の民話·唄・遊びと年中行事, 2004, p. 285-337.

9. Voir ci-après, p. 497-512. 
Pour ce faire, mon analyse des rites annuels s'organise autour de trois axes : lieux, acteurs et finalités, ce qui permet d'appréhender la double dynamique de l'espacetemps et de l'intérieur-extérieur des groupes sociaux.

Enfin, pour avoir une idée de l'évolution de la population de Sasaguri, il faut savoir qu'en I898 (Meiji 30), la totalité de la population s'élevait à 4993 habitants (dont I 733 à Sasaguri et 2260 à Seto), et qu'elle a ensuite régulièrement augmenté, atteignant 10612 habitants en 1935, puis 14039 habitants en 1960, et 31635 habitants en 2013 . Or durant cette même période, la moyenne du nombre des membres de la famille résidant sous le même toit est passée de 5,55 en 1898, à 4,5 en 1965, 3,59 en 1975, puis à 2,55 en 2012. Les faits analysés ici s'étalent sur la période allant de 1935 à 2010.

\section{L'apport des recherches sur les rites domestiques}

Tout d'abord, un rapide bilan de l'apport des recherches sur cette thématique nous permettra de mieux situer mon propos. Les premiers travaux proposant une vision de synthèse sur les rites annuels remontent à Yanagita Kunio 柳田国男 et à Orikuchi Shinobu 折口信夫 ${ }^{10}$. Yanagita a défini deux notions de base, celle du «festif » (bare ハレ) 一 qui désigne l'espace-temps particulier des grandes célébrations, des rites annuels, du cycle des rites de la vie individuelle et aussi des ritualités liées à des événements exceptionnels-, et celle de l'«ordinaire » $(k e$ ケ) - qui caractérise l'espace-temps du travail et du repos de la vie quotidienne. Pour lui, c'est dans le rythme cyclique d'alternance du festif et de l'ordinaire que doit se faire l'analyse des faits coutumiers. Dans son approche, Yanagita a globalement privilégié le champ du religieux, mais il n'en a pas moins attiré l'attention sur le fait que les rites représentaient aussi un angle intéressant pour l'étude de la vie économique qui sous-tend ces ritualités. Pour lui, l'aspect religieux des rites correspond à la partie festive (bare) de la culture, et leur aspect économique à celui de la vie ordinaire $(k e)^{11}$. Pour Orikuchi Shinobu, qui a davantage approfondi le domaine

Io. Voir Tanaka Sen.ichi 田中宣一, Nenjū gyōji no kenkyū 年中行事の研究, 1992, “Introduction 》. Les documents historiques relatant les rites annuels sont extrêmement nombreux : journaux personnels des grands pour le Moyen Âge ; observations et annotations des rites citadins par les savants des Études nationales (kokugaku 国学) pendant l'époque d'Edo ; rapports et analyses dans les revues d'anthropologie et d'ethnologie du Japon, Jinrui gakkai bōkoku 人類学会報告 et Kyōdo kenkyú 郷土研究, pour la période allant de la deuxième moitié du $\mathrm{xIx}^{\complement}$ à la première moitié du $\mathrm{xx}^{\mathrm{e}}$ siècle ; et après la seconde guerre mondiale, compilations cartographiées à l'échelle du Japon, par l'Office des affaires culturelles (Bunka-chō 文化庁, éd., Nenjū gyōji 年中行事, 1969-1971, vol. I et 2, de la série intitulée Nibon minzoku cbizu 日本民俗地図, 9 vol., 1969-2003). - En français, voir la compilation des rites agraires faite par Laurence Caillet, Gabriel Feat et al., éd., Fêtes et rites des quatre saisons au Japon, I980. (N.D.T.)

II. Yanagita a attiré l'attention sur l'importance des recherches sur les rites, dans des études comme 《Minkan reki shōkō 》 民間暦小考, dans Teibon Yanigita Kunio shü 定本柳田国男集, vol. 13, 1963, p. 275-291 ( ${ }^{\mathrm{re}}$ éd., 1931) ou Yanagita Kunio et Seki Keigo 関敬吾, Shinpan Nibon minzokugaku nyūmon 新版:日本民俗学入門, 1998. Mais il n'a pas publié de synthèse sur sa théorie du festif et de l'ordinaire. Voir à ce sujet Fukuta Ajio et al., éd., Nibon minzoku-daijiten, vol. 2, 2000, p. 401-402, article Hare-ke ハレ.ケ. 
du festif, l'année est partagée en deux moitiés par les rites annuels qui s'organisent en deux groupes au cours de l'année, la première allant du premier au sixième mois, et la seconde du septième au douzième, avec la réitération de ceux du Nouvel An au milieu $^{12}$. Outre cette partition duelle du cours annuel du temps, il a mis en évidence la répétition rituelle, notamment celle de l'appel et du renvoi des dieux (kami mukae 神迎え, kami okuri 神送り $)^{13}$. À partir de critères d'interrelations des rites, une typologie de leur organisation a été proposée par Tanaka Sen.ichi 田中宣一, qui les a classés en deux grandes catégories, celle des ritualités perpétuées et cycliques, et celle des rites indépendants. Cette dernière est elle-même divisée en rites parallèles, intermittents et indépendants ${ }^{14}$. Ceci a permis d'avoir une vision d'ensemble sur les rites annuels.

Le rôle de marqueur temporel de la vie quotidienne rempli par les rites a été analysé par Wakamori Tarō 和歌森太郎, pour qui le rythme des saisons détermine le calendrier de production, lequel fixe lui-même les rites annuels ${ }^{15}$. Ainsi la formule "Lorsque les pruniers fleurissent (calendrier saisonnier), on commence le labourage (début des travaux rizicoles commandé par la saison) et l'on accueille le dieu des rizières (premier rite des activités de production) » est représentative de cette interrelation. Les rites annuels rompent la monotonie de la vie quotidienne en la ponctuant de césures ${ }^{16}$. Mais le calendrier de production dépend du type d'activité économique principal de chaque maison. À l'époque où celui-ci était dominé par un mode quasi autarcique de subsistance, les rites annuels liés à l'agriculture se retrouvaient dans presque toutes les maisons. Néanmoins, selon les régions, ceux-ci étaient associés à des ritualités relatives à la sylviculture ou à la pêche, et dans un même territoire existaient également des différences liées au type de métier ou encore au statut social. En outre, avec le développement économique moderne, beaucoup de maisons sont passées au secteur secondaire ou tertiaire, ce qui a causé des bouleversements drastiques dans les rites annuels liés au secteur primaire des activités de production. À la suite de ces travaux, Kura.ishi Tadahiko a signalé l'importance du décalage entre le rythme de vie des salariés, dont la population a brusquement augmenté à partir de la période de haute croissance économique (1955-1973), et celui de la vie centrée sur le calendrier agricole, ainsi que l'impact de ce décalage sur les rites annuels hérités des traditions locales ${ }^{17}$.

12. Jusqu'en 1872 , année de l'adoption officielle du calendrier occidental, le calendrier était luni-solaire et les mois avaient un décalage d'environ un mois par rapport à aujourd'hui (le $\mathrm{I}^{\text {er }}$ mois correspondant à peu près au mois de février). (N.D.T.)

13. Orikuchi Shinobu, "Nenjū gyōji. Minkan gyöji denshō no kenkyū », dans Orikuchi Shinobu zenshū 折口信夫全集, vol. 17, 1996, p. 13-84.

14. Tanaka Sen.ichi, Nenjū gyōji no kenkyū, 1992, p. 241-250.

15. Wakamori Tarō 和歌森太郎, Nenjū gyōji 年中行事, 1957, p. 7.

16. Kura.ishi Tadahiko, « Nenjū gyōji no kōsei », dans Jikan no minzoku 時間の民俗, Kōza. Nibon no Minzokugaku 辚座:日本の民俗学, vol. 6, p. 125.

17. Selon Kura.ishi, op. cit., p. 133, "Pour les salariés, le temps de la vie publique est fondamentalement organisé par le calendrier, et a pour base la semaine et le mois. Généralement l'unité des jours de congé est la semaine et celle du salaire, le mois. Dans les entreprises, pour des questions de gestion, l'année est partagée en deux. De l'état des comptes de chacune de ces deux moitiés dépendent les primes, qui elles-mêmes régissent les dépenses pour les échanges de 
Ces transformations des fondements économiques ne sont pas un problème limité aux maisons, mais touchent également la vie locale et les rites communautaires qui en ont été grandement bouleversés ${ }^{18}$. Les travaux sur la question ont d'abord présenté les rites annuels des maisons comme étant aussi ceux des villages, qui étaient alors considérés comme la réunion de l'ensemble des familles y résidant ${ }^{19}$. Mais un chercheur comme Miyamoto Tsune.ichi 宮本常一 soutenait que c'est à partir des rites collectifs des unités territoriales, à l'intérieur des villages, que les ritualités se dispersent dans chacune des familles où elles ont tendance à disparaître. Selon lui, c'est pour cette raison que la forme propre prise par les rites d'une entité villageoise finit par se défaire et que naissent les divergences entre chaque maison ${ }^{20}$.

L'aspect social des rites ancré dans leur relation avec le groupe local a notamment été étudié par Sakurai Tokutarō 桜井徳太郎 ${ }^{21}$. Celui-ci a montré que les ritualités propres à chaque maison et sans lien avec celles de la communauté locale ont une forte tendance à présenter de grandes différences entre elles et à disparaître ; alors qu'à l'inverse, celles qui sont rattachées aux rites du groupe social local, ou celles qui réunissent tous les membres de celui-ci, tendent à se perpétuer. Sakurai met ainsi en évidence l'importance des rapports réciproques entre rites villageois et familiaux, ainsi que celle de leur prise en charge par les unités locales pour leur pérennité.

Concernant la fonctionnalité des rites pour les maisons et les communautés locales, de nombreux auteurs ont mis en avant le rôle que ceux-ci jouent dans le renforcement des liens des groupes familiaux et territoriaux. Mais Gōda (Tsuboi) Hirofumi 郷田(坪井)洋文 attire l'attention sur le fait qu'on ne peut négliger celui d'instrument de prise de conscience pour l'individu de sa place et de ses responsabilités à l'intérieur du village et de la maison. C'est notamment le cas lorsque ces rites correspondent aux étapes successives du parcours de la vie humaine, comme par exemple ceux de l'île de Kakara 加唐島 (département de Saga 佐賀県) dont il fait l'analyse, et qui sont une forme de rites de passage ${ }^{22}$. L'approche fonctionnelle

cadeaux internes à la famille (Jour de l'an et été), et les projets de voyage. De même, les montées en grade ou les augmentations de salaire ont généralement pour unité l'année calendaire. »

18. Toutes les fêtes et célébrations locales avaient lieu originellement à une date fixe chaque année. Mais lorsque la majorité des maisons qui gèrent ces fêtes annuelles devinrent des foyers de salariés, ces dates furent changées pour le plus proche samedi ou dimanche. Ces modifications s'intensifièrent tout particulièrement à partir de la période de haute croissance économique.

19. Voir Fujiwara Osamu 藤原修 《Ie no gyōji, mura no gyōji » 家の行事·ムラの行事, dans Jikan no minzoku 時間の民俗, Köza. Nibon no Minzokugaku 講座:日本の民俗学, vol. 6, 1998, p. 137-152. L'auteur signale que, comme Yanagita pensait que l'étude des faits coutumiers (minzokugaku 民俗学, l'ethnologie du Japon) était l'histoire des " gens ordinaires " (jömin 常民), pour lui les rites annuels prenaient pour unité non pas le village, mais la maison, ce qui fut pris comme point de départ par les chercheurs qui lui succédèrent.

20. Miyamoto Tsune.ichi 窝本常一, Minkan-reki 氏間暦, Miyamoto Tsune.ichi chosakushū 宫本常一著作集, vol. 9, 1978 ( $\mathrm{r}^{\mathrm{re}}$ éd. 1942), p. I14-115.

21. Sakurai Tokutarō 桜井徳太郎, “Shūzoku henka no katei to yō.in 》習俗変化の過程と要肉, dans Sakurai Tokutarō, éd., Shinbutsu kōshōshi kenkyū 神仏交涉史研究, 1968, p. 434.

22. Gōda (Tsuboi) Hirofumi 鄉田(坪井)洋文, «Nenjū gyōji no shakaisei to chiikisei 》 伊中行 才社会性と地域性, dans Seikatsu to minzoku 生活と民俗, vol. 2 [Nibon minzokugaku taikei 月本民 俗学大系, vol. 7], 1957, p. 226. Il y analyse les rites annuels comme un système qui, par le biais de 
des rites signale également la différenciation de leur valorisation selon le groupe concerné. Ainsi, Fujiwara Osamu 藤原修 montre qu'il existe un ordre de prévalence inversé entre le caractère social et le caractère religieux des rites collectifs, selon qu'ils sont villageois ou familiaux - les premiers valorisant principalement le social et les seconds le religieux ${ }^{23}$.

Quant à la question de la transmission rituelle, Miyamoto et Gōda soutiennent que celle-ci varie et dépend du type de relation établie entre la maison et le village ${ }^{24}$. Or, si l'on considère que le village est constitué par la réunion des maisons, il est possible d'aborder ce sujet sous l'angle du rapport entre le dedans et le debors des habitations et des familles.

Aussi examinerai-je ici les ritualités, à partir des critères de base que sont les lieux, les acteurs et les finalités, en cherchant à voir comment et en quoi les rites annuels sont en rapport avec l'intérieur ou l'extérieur des groupes sociaux (maisons et groupe local ${ }^{25}$ ) et des lieux (habitations et espace villageois). Pour cela, nous nous interrogerons sur les objectifs des acteurs rituels, comme par exemple ceux du maître de maison qui accomplit les rites du Jour de l'an dans l'habitation ou bien, à l'extérieur, dans le cimetière, pour les célébrations des morts du bigan 彼岸 (équinoxe) de printemps et d'automne, lors de la visite aux tombes pour la fête des morts (obon お盆), ou encore à l'arrivée de l'eau (minakuchi 水口) dans la rizière pour la célébration du dieu de la rizière (ta no kami 田の神). Nous nous demanderons également quels sont les dispositifs permettant de transformer en espace festif ce même espace de vie ordinaire qu'est l'habitation.

Pour ce qui est des rites annuels villageois, comme la fête de printemps (baru matsuri 春祭り) du sanctuaire du dieu tutélaire (uji-gami 氏神) ou celle du bodhisattva Kannon (Kannon matsuri 観音祭り), la première se déroule dans le sanctuaire (ujigami-sba 氏神社) et la seconde dans l'oratoire de Kannon (Kannon-dō 観音堂). Ces rituels étant ceux de la communauté villageoise, les acteurs principaux en sont les représentants de celle-ci, chaque maison y participant par le biais de la présence de l'un des siens. En centrant l'analyse sur la question du lieu, on examinera par exemple le sens que donnent les participants à leur réunion dans ces espaces. Il y a en outre des rites qui, tout en relevant de la catégorie du collectif (extérieur de la maison), se déroulent à l'intérieur de l'habitation. Par leur situation intermédiaire, ils nous permettront de réfléchir aux relations entre maisons et communauté.

Je m’intéresserai enfin à ce que le passage du temps occasionne comme changements dans les mentalités et dans la volonté de perpétuer ces rites chez les acteurs

la participation, faisait prendre conscience aux acteurs de leur rôle et de leur place dans le village et la maison. Il signale également que les rites familiaux étaient en diminution, alors même que les confréries religieuses locales étaient très actives.

23. Voir Fujiwara Osamu, «Ie no gyōji, mura no gyōji » dans Jikan no minzoku, Kōza. Nibon no Minzokugaku, vol. 6, p. 137-152.

24. Voir Miyamoto Tsune.ichi, Minkan-reki, Miyamoto Tsune.ichi chosakushū, vol. 9 ; Gōda (Tsuboi) Hirofumi, "Nenjū gyōji no shakaisei to chiikisei ", dans Seikatsu to minzoku, vol. 2 [Nibon minzokugaku taikei, vol. 7], p. 167-238.

25. Ici, " groupe local " désigne les quartiers et leurs sous-divisions que sont les sections (kumi.ai), en tant que communauté de vie constituée par un groupe de maisons. 
et les participants, afin de mieux comprendre la place et le ressort de ceux-ci dans les groupes familiaux. Ceci établira un lien avec les recherches actuelles sur les modalités contemporaines de la famille et de la transmission rituelle.

\section{Métamorphoses des rites à l'intérieur de la maison}

On peut classer les ritualités familiales en quatre grandes catégories : les rites de vénération des dieux et bouddhas, et ceux de célébration des morts et des ancêtres; ceux qui sont orientés vers la demande de prospérité des activités de production et dc sécurité familiale ; ceux qui ont pour origine des rites agraires ; ceux qui impliquent la participation aux rituels communautaires villageois. Il est difficile de définir réellement ces derniers comme des "rites familiaux ». Mais lors de mon enquête, nombreux furent les interlocuteurs qui m'ont donné pour tels les rites du village auxquels ils se rendent. Puisque le maître de maison ou le représentant de la famille y est présent en tant que membre à part entière de la communauté villageoise, ces rites communautaires sont considérés comme étroitement liés à ceux de la maison. Aussi les ai-je introduits malgré tout dans cette catégorie, mais ils seront abordés dans la partie suivante.

Nous partirons de la présentation d'un certain nombre d'exemples de rites annuels qui se déroulent dans les habitations à Sasaguri ${ }^{26}$.

\section{Espaces rituels dans l'intérieur domestique}

LES DISPOSITIFS DE TRANSFORMATION FESTIVE. - Les rites annuels familiauX ont lieu principalement à l'intérieur des habitations et réunissent les seuls membres de la famille ${ }^{27}$. Les fêtes villageoises se déroulant dans les sanctuaires, les temples ou les oratoires, devant des stèles, qui tous sont considérés comme des lieux sacrés, il suffit de se rendre dans ces espaces pour accomplir les rites. Mais accueillir les dieux ou les bouddhas à l'intérieur de la maison et les y célébrer implique de modifier les dispositions ordinaires des lieux, transformant ainsi cet espace quotidien en un espace festif.

Le premier dispositif est la mise en place des objets nécessaires au rite. Ainsi, à Oto.inu (famille S. N. ${ }^{28}$ ), pour le Nouvel An, on tend une corde de paille (sbime nawa 注連縄) dans l'entrée et devant l'étagère des dieux (kami-dana 神棚) qui se trouve dans l'une des pièces de la maison, et l'on place un grand mochi dans le tokonoma; pour la fête des morts, on sort de l'autel bouddhique (butsudan 仏壇) les plaquettes funéraires portant le nom des défunts (ibai 位牌) pour les exposer sur la tablette de

26. Voir à la fin de cette contribution le tableau des rites annuels de la maison à Sasaguri.

27. D'autres rites familiaux, comme la visite du i ${ }^{\text {er }}$ janvier au sanctuaire du dieu tutélaire (batsu-mōde 初毗), le pèlerinage sur les tombes (baka-mairi 墓参り) pour le bigan et la fête des morts, ont lieu à l'extérieur de la maison, là où résident dieux et défunts.

28. Tous les exemples cités au cours de l'analyse se retrouvent dans le tableau des rites annuels de la maison à Sasaguri à la fin de cette contribution. 


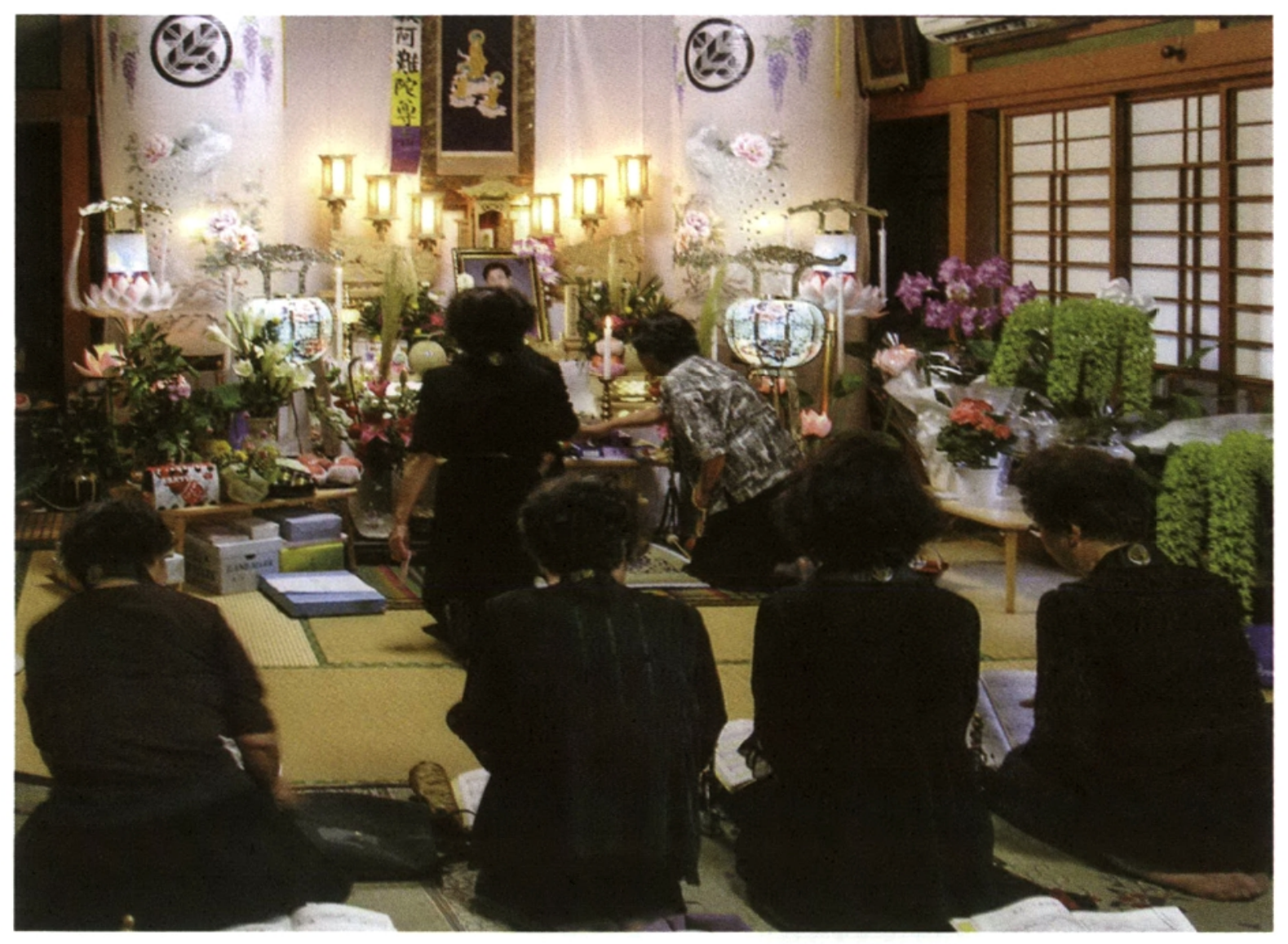

Fig. I : La première fête des morts après le décès : l'autel, l'apparat rituel et les offrandes dans la pièce principale de la maison de la défunte (portrait au centre) (Famille K., Wada, 12 août 2009). (Tous les clichés sont de l'auteur.)

célébration (bon-dana 盆棚), qui sert d'autel durant la fête et où l'on place aussi de nombreuses offrandes (fig. I). Ces instruments sont déjà eux-mêmes des objets de culte ${ }^{29}$, et ils servent alors à signaler et délimiter l'espace rituel.

Le second dispositif consiste en la préparation et la prise de nourriture faite spécialement pour ces occasions. Ainsi pour le Jour de l'an, ce sont un bouillon dit $z \bar{n} n i$ 雑煮 (les recettes en sont variées selon les régions et selon les familles, mais il contient toujours du mocbi) et un ensemble de mets festifs (o-sechi ryōri おせち料理) qui ne sont pas consommés en temps ordinaire. Cela concerne également le changement de lieu des repas, qui ordinairement sont pris dans l'espace où l'on fait la cuisine (daidokoro 台所), alors que pour le Nouvel An, la famille se rassemble autour de la table située dans la pièce de réception (zashiki 座敷) (exemple 6 : voir ci-dessous, p. 492). Dans cette pièce se trouvent le tokonoma où est déposé le mochi-miroir,

29. La corde de paille est l'instrument marqueur qui délimite un espace dont l'intérieur est considéré comme sacralisé par la présence d'un dieu ou de toute autre entité, et/ou d'objets consacrés ou purifiés. Le mochi-miroir est un aliment dans lequel réside le dieu de l'An (toshi$g a m i$ 年神 ou 藏神). 
et l'autel bouddhique domestique. C'est le lieu où l'on vénère les dieux et où les repas sont partagés avec eux.

LA BANALISATION DES DISPOSITIFS FESTIFS. - Mais si cet appareil rituel en vient à n'être plus perçu comme tel et à entrer dans le domaine de l'ordinaire, les ritualités elles-mêmes s'en trouvent affectées. C'est le cas lorsque ces dispositifs ne sont plus regardés que comme de simples décorations. Ainsi, depuis la fin des années i980, s'est répandue la mode consistant à mettre des couronnes de l'Avent à l'entrée des maisons, notamment parmi les jeunes générations. Sur ce modèle ont été imaginées des cordes de paille du Nouvel An en forme de couronnes qui sont vendues en masse dans les supermarchés, les acheteurs pensant qu'elles sont micux adaptées au style occidental de l'entrée des maisons actuelles.

Néanmoins, la sacralité des cordes de paille n'en est pas pour autant totalement oubliée. À Sasaguri, celles-ci, de même que tous les autres ornements rituels du Nouvel An, sont brûlées dans un grand feu dit bokkengyō ホッケンギョウ ${ }^{\mathbf{3 0}}$, qui est lui-même un rite assuré par les enfants. L'objectif est de faire repartir le « dieu de l'An » (toshi-gami). Ce feu rituel, qui se faisait partout, est aujourd'hui tombé en désuétude dans la plupart des régions. Mais sa pérennité ici montre qu'est ressentie une réticence à considérer ces objets rituels comme de simples ordures, même chez les jeunes générations.

Il en va de même pour le mochi-miroir exposé dans le tokonoma. Aujourd'hui, dans la majorité des cas, il est acheté en pack de plastique sous vide. Comme la chaleur des pièces cause la rapide prolifération de moisissures, ce mocbi sous vide est préféré, car il se conserve parfaitement jusqu'au moment de sa consommation, un jour après le 7 janvier (généralement le iI). Bien plus, on a vu augmenter le nombre de ceux qui achètent des paquets dans lesquels le mochi est déjà prédécoupé en petites portions. Originellement, couper en morceaux le mocbi, dans lequel est descendu le dieu de l'An, pour le distribuer entre les membres de la famille, avait une signification rituelle. Il s'agissait d'un repas partagé entre ceux-ci, et entre eux et cette divinité. Mais ce type d'offre commerciale a aujourd'hui du succès car cela épargne l'effort de couper le mocbi durci. Bien plus, on a vu apparaître des mochi-miroirs de porcelaine, celui-ci étant alors transformé en un simple objet de décoration. Ceci tient au fait que de moins en moins de familles pilent elles-mêmes le riz dans un mortier pour en faire du mochi et préfèrent l'acheter tout prêt. Or le mochi qui était le mets festif et rituel par excellence, est aujourd'hui vendu toute l'année dans les supermarchés, ce qui empêche de l'associer aux célébrations annuelles.

Il en va de même pour tous les plats originellement préparés pour les seuls rites annuels. Dans les années 1965-1974, lorsqu'on servait des plats fastueux à l'occasion d'un repas ordinaire, on disait que c'était " comme si le Nouvel An et la fête des morts avaient lieu en même temps ». Mais cette expression courante a aujourd'hui disparu du vocabulaire, car il est devenu possible de manger tous les jours une nourriture qui, autrefois, était qualifiée de festin. Quant à la cuisine festive pour le Nouvel

30. En certains endroits du département de Fukuoka, on utilise le terme bokkengyō pour désigner ce rite du feu du Nouvel An, généralement appelé ailleurs sagichō tr.義長. Voir ci-après l'exemple in, p. 504 . 
An, elle est l'une des ventes phares des grands magasins ${ }^{31}$. Introduire de l'extérieur des dispositifs festifs spécifiques aux rites domestiques ne suscite plus de résistance.

Dans la vie quotidienne, à l'intérieur de l'habitation, la distinction entre festif et ordinaire a ainsi tendance à disparaitre. Avec la banalisation du festif, la transformation des lieux quotidiens en espace de fête, qui se faisait traditionnellement au moyen de dispositifs rituels, n'est plus claire, et la perception de la sacralité d'un espace a tendance à se perdre. Tout ceci provoque des transformations dans le sens et l'objet même des rites annuels.

\section{Les acteurs des rites familiaux}

MaîtRe de MAison ET SPÉCiAListe RELigieuX. - Dans les maisons placées sous le régime du patriarcat, c'est le maître de maison qui détenait le droit d'accomplir les rites annuels en tant qu'acteur principal et spécialiste religieux ${ }^{32}$.

Ainsi, d'après un article sur les rites annuels dans le département de Fukuoka, la coutume voulait que, pour le rite du "puisage de l'eau nouvelle » (wakamizu kumi 若水汲み) du Jour de l'an :

L'homme "de l'année ${ }^{33}$ » ou le maître de maison, levé à l'aube de ce premier jour de l'année, puise de l'eau soit au puits soit dans la rivière situés dans une direction faste, au moyen d'un puisoir et d'un broc neufs. À ce dernier, est parfois fixée une corde de paille ou de l'argent enveloppé dans du papier, «trésor de l'an 》 (o-toshidama fj年玉). Il prend de l'eau après avoir prononcé ces paroles : «Puisant l'eau au début de cette précieuse année nouvelle, je puise ro ooo trésors ", et il la rapporte dans la maison. Là, à sa suite, chacun à tour de rôle se lave le visage avec cette eau en se servant d'une serviette neuve. C'est lui aussi qui, avec des aiguilles de pin, allume dans les fourneaux le feu du matin,

31. Récemment, les ventes par internet de ces plats du Nouvel An ont connu une brusque augmentation. Ceci a donné lieu à ce genre d'incidents : à la fin de l'année 20ro, tous les acheteurs se sont précipités pour participer à une vente aux enchères par internet d'o-sechi ryōri très bon marché, qui, lors de sa consommation, se révéla exécrable.

32. Le système patriarcal, qui reposait sur l'autorité absolue du père-maître de maison, a été la norme dans le groupe social des guerriers jusqu'en $\mathbf{1 8 6 8}$. Ce système servit de modèle pour le Code civil de Meiji (mis en application en 1898), qui imposa par là le droit absolu du chef de famille également au reste de la population. Après la seconde guerre mondiale, ce droit absolu du chef de famille fut abrogé lors de la révision du Code civil. Mais dans les pratiques coutumières, celui-ci conserva le statut d'héritier de la charge rituelle. En outre, l'une des conséquences de la démocratisation et de la stabilisation des salaires dans l'ensemble de la société fut l'apparition et la généralisation des femmes au foyer. Ceci renforça la division des tâches féminines et masculines et, par là, fit perdurer le patriarcat après sa suppression légale. Avec la période de haute croissance économique (1955-1973), l'augmentation des familles nucléaires et des femmes ayant une profession ébranlèrent le patriarcat, mais aujourd'hui, bien qu'il y ait des différences d'une maison à l'autre, dans celles où vivent des personnes âgées, il arrive que ce système soit encore en vigueur.

33. Tosbi otoko 年男. Originellement, c'est le titre donné à l'homme qui est responsable des rites du Nouvel An. Mais ici « homme de l'année » désigne l'homme dont les signes zodiacaux de l'année de naissance correspondent à ceux de l'année nouvelle selon le calendrier sino-japonais, ou celui qui atteint cette année-là l'un des âges dits «funestes » (yakudoshi 厄年). 
qui servait à faire bouillir l'eau pour le thé. Ce dernier est appelé « thé de la grande fortune/du grand bonheur» (ofukucha 大福茶) ${ }^{34}$.

À Sasaguri, dans les années 1950, existait aussi ce puisage de l'eau nouvelle (wakamizu kumi) par le maître de maison.

Exemple I. - À Oto.inu, dans la maison conjugale de S. N. (née en I925), dès que la cloche de minuit sonne, le maître de maison va puiser de l'eau au puits. Après avoir secoué bruyamment un morceau de charbon de bois mis dans le puisoir, il le jette et puise l'eau.

Tous les membres de la famille se lavent le visage avec cette eau en se servant chacun d'une serviette neuve. Après avoir fait bouillir cette eau, on en fait du thé. Sur une assiette, on dispose, comme accompagnement, des kakis séchés, des prunes au sel, des mandarines.

À Sasaguri aussi, c'est donc bien le maitre de maison qui, pour commencer l'année, manipulait l'eau comme quelque chose de sacré35. C'est également lui qui, avant le repas, versait à chacun un bol d'o-zōni et une coupe d'o-toso 屠蘇 ${ }^{36}$ ou de sake en prononçant les vœux de bonne année. On peut considérer ces actes comme un moyen de (ré)activer, chez les membres de la famille, la prise de conscience du rôle prédominant, voire religieux, du maître de maison. La participation de tous aux rites annuels était alors une obligation qui n'était pas remise en cause, et qui était au fondement de l'unité familiale. En outre, on a vu ci-dessus que dans le département de Fukuoka, le maitre de maison allume aussi le feu dans les fourneaux, alors même qu'il ne s'occupe jamais de la cuisine au quotidien. Ainsi, par cet acte qui ne se fait pas en temps ordinaire, ce rituel fait ressortir le caractère festif de ce jour particulier ${ }^{37}$.

La création de l'espace rituel interne peut néanmoins être le résultat de l'intervention de quelqu'un qui est extérieur à la maison. Il s'agit alors presque toujours de spécialistes religieux comme le moine du temple paroissial, ou de collectifs cultuels comme la confrérie du nenbutsu ${ }^{38}$, qui viennent réciter les sūtra devant l'autel familial pour la fêtes des morts ; ou encore de spécialistes religieux à qui l'on demande d'y accomplir les rites de protection de l'habitation et de ses habitants ${ }^{39}$. C'est également

34. Kadokawa chimei daijiten hensan iinkai 角川日本地名大辞典編籍委員会, éd., «Fukuokaken nenjū gyōji, II, Minzoku » 福岡県年中行事, II, 民俗, dans Kadokawa Nibon chimei daijiten 角川 日本地名大辞典, vol. 40, Fukuoka-ken 福岡県, 1991, p. 1996.

35. Selon le "Grand dictionnaire d'ethnologie du Japon " (Nibon minzoku daijiten, vol. 2, p. 824 , s.v. "wakamizu»), dans l'ouest du pays, il y a des régions où c'est la femme qui va puiser l'eau nouvelle. Mais au cours de mes enquêtes, ceci n'a jamais été confirmé.

36. Sake ou mirin 味 (sake sucré) parfumé avec des herbes médicinales.

37. Ici l'acte rituel festif se différencie à la fois du geste ordinaire (allumer le feu) et du rituel quotidien accompli par la maitresse de maison (par exemple, les offrandes journalières aux dieux et aux ancêtres).

38. Nenbutsu kō 念仏講, confrérie, généralement de femmes âgées qui, selon les lieux, récitent ou chantent le nenbutsu (invocation du bouddha Amida 阿弥陀仏) pour les rites funéraires et plus généralement, pour toutes les fêtes et rites relatifs aux défunts. (N.D.T.)

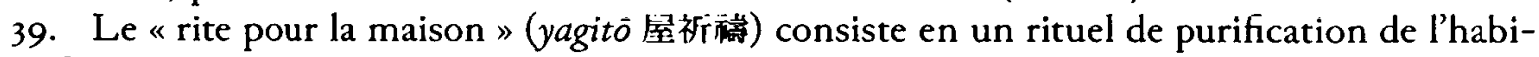
tation fait par un spécialiste religieux afin de demander protection et prospérité pour la famille. La « célébration des étoiles» (bosbi-matsuri 星祭) est une célébration de l'étoile ou de la planète 
le cas lorsque la maison est le lieu où se rassemblent les membres d'un groupe cultuel qui en font l'espace de ritualités collectives (voir ci-après, p. 497-521).

DeVEnIR UN ACTEUR RITUEL. - La transformation du dedans de la maison en un lieu festif est aisément perceptible quand elle s'accomplit avec la venue d'un spécialiste cultuel extérieur. Mais lorsque cette modification qualitative est effectuée par un ou des membres de la famille remplissant le rôle de célébrant(s), des dispositifs spécifiques sont nécessaires. Ainsi, d'une façon générale, il est d'usage que, pour toute occasion festive, le célébrant effectue préalablement des purifications corporelles (bain, lavage du visage et des mains, sel mis sur le corps) et revête des habits neufs ou de fête qui ne sont pas portés habituellement. L'un des instruments de cette métamorphose est « l'eau nouvelle » (waka-mizu 若水, littéralement « l'eau jeune ou de jeunesse ») qu'on puise au tout début de la nouvelle année. Différente de l'eau de tous les jours, elle est considérée comme "sacrée » et, par là, comme ayant le pouvoir de nettoyer de la souillure de la vieille année. C'est ce qui se passe à Sasaguri, lorsque les membres de la famille utilisent ses vertus purificatrices en se « lavant " le visage, et en absorbent la puissance dans leur corps sous forme de thé.

Dans ce but, cette eau nouvelle peut être puisée dans des lieux eux-mêmes qualifiés de sacrés.

Exemple 2. - Dans la maison conjugale de K. A. (née en 1917), pour puiser l'eau nouvelle, son beau-père se rendait jusqu'à la cascade du Nanzō-in 南蔵院 au petit matin du Jour de l'an vers 4 ou 5 heures, avant que les femmes ne se lèvent. Il la rapportait dans une tige de bambou, en déposait en offrande sur l'étagère des dieux de la maison, et en faisait du thé qu'il offrait aux âmes des défunts de la famille sur l'autel bouddhique domestique. Ensuite, ce thé était bu par tous les membres de la famille.

La cascade du Nanzō-in est l'endroit où les pèlerins des 88 temples de Sasaguri et les spécialistes religieux pratiquent l'ascèse de la cascade ${ }^{\mathbf{4 0}}$. Mais avec l'installation des conduites d'eau, les rites de puisage de l'eau nouvelle ont progressivement disparu.

Beaucoup d'habitants de Sasaguri m'ont dit qu'après le bain de la veille du Jour de l'an, ils mettaient des sous-vêtements neufs et/ou des habits de fête pour le Premier, soulignant ainsi qu'ils marquaient le passage de l'ordinaire au festif en revêtant des tenues différentes de celles du quotidien. Ces habits neufs étaient généralement confectionnés avec des tissus achetés au marché de fin d'année, qui fait lui aussi partie de l'enchaînement des événements festifs. Mais avec la généralisation du bain quotidien dans la salle d'eau familiale, et ensuite de celle du «shamp (shampoing) du matin » (asa sban 朝シャン) chez les jeunes générations à partir des années 1975, la notion de «purification » en est venue à ne plus signifier grand-chose. C'est aussi vers la même

de l'année de naissance d'un ou des membres de la famille effectuée par un spécialiste religieux pour demander protection et prospérité.

40. Cette pratique indique peut-être qu'avant de devenir un lieu d'ascèse, cette cascade était aussi le point d'arrivée d'eau le plus ancien de ce quartier, comme le suggèrent des rites du Nouvel An dans d'autres localités où la règle est d'aller puiser l'eau du Nouvel An à la source la plus ancienne (notamment à Kami-Yahagi 上矢作, où mon enquête de 2005-2006 a montré qu'on allait puiser de l'eau du Nouvel An à la source ou au puits qui étaient utilisés auparavant, même après l'installation des conduites d'eau). 
époque que la fabrication et l'achat de vêtements neufs ont eu tendance à perdre leur valeur cultuelle, car ils n'ont plus été nécessairement associés à un événement rituel.

LA FEMME, GESTIONNAIRE DE LA VIE PRATIQUE. - Si l'officiant principal des rites domestiques est d'abord l'homme, la femme, elle, est son auxiliaire. Comme nous l'avons vu, les ritualités du Nouvel An sont sous la responsabilité soit du maître de maison, soit de "l'homme de l'année », mais la femme est aussi monopolisée par toute la logistique, notamment par la cuisine et la préparation des instruments rituels. À partir de la fin de l'année, la grande majorité d'entre elles est occupée à la confection des plats festifs du Nouvel An (o-sechi ryōri). On entend souvent dire : "Les plats du Nouvel An permettent aux femmes de se reposer durant ces jours de fête. » Mais avant l'introduction des réfrigérateurs, c'étaient bien les femmes qui, à chaque repas, réchauffaient les mets qu'elles avaient préparés les jours précédents, ou qui cuisinaient le zōni. En outre, durant les fêtes du Nouvel An, les visiteurs ne cessent d'aller et venir. Les accueillir comme il se doit implique que les femmes soient en fait constamment dans la cuisine.

Tant qu'a prévalu une économie autarcique ${ }^{41}$, tout au long de l'année, la cuisine était entièrement liée aux productions saisonnières ${ }^{42}$. Les femmes avaient donc une excellente connaissance de leurs variations, et la gestion des rites annuels leur était particulièrement aisée. En effet, les travaux agricoles étaient faits conjointement par les hommes et les femmes, mais la culture des condiments et la préparation des repas étaient des tâches exclusivement féminines ${ }^{43}$. Les femmes dont il est question ici sont les plus âgées de la famille : ce sont celles qui avaient la responsabilité des préparatifs des rites annuels. Il s'agit généralement soit de l'épouse du maître de maison en titre, soit de sa mère ou de sa grand-mère, c'est-à-dire de la " maîtresse de maison » (sbufu 主婦) selon la définition de l'ethnologie du Japon ${ }^{44}$. Or, c'est elle qui, dans la quasi totalité des maisons, réalisait la gestion matérielle des rites annuels : cuisine des mets

4I. Voir Imada Setsuko 今田節子, “Chiiki ni okeru shoku no denshō »地域における食の伝承, dans Ehara Ayako 江原絢子, éd., Shoku to kyōiku 食と教育, Shoku no bunka fōramu 食の文化フォー ラム, vol. 19, 2001, p. 70-92. La durée de l'époque d'économie autarcique differe selon les lieux. Si les milieux citadins ont très tôt dû avoir recours aux achats de nourriture, c'est seulement à partir des années 1960 que les familles qui avaient des terres agricoles se sont mises elles aussi à acheter des légumes.

42. Ainsi à Sasaguri, K. A., maîtresse de maison à Kido 城戸, tout en tenant une auberge de pèlerins, cultivait de quoi nourrir sa famille et assurer les repas des hôtes de passage. Elle enchaînait les travaux agricoles de la culture du riz, du blé, de l'orge et des fèves. Sur les diguettes des rizières, elle plantait haricots rouges et haricots de soja. À cela s'ajoutait la culture des condiments et des produits de réserve, comme les légumes mis en saumure et le miso 味噌 de blé.

43. Voir Murasaki Kazuko むらさき数子, «Shoku bunka no henyō” 食文化の変容, dans Minzoku no shisō 民俗の思想, Gendai minzokugaku no shiten 現代民俗学の視点, vol. 3, 1998, p. 74-84 : l'auteur y soutient qu'autrefois, les hommes faisaient aussi la cuisine. Mais on peut penser que s'il y avait un partage des tâches domestiques, la principale responsable de la cuisine était néanmoins la femme.

44. Pour la sociologie, la maîtresse de maison de l'époque contemporaine est née lorsque prit forme la notion de système de répartition des tâches masculines et féminines. Mais en ethnologie du Japon, la « maîtresse de maison » est conçue par comparaison avec le maître de maison qu'elle assiste. Responsable de la gestion de la vie domestique interne, elle est à la position la plus haute parmi toutes les femmes de la famille. 
du Nouvel An, cuisine des plats déposés en offrande sur les autels pour la fête des morts, mais aussi préparation et changement des offrandes quotidiennes aux dieux et aux morts. Depuis les petits rituels journaliers jusqu'aux grandes ritualités du cycle de la vie individuelle, préparatifs, réalisation, disposition, rangement, tous ces actes sur lesquels reposent les rites annuels étaient sous leur responsabilité.

Comme la maîtresse de maison avait sous son autorité la gestion du domaine privé de la vie familiale, pour tout changement de contenu à ce niveau, et donc dans les rites, son autorisation était nécessaire. À l'inverse, elle pouvait prendre la décision d'effectuer des modifications.

Exemple 3. - S. N. est venue habiter chez son époux à partir de son mariage. Elle était chargée de la vente ambulante des produits agricoles; aussi est-ce sa belle-mère qui gardait les enfants. Avant leur naissance, les rites de jet des haricots du setsubun 節分 ${ }^{45}$, ou la décoration avec des bambous pour la fête de tanabata $t \$^{46}$ n'étaient pas pratiqués dans cette famille. Mais comme les enfants en avaient pris l'habitude au jardin d'enfants et à l'école, sa belle-mère prit l'initiative de les mettre en place " pour faire plaisir aux enfants », alors même que leur mère n'avait pas été consultée.

Il faut néanmoins remarquer que ce droit de décision ne s'applique ici qu'à des fêtes « pour faire plaisir au enfants », limitées à certaines familles où il y a des enfants en bas âge, et non à un rituel familial généralisé.

La cuisine rituelle est faite par la maîtresse de maison assistée de la plus jeune des belles-filles. Les droits que la première détient dans l'exercice de la vie de tous les jours sont encore renforcés lors des rites annuels. En effet, comme la cuisine quotidienne et l'ensemble des travaux ménagers sont des pratiques habituelles sans cesse répétées, leur mémorisation se fait rapidement. Il n'en va pas de même avec les rites annuels qui ne reviennent qu'une fois chaque année. C'est à ce moment-là que la jeune belle-fille peut apprcndre de sa belle-mère les différentes sortes de plats et la façon de les cuisiner.

À Sasaguri, le dernier jour de la fête des morts, le is août, dès le matin on renouvelle fréquemment les offrandes de thé faites aux ancêtres. On dit que plus le nombre de fois est élevé, mieux c'est. De là vient l'expression courante qui reflète le

45. Setsubun 節分 : la fête de la veille du premier jour de la période dite de « l'établissement du printemps » (risshun 立春). La date de ce jour varie selon les années, mais se situe généralement aux alentours du 3 février. Pour chasser des maisons les démons et toutes les forces néfastes, on jette des haricots grillés depuis la porte vers l'extérieur en criant : "les démons dehors ! " (oni wa soto 鬼は外), et vers l'intérieur en criant « la fortune dedans!»(fuku wa uchi 福は内). Avant le changement de calendrier à Meiji, cette date était proche du Nouvel An luni-solaire ; aussi ce rite faisait-il partie du cycle festif du début de l'année. Il a en outre été assimilé à partir du XIve siècle au rituel de l'expulsion des malheurs (tsuina 追鹰) qui était fait dans le même but dès l'Antiquité à la cour.

46. Tanabata $七$ 夕 : s'appuyant sur une légende voulant que, la nuit du $7 \mathrm{du} 7^{\complement}$ mois, les étoiles du bouvier (Altaïr) et de la tisserande (Véga) peuvent se rencontrer en traversant le fleuve Céleste (Vuie lactée), a été introduite dès le viIr siècle la coutumc chinoisc dite kikōden (ch. qiqiaodian) 乞巧突, consistant à faire des offrandes aux deux étoiles en demandant la maîtrise dans les arts. Elle s'est diffusée à l'époque d'Edo dans les milieux populaires où elle a été associée aux coutumes autochtones de la tisserande du bord de l'eau (tanabata tsu me 棚機つ女) et de la fête des morts. 
souhait d'avoir une belle-fille appliquée dans ses tâches : «J'aimerais que ma future belle-fille soit une femme à changer sept fois le thé sur l'autel. »

LA RELÈVE DES ACTEURS RITUELS. - Pour assurer la bonne exécution des ritualités familiales, il est nécessaire que celui qui en est responsable soit à la maison. C'est le cas des familles d'agriculteurs ou de celles dont l'activité professionnelle se pratique dans l'habitation. Alors que les agriculteurs représentaient la majorité des familles de Sasaguri, beaucoup d'entre elles durent cumuler une seconde activité de subsistance à compter de l'après-guerre, en raison du marasme économique qui toucha l'agriculture et du développement de la mécanisation. Cette activité secondaire allégea le travail et libéra des marges temporelles, mais rendit indispensables les revenus en espèces pour l'achat des machines. C'est ainsi que les hommes sortirent à l'extérieur des maisons pour aller travailler ${ }^{47}$. Lorsque le maitre de maison âgé pouvait rester sur place, il put continuer à assumer son rôle rituel. Mais lorsque les hommes durent quitter l'habitation pour gagner des lieux de travail situés à l'extérieur de la commune, le maître de maison ou son successeur en vinrent à passer de moins en moins de temps sur place, ce qui rendit difficile l'accomplissement de leurs fonctions rituelles quotidiennes et annuelles.

Pour perpétuer les rites, il fallut donc soit adapter le calendrier rituel des fêtes domestiques à celui des jours de congé des hommes, soit transférer la charge rituelle aux femmes. C'est cette seconde solution qui, avec le temps, est devenue majoritaire. Par là, les femmes en sont arrivées à détenir la clé de la continuation des rituels familiaux. Les bouleversements des activités économiques ont ainsi entraîné la généralisation de la reprise des fonctions rituelles par les femmes. Mais avec l'allègement des travaux domestiques, suite à la diffusion des appareils électro-ménagers, de l'achat des produits alimentaires et des vêtements de confection, les maitresses de maison elles-mêmes en vinrent à travailler de plus en plus à l'extérieur, ce qui contribua à imposer la réduction, voire la disparition, des rites familiaux.

Bien plus, la transmission à la génération suivante est elle-même devenue problématique. Lorsque chaque membre de la famille est lié à un groupe extérieur différent, ce sont finalement ces liens qui sont davantage favorisés par chacun d'entre eux plutôt que ceux existant avec la maison ou la famille. En particulier quand il s'agit de l'entreprise ou du lieu de travail, le reste de la famille est obligé d'accepter la situation. Cet éclatement individuel des groupes familiaux fut à l'origine de la liberté de choisir entre continuer et arrêter l'accomplissement des rites domestiques. Là où la pression dans le sens d'une continuation et le sentiment de la nécessité des ritualités elles-mêmes se font moins manifestes, celles-ci finissent par disparaître. Pourtant, certains choisissent de les perpétuer.

Exemple 4 - M. R. (née en 1962) qui, à son mariage, est venue habiter dans la famille de son époux, est fière de dire qu'elle a «tout changé dans la maison ». Cette famille tient une auberge, et les modifications dont parle $\mathrm{M}$. R. concernent la manière de faire la lessive des vêtements de nuit ou celle de changer les draps. Mais pour les rites annuels, elle a plutôt respecté la tradition familiale. Par exemple, dans cette famille, la veille du Jour de l'an, vers

47. Le pourcentage des familles vivant exclusivement de l'agriculture a évolué de la façon suivante : en 1960, elles représentaient $20 \%$ des 655 familles pratiquant l'agriculture ; en 1965 , $11 \%$ des 602 ; en $1970,6 \%$ des 558 ; en $1975,4 \%$ des 510 ; en $1980,9 \%$ des 500 ; en $198 \varsigma, 9 \%$ des 442. 
20 heures, a lieu le rite appelé «le Passeur de l'An» (Toshikoshi sama 年越し様). On place un mochi-miroir dans le tokonoma et l'on dispose devant lui des offrandes de sake (o-miki f神酒). On allume une bougie, et à la suite du maître de maison, chaque membre de la famille à tour de rôle s'incline en disant : "Passeur de l'An, merci de me faire changer d'année. » Ou alors, le $\mathrm{i}^{\text {er }}$ et le 15 de chaque mois, on purifie les quatre coins (orients) de la maison en y versant du sel et du sake, et l'on place sur l'étagère des dieux une branche fraîche de kamisbiba カミシバ (« feuille des dieux », une variété de sakaki 槦, Cleyera japonica).

Comme la famille de M. R. gère une auberge pour les pèlerins, à laquelle était adjoint l'un des 88 oratoires du circuit de pèlerinage, cette femme moderne a néanmoins le sentiment que ne pas respecter les pratiques cultuelles peut sans doute avoir des conséquences néfastes pour l'activité familiale. C'est elle qui, percevant la dimension religieuse des rites domestiques, a décidé d'en assurer la continuation.

\section{Teneur et finalités}

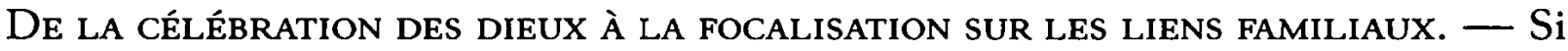
l'on prend pour exemple le cas de l'ensemble des rites annuels de la maison de S. N. ${ }^{48}$ citée précédemment, on relève les caractères suivants.

Pour la maison, le Nouvel An est d'abord la célébration de la venue du dieu de l'An (toshi-gami 歳神) à l'intérieur de l'habitation. Cet accueil est concrétisé par un enchaînement de ritualités propitiatoires et de célébrations : grand nettoyage de l'habitation et délimitation de l'espace avec la corde de paille, fin décembre ; préparation des offrandes (mocbi) et des mets festifs (dont les « nouilles de sarrasin de la bonne fortune », un-soba 運帛麦 ${ }^{49}$, mangées au moment du changement d'année) ; purification familiale (" eau nouvelle ») et accueil des dieux avec des offrandes (sake sur l'étagère des dieux), le matin du Premier de l'An ; thé et toso, puis repas festif ${ }^{50}$ considéré comme partage entre les membres de la famille et le dieu de l'An. À ces rites internes sont associées des pratiques cultuelles et festives externes : pèlerinage du Jour de l'an (batsu mōde 初詣) au sanctuaire tutélaire local, uji-gami 氏神 (sanctuaire Hachiman d'Oto.inu 乙犬八幡社) pour demander protection et prospérité familiales ; tour des maisons de la parenté et des voisins ${ }^{51}$ qui renforcent les relations amicales.

48. Voir le tableau des rites annuels de la maison à Sasaguri à la fin de cette contribution.

49. Une légende veut que ces « nouilles de la bonne fortune 》 (un-soba 運蓄麦) aient été faites par un artisan travaillant l'or qui mêla des copeaux d'or à la farine de sarrasin. Elles auraient ainsi la vertu «d'attirer l'or ». - Ces nouilles de sarrasin sont appelées plus généralement toshikoshisoba 年越し萫麦, c'est-à-dire « nouilles de sarrasin du passage de l'An ». (N.D.T.)

5o. Dans la famille de S. N., le bol de zōni du 3 I est un bouillon de poisson assaisonné de sauce de soja (shōyu dans lequel a été placée une brochette avec petit mochi rond, tōfu 豆腐 grillé, colocase, carotte, feuilles de légumes verts (katsuo-na カツオ菜, de la famille des Brassicaceae). Les plats (o-sechi ryöri) consistent en légumes cuits en bouillon, racines de lotus au vinaigre, osmondes (zenmai ゼンマイ) cuites en bouillon, rouleaux de laminaire cuits en bouillon, pâtés de poisson, petites sardines avec glaçage sucré, patates douces écrasées, œufs de harengs, haricots noirs, filaments de carottes et de radis blanc au vinaigre doux, maquereaux vinaigrés, navets vinaigrés.

51. “Tour du début de l'An 》 (nenshi mawari 年始回り) chez les voisins et dans la parenté. Sato aruki 里歩き est la visite de la belle-fille à sa propre famille. 
Tous ces rituels sont répétés à la date du iter de l'an selon l'ancien calendrier lunisolaire $^{52}$ (utilisé jusqu'en 1872 ), jour qui, à Sasaguri, est appelé " (le jour où) l'on reprend un an 》(toshi torinaoshi 年取り直し), ou encore le 7 janvier. Cet ensemble rituel se termine par le renvoi du dieu de l'An avec le décrochage de l'apparat rituel qui est brûlé dans le feu du bokkengyō, à l'extérieur. Les rites du setsubun sont aussi inclus dans le cycle des festivités du Nouvel An (mais à Sasaguri, la fête du setsubun est récente). Avec ces derniers se termine ce cycle qui a pour but d'accueillir le dieu de l'An pour lui demander la sécurité de la maison, la santé de ses membres et la prospérité professionnelle pour toute l'année.

Aux mois de mars et avril, au moment de la reprise des travaux agricoles, se succèdent des célébrations collectives externes : la fête des ancêtres (bigan 彼岸) de printemps avec la visite aux tombes le jour de l'équinoxe du printemps; la réunion du groupe de voisinage (kumi.ai sōkai 組合総会) $)^{53}$; la « veille » communautaire (okomori おこもり) au sanctuaire tutélaire $\mathrm{S}^{54}$ et le repos après le repiquage du riz (sanabori サナ ボリ), auxquels participe le représentant de la maison.

Ầ ces rituels anciens la maison de S. N. a ajouté depuis une date récente des fêtes calendaires internes, introduites par imitation d'initiatives prises dans les écoles, sur le modèle de célébrations marquant la rupture des saisons : expulsion des forces néfastes assimilées à des haricots grillés qu'on jette à l'extérieur de la maison, à la rupture saisonnière du setsubun ; fête des poupées ${ }^{55}$ et fête du $5^{\mathrm{c}}$ mois $^{56}$, respecti-

52. La date en varie chaque année et on l'appelle «le petit Nouvel An » (Ko-shōgatsu 小正月) ou encore «l'ancien Nouvel An» (Kyü-shögatsu 旧正月). Le 7, dit "Nouvel An du 7 " (Nanuka shögatsu 七日正月), on partage chez S. N. la « bouillie aux 7 herbes", dite " bouillon des 7 herbes » (nanakusa jiru 七草汁) (plus généralement appelé nanakusa gayu 七草枵, “ bouillie de riz aux sept herbes ").

53. À Sasaguri, les sections territoriales internes aux quartiers constituent des unités sociales de voisinage et d'entraide nommées kumi 組 ou kumi.ai 組合, qui n'ont rien à voir avec les syndicats ou les coopératives appelées également kumi.ai 組合. (N.D.T.)

54. Voir ci-dessous p. 498-509.

55. La fête des poupées (hina matsuri ひな祭り) (le 3 mars) a son origine dans un rite de purification/expulsion, consistant en la mise rituelle à la rivière ou à la mer d'effigies humaines ou de poupées sur lesquelles ont été fixées les forces néfastes. Dans la haute société des guerriers et des aristocrates, elle devint une fête des petites filles avec exposition de somptueuses estrades de poupées. Mais parallèlement à cela, existe aussi à cette date la coutume de partager un pique-nique dans la montagne, appelée banami 花見, "fête des fleurs " (littéralement « regarder les fleurs 》) ou yamami 山見, " fête de montagne " (littéralement " regarder la montagne »), qui correspond à l'accueil du dieu de la montagne avant le repiquage du riz. À Sasaguri, c'est le sens de fête des filles qui prévaut dans la compréhension générale. D'autre part, à Tsubakuro, l'école primaire organise un événement pour les enfants. Ceux-ci, après avoir reçu les bulletins de la fin du trimestre, vont dans les champs cueillir les pousses de prêle tsukushi 土筆 (Equisetum arvense), puis les cuisent et les mangent. Cet événement est appelé menjō-yori 免状寄り, “ rassemblement des diplômes 》 (« diplôme » étant pris ici dans le sens de «bulletin de note »). Cet événement peut avoir le sens de rite agraire de l'accueil du dieu de la montagne dans les rizières.

56. La fête du $\varsigma^{c}$ mois (tango no sekku 端午の節句) (le $\varsigma$ mai) est une fête chinoise de changement de saison reprise au Japon. Mais ce même mois, existe aussi la coutume japonaise dite « fête de l'acore " (shōbu no sekku 葛蒲の節句), à l'occasion de laquelle on recouvrait d'acores odorantes, à vertus apotropaïques, le toit de la cabane où se retiraient pour la nuit les femmes qui allaient 
vement aux $3^{\mathrm{e}}$ mois et $\varsigma^{\mathrm{e}}$ mois de l'ancien calendrier ; mise en place de décors de bambous pour la fête de tanabata en juillet ${ }^{57}$.

Les rites de la fête des morts (obon お盆) au mois d'août, qui sont le pendant des célébrations du Nouvel An, sont centrés sur l'accueil des âmes des disparus, par la famille et la parenté, à l'intérieur des habitations. Cet accueil est associé à la circulation des groupes familiaux entre plusieurs pôles religieux et sociaux : cérémonie pour tous les défunts et les âmes « affamées 》 (segaki 施餓鬼) au temple paroissial où se rendent les représentants de chaque maison; préparatifs domestiques pour l'accueil des morts (nettoyage des tombes, montage de l'autel des morts, préparation des mets festifs) ; déplacement de toute la famille, dont le maître de maison, jusqu'aux tombes, le 13 août, pour aller chercher les défunts et les guider vers la maison au moyen de ce support des âmes qu'est le feu des lanternes; accueil des morts sur l'autel du bon (bondana 盆棚) où sont disposées les offrandes (boulettes de riz, plateaux des âmes, reizen 霊瞨) changées trois fois par jour jusqu'au soir du 15 ; renvoi des âmes le is au soir avec des boulettes de riz qu'on porte à la rivière, ou bien aux tombes, où l'on brûle le «feu de renvoi » (okuribi 送り火). La danse du bon (bon odori 盆踊り), dont la fonction est l'apaisement des âmes et leur renvoi dans l'au-delà par le groupe local, se déroulait autrefois devant les maisons où il y avait eu des morts depuis le bon de l'année précédente. Elle a lieu aujourd'hui dans un espace collectif public où se retrouvent en grand nombre les membres des familles du quartier, et elle est surtout conçue comme l'occasion de resserrer les liens du groupe local.

L'automne est ponctué de fêtes des morts et des récoltes, qui sont symétriques à celles du printemps : fête des ancêtres (bigan 彼岸) le jour de l'équinoxe d'automne avec visite aux tombes, en septembre, et fête des moissons communautaire (okunchi おくんち) au sanctuaire tutélaire (chez soi, on mange des boulettes de riz à la pâte de haricots sucrés), en octobre; fête communautaire de Yakushi (o-Yakushi-sama お楽 師様) devant l'oratoire de Yakushi, en novembre. À toutes ces fêtes les membres des familles participent en grand nombre.

Ce calendrier des rites familiaux montre que ces derniers sont centrés sur l'accueil, le partage et le renvoi des dieux et des âmes des morts dans les maisons et dans les communautés de voisinage. Cependant, depuis la fin des années I980, ces fêtes sont surtout devenues l'occasion de recevoir des invités à la maison.

faire le repiquage du riz. Dans les maisons de guerriers, le jeu phonétique sur sbōbu 尚武 (terme exaltant la valeur guerrière) fit de cette fête celle des garçons, pour qui l'on dresse des bannières et expose des poupées représentant des guerriers. À Sasaguri, on mange ce jour-là du mochi sucré entouré de feuilles de Smilax china (gamenoba mochi ガメハハ餅), qu'on mangeait autrefois pour le repiquage du riz. Cette coutume est sans doute à relier à la première acception, agraire, de la fếte, alors que les manches à air de carpes (koi-nobori 鯉幟) sont à rattacher à la seconde.

57. Comme la fête des poupées ou celle du $5^{\complement}$ mois, on se mit à les célébrer dans les maisons aisées à partir de 1925, et plus généralement vers 1975. À Sasaguri, le lancer des haricots du setsubun et la décoration de tanabata n'existaient pas dans les familles avant les années 1960, date à laquelle on commença à les organiser dans les jardins d'enfants et les écoles. Les membres de la famille se réunissent pour ces occasions autour des enfants, mais toutes ces célébrations cessent lorsqu'ils ont grandi. 
Exemple 5. - I. A. (née en 1943) a appris de sa belle-mère la façon de cuisiner les mets du Nouvel An. Lorsque son mari devint maître de maison, ses frères cadets avaient l'habitude de venir avec leur épouse le 30 décembre pour piler le mocbi et préparer ensemble les plats du Jour de l'an. Chaque ménage remportait ensuite une part de ce qui avait été confectionné par tous. Lors de la visite rituelle des ménages des cadets à la maison de l'ainé pour le Jour de l'an, ceux-ci retrouvaient évidemment les mêmes plats que ceux qu'ils avaient mangés chez eux, ce qui fut la source de critiques. Aussi fut-il décidé d'arrêter les préparations du Jour de l'an en commun. Chaque ménage fit donc une cuisine différente pour le Nouvel An, et I. A. y introduisit du poulet frit, particulièrement apprécié de ses enfants.

Même s'ils n'habitaient pas sous un même toit, tous les membres d'une même famille, de génération en génération, consommaient ainsi une nourriture festive identique le Jour de l'an : c'était précisément ce qui entretenait la conscience de leur appartenance à une même maison. En outre, ce repas festif, qui dans son sens premier était considéré comme une offrande au dieu de l'An, était aussi un partage entre divinité et humains. L'exemple précédent témoigne d'un glissement dans la perception des rites, qui en viennent à être centrés, non plus sur la célébration des dieux, mais sur les goûts des membres de la famille.

Exemple 6. - Habitant de Tsubakuro, K. S. (né en 1947), a repris à la suite de son père, la direction de l'entreprise familiale à Yoshizuka 吉塚 (Fukuoka, arrondissement de Hakata 福岡市博多区). Lors de son mariage avec K. Y. (née en 1952), il a déménagé à Sasaguri dans une maison qu'il avait fait construire ${ }^{58}$. Ils ne vivaient pas avec les parents de K. S. mais, chaque année, le 30 décembre, K. Y. allait faire le grand ménage de fin d'année dans la maison de ses beaux-parents, faisait les courses pour les plats festifs du Jour de l'an. Le 31, elle allait les confectionner chez eux et préparer la table pour le lendemain. Le $\mathrm{i}^{\mathrm{er}}$ janvier, elle se rendait chez ses beaux-parents avec son mari et ses enfants pour partager le repas du Nouvel An. Après la mort de son beau-père, sa belle-mère vint habiter chez elle, mais c'est elle qui continua à préparer le repas du Jour de l'an. Une année, son fils qui était allé pour le Jour de l'an dans la famille de la mère de K. Y., revint en disant qu'il n'avait « rien trouvé à son goût » dans ce qui lui avait été servi. Cette année-là, comme sa grand-mère maternelle, qui d'habitude faisait la cuisine pour le Nouvel An, était hospitalisée, c'est la belle-fille qui avait acheté tout faits les plats festifs. "Tant qu'à mettre une telle somme, autant acheter du crabe et des langoustes ! "critiqua-t-il. À la suite de ce souhait de son fils, K. Y. ajouta crabe et langouste à la cuisine du Jour de l'an chez elle.

Cet exemple reflète deux types d'attitudes différentes face à l'héritage familial des mets rituels. En tant qu'épouse de l'héritier K. S., l'aîné de sa famille, K. Y. a repris et perpétué les recettes de sa belle-mère, tout en y faisant quelques aménagements pour que les mets soient aussi au goût de ses enfants. Tandis que sa belle-sœur, belle-fille de sa propre mère, n'a pas fait ce choix et se contente d'acheter des plats préparés.

Néanmoins, les exemples 5 et 6 des maisons d'I. A. et K. Y. sont semblables en ce que le Nouvel An n'est plus l'occasion d'accueillir le dieu de l'An, mais de recevoir les membres de la famille qui sont partis vivre à l'extérieur. Si l'on considère que le lieu où l'on reçoit les visiteurs (membres de la famille du debors) est différent

58. En train, Yoshizuka est à to minutes de Sasaguri. 
de l'espace quotidien et possède donc un sens festif, on peut dire que le rite est continué. Dans ce cas, le rite du Nouvel An devient l'espace-temps de la réunion familiale où la dimension sacrée n'est plus ressentie comme nécessaire.

Si l'on fait la comparaison avec les ritualités de la fête des morts, pour lesquelles le dispositif de purification n'est pas aussi indispensable que pour le Nouvel An, on constate néanmoins que subsiste l'apparat rituel de l'autel des âmes et des lanternes. Nous avons vu que le bon est un rite d'accueil des âmes des défunts. Le 13 août, non seulement les membres de la famille mais aussi de nombreuses personnes du voisinage viennent en visite, apportant pour les morts des offrandes en espèces. À Sasaguri, c'est plutôt la fête des morts qui est le grand moment des visites et de la sociabilité locale. C'est notamment le cas dans les maisons de «premier bon " (batsu-bon 初盆), c'est-à-dire celles où il y a eu un mort durant l'année écoulée, et où les ritualités prennent une dimension considérable ${ }^{59}$. Le " premier bon » est l'un des rituels du cycle de la vie individuelle. Mais comme chaque année, il y a toujours dans le quartier ou dans le groupe de voisinage une ou plusieurs familles endeuillées, les membres des autres maisons doivent leur rendre la "visite du premier bon " (batsu-bon mairi 初盆参り). Ces visites constituent donc aussi l'un des rites annuels collectifs pour le groupe local. À ceci est associée la danse de la fête des morts (bon odori 盆踊り), récemment rebaptisée " fête de l'été 》 (natsu matsuri 夏祭り), pour attirer les jeunes. À cette occasion, les plaquettes funéraires (ibai 位牌) des "nouveaux défunts 》 sont sorties à l'extérieur des maisons et disposées sur un autel commun devant lequel tout le monde danse (fig. 2). Ainsi, c'est tout le groupe local qui célèbre collectivement ce rite du cycle de la vie individuelle des maisons.

Les couples des jeunes générations, qui n'ont pas d'autel bouddhique pour les morts chez eux, n'accueillent pas les âmes. Mais ils se rendent dans leurs familles respectives et pour eux, le bon est un rituel du debors de la maison d'habitation. Aujourd'hui, la fête des morts a tendance à être de plus en plus considérée comme une réunion de famille.

Les fêtes implantées à Sasaguri au $\mathrm{XX}^{e}$ siècle, comme celle des poupées, celle du $5^{\mathrm{c}}$ mois, le lancement des haricots du setsubun ou encore tanabata, qui sont centrées sur les enfants et ne sont généralement plus continuées lorsque ceux-ci sont devenus grands, sont autant d'occasions de réunir la famille. Cet objectif est aussi

59. À Sasaguri, le «premier bon » est organisé de façon aussi solennelle que les funérailles. À côté de l'autel bouddhique ou dans le tokonoma, on dresse une grande estrade sur laquelle sont déposées les offrandes et le "plateau de l'âme » du défunt (reizen 霊膳) et sur le côté de laquelle est suspendue au plafond l'imposante lanterne du bon de 2 mètres de haut et $50 \mathrm{~cm}$ de large. Le 13 août, les habitants de la section, les responsables du quartier et la parenté viennent rendre visite à la famille et déposer une offrande en espèces, tout à fait comme lors des funérailles. Cette pratique s'est transmise dans les maisons où vivent des personnes âgées, mais dans les familles des jeunes générations, souvent par manque de connaissances, on fait appel aux pompes funèbres pour la disposition de l'apparat rituel. Autrefois, c'est la section qui, en tant que groupe d'entraide, prenait en charge toute l'organisation des funérailles, et par là était le corps de transmission des savoir-faire tant pour les funérailles que pour le premier bon. Lorsque les entreprises de pompes funèbres se sont mises à remplacer les sections, ce sont donc elles qui ont récupéré l'ensemble des coutumes et qui désormais les transmettent. 


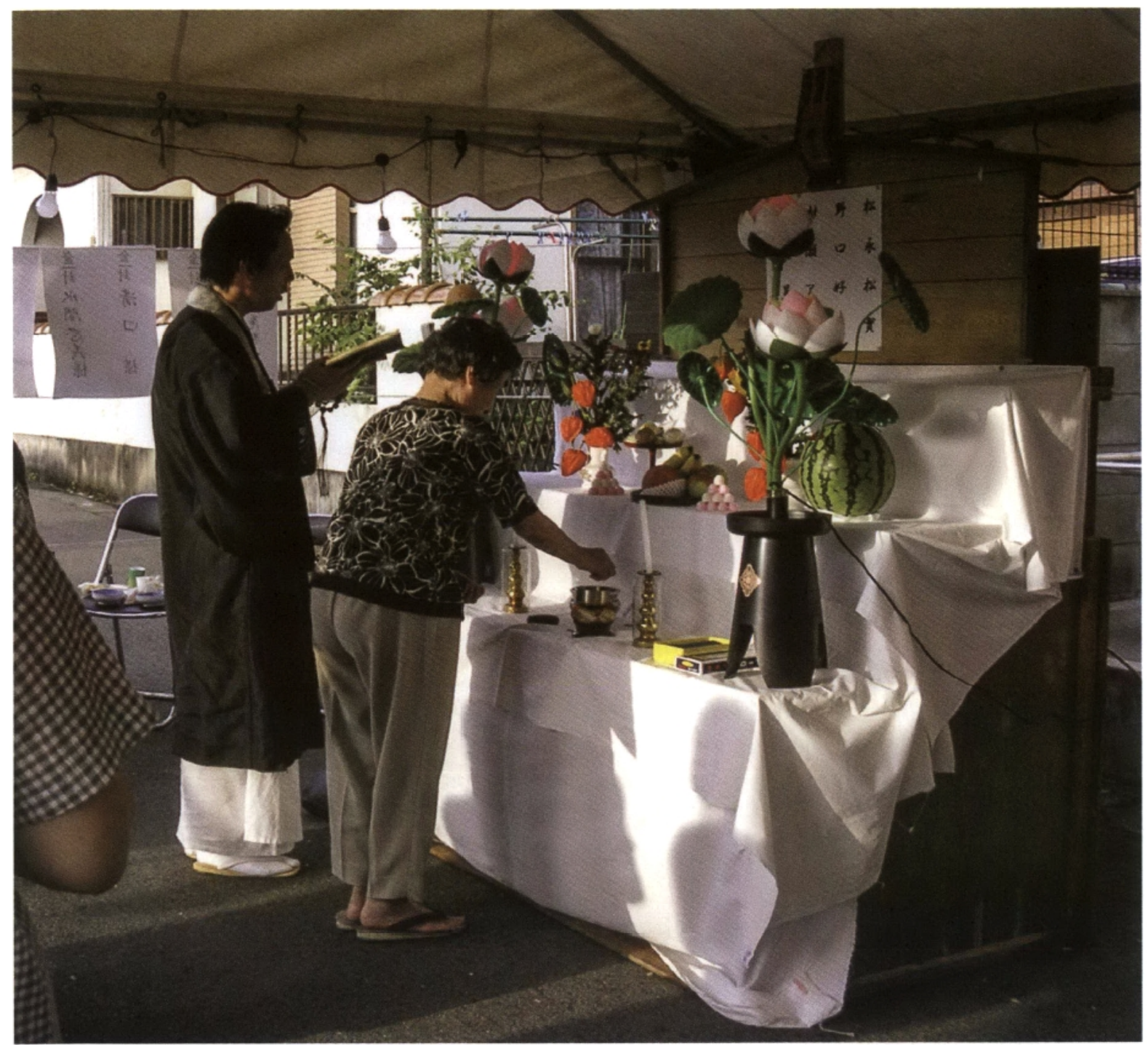

Fig. 2 : Autel pour les plaquettes funéraires, les photos des défunts de l'année et les offrandes (le nom des défunts est inscrit au-dessus de l'autel)

(place où, le soir, aura lieu la danse de la fête des morts, quartier Meiji, 9 août 2009).

celui d'autres fêtes qui ont fait leur apparition récemment, comme anniversaires, anniversaires de mariage, fête des Pères, fête des Mères, Noël, Saint-Valentin, et qui ont commencé à se répandre dans les familles à partir de 1965 . Aujourd'hui, en tant qu'événements familiaux festifs, ces nouvelles fêtes ont tendance à supplanter les célébrations traditionnelles.

Lorsque les familles tendent à l'individualisation en perdant le cadre des maisons, fêtes et célébrations deviennent le moyen permettant de « jouer à la famille », fait remarquer Takeda Michi 竹田美知 ${ }^{60}$. Même si faire reposer la cohésion familiale sur les seules fêtes de famille peut sembler un peu extrême, il n'en est pas moins vrai

6o. Takeda Michi 竹田美知, « Katei seikatsu no kobetsuka 》家庭生活の個別化, dans Kanbara Fumiko 神原文子 et al., éd., Yoku wakaru gendai kazoku よくわかる現代家族, 2010, p. 70. 
que les occasions festives et rituelles jouent un rôle important dans ce qui lie entre eux les membres des familles actuelles.

LE FESTIF SORTI HORS DE LA MAISON. - L'analyse de la façon dont les jeunes générations passent le Jour de l'an va nous permettre de comprendre quel lieu représente la maison d'habitation pour elles.

Exemple 7. - N. Y. (née en 1976) est la fille de K. S. (exemple 6). Elle a grandi à Sasaguri, mais durant son enfance, elle avait l'habitude d'aller avec sa mère $\mathrm{K}$. Y. chez ses grandsparents à Yoshizuka pour aider à préparer les plats festifs et les offrandes du Nouvel An et de la fête des morts. Elle s'est ensuite mariée avec un fils de la famille N. de Munakata 宗像 (dans le département de Fukuoka). Son mari n'étant pas l'aîné, les nouveaux époux ne se sont pas installés chez ses beaux-parents, mais habitent dans une maison qu'ils ont fait construire à Shingū 新宮 (département de Fukuoka, canton de Kasuya 糟屋郡). Ses beaux-parents tiennent un restaurant, et comme ils sont très occupés en fin et en début d'année, ils ne font pas de mets rituels chez eux pour le Jour de l'an. N. Y. n'ayant donc aucune tradition culinaire rituelle à perpétuer à la suite de sa belle-mère, elle s'est trouvée dans une position lui permettant d'imposer celle de sa grand-mère maternelle. Or, depuis son mariage, chaque $\mathrm{I}^{\text {er }}$ janvier elle va avec son mari chez ses beaux-parents, puis dans sa propre famille où ils partagent le repas du Jour de l'an, avant de rentrer chez eux en rapportant des plats festifs. Aussi ne cuisine-t-elle quasiment pas elle-même pour le Nouvel An.

Exemple 8. - Habitante de Yamate 山手, T. K. (née en 1960) ne cuisine, en dehors du $z o ̄ n i$, aucun plat spécial pour le Nouvel An. C'est la mère de son mari qui fait la cuisine pour la fête, et $\mathrm{T}$. $\mathrm{K}$. ne fait que l'aider. Le 28 décembre, elles pilent le riz pour faire le mochi, et son rôle est de façonner la pâte en boules. Le 31 au soir, elle va avec son mari chez ses beaux-parents, où ils passent la nuit et partagent avec eux les plats festifs du Nouvel An, préparés entièrement par sa belle-mère, ainsi que des produits frits qu'elle-

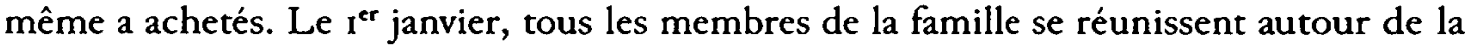
table, et commencent par boire du thé accompagné de kakis secs. Son beau-père verse ensuite le zōni dans le bol de chacun. Et tous le prennent avec des morceaux de seiche et de laminaire séchés. Ce soir-là, ils rentrent chez eux. Le 2 janvier, ils mangent les plats du Jour de l'an rapportés de chez les parents du mari, accompagnés d'un zōni confectionné par T. K. selon la recette de sa propre maison.

Ces deux exemples sont loin d'être des exceptions. On constate une augmentation du nombre de couples des jeunes générations qui prennent le repas du Jour de l'an dans les deux maisons de leurs parents respectifs et ne font aucune cuisine chez eux pour cette occasion. $\mathrm{Si}$, malgré la non-cohabitation avec les parents, les rites des maisons des parents ou des beaux-parents étaient perpétués par ces jeunes couples, on pourrait sans doute parler de continuation rituelle. Mais, à l'instar des exemples 7 et 8, ceux-ci ne reproduisent pas chez eux les rites de leurs familles respectives. On a plutôt l'impression que, le rituel festif étant accompli chez leurs parents, pour eux, leur logement est un lieu réservé au seul repos et à la détente après le stress. De retour dans leur propre maison après ce moment dans leurs familles, N. Y. et T. K. sont unanimes pour dire : « Nous passons tranquillement le reste des congés du Nouvel An. » Faire des préparatifs pour transformer l'habitation en un espace rituel est ressenti comme contraignant et dérangeant. On constate le renforcement du désir de ne considérer la maison que comme un lieu de vie ordinaire. L'habitation 
n'est plus que l'endroit où l'on se repose de la fatigue ou, comme le dit Nishimura Junko 西村純子, celui de la reproduction des forces de travail ${ }^{61}$. La tension du festif, c'est-à-dire la modification du quotidien, n'est pas souhaitée.

C'est pourquoi le festif, exclu de la maison, est sorti à l'extérieur de celle-ci. Ainsi, pour le Nouvel An, au lieu de rester en famille à la maison, on préfère partir tous ensemble passer les fêtes de fin d'année dans un hôtel de sources chaudes. Pour Noël, on mangeait un gâteau ou un repas de fête à la maison; aujourd'hui, le repas se fait au restaurant. Même si l'événement reste l'occasion d'une réunion familiale, la tendance est d'exporter celle-ci au-dehors. Antérieurement, ces déplacements représentaient de fortes dépenses, que seules quelques maisons privilégiées pouvaient se permettre. Mais avec l'amélioration de l'offre des entreprises de restauration en ville, faire un repas à l'extérieur en est arrivé à aller de soi, ce qui a contribué à déplacer le festif au-dehors. Ainsi, on célèbre en faisant un repas au restaurant, non seulement les anniversaires, les fêtes des Pères et des Mères, c'est-à-dire les " nouvelles fêtes », mais aussi les rites annuels traditionnels comme le Nouvel An et la fête des morts. C'est au-dehors qu'on renforce les liens familiaux. Les mariages et les funérailles, qui ne sont pas des rites annuels mais se déroulaient à la maison jusqu'à une date récente, sont aujourd'hui, eux aussi, majoritairement célébrés à l'extérieur. Tout ceci fait que l'habitation est de moins en moins un espace festif et rituel.

On peut se demander, en retour, pourquoi les jeunes générations ne perçoivent nullement les rites annuels familiaux comme quelque chose de religieux ou de cultuel. L'une des raisons en est sans doute la transformation des instruments et ustensiles domestiques. La révolution matérielle de l'appareillage ménager et son amélioration ont provoqué des modifications voire l'extinction des rites eux-mêmes. Ainsi le puisage de "l'eau nouvelle ", analysé précédemment, a brusquement disparu avec le changement du point d'eau, lorsque les puits et les fontaines ont été remplacés avec la généralisation des canalisations. Les cuisinières à gaz ont pris la place des fourneaux à bois, ce qui a permis d'allumer le feu facilement et en toute sécurité, faisant de la cuisine un espace agréable et débarrassé du noir de suie. Et le dieu du feu (bi no kami 火の神), Kōjin sama 荒神様, qui était vénéré sur tous les fourneaux, s'est éloigné du feu. Aujourd'hui, avec un seul bouton, il est désormais possible d'allumer du feu. Cette facilité encore plus grande permet de ne plus avoir besoin de compter sur le dieu du feu, puisqu'on est sûr de pouvoir cuisiner à tout moment. Aussi Kōjin a-t-il été relégué dans un recoin de la cuisine, ou même n'est plus du tout objet de culte. Selon une femme de Sasaguri qui a une trentaine d'années : "L'image de Kōjin (ofuda お札) près de la cuisinière propre n'a rien d'agréable. » Ou encore, depuis que les vêtements sont pour la plupart achetés, la couture, qui était une tâche ménagère indispensable, n'est plus une nécessité. Aussi les aiguilles ont-elles disparu des maisons. Pour cette raison, le rite annuel

6I. Nishimura Junko 西村純子, «Kindai kazoku no naka no josei » 近代家族の中の女性, dans Shimizu Hiroaki 清水浩昭 et al., éd., Kazoku kakumei 家族革命, 2004, p. 6r. L'auteur analyse la façon dont la dissociation de la famille et de l'activité de production a fait du lieu de vie un endroit spécialement dédié au " care ", ensemble de soins, de gestes d'entretien matériels, de liens affectifs, dont a été évacuée toute dimension économique. 
de « service de reconnaissance aux aiguilles » (bari kuyō 針供養) n'est plus pratiqué que par les professionnels de la couture.

Incommodités et difficultés rendaient nécessaires la bienveillance des dieux. À l'inverse, les facilités de la vie quotidienne ont fait oublier leur existence. Par là, la dimension religieuse et cultuelle des rites s'est estompée, allant même jusqu'à rendre inutile l'accomplissement de ceux-ci. Aussi, comme l'a montré l'analyse précédente, ce ne sont plus les célébrations religieuses des dieux ou des morts, par le biais desquelles se réalisait antérieurement la cohésion des maisons, mais les liens familiaux eux-mêmes qui sont devenus le centre des ritualités. Qu'en est-il alors des rites communautaires des groupes locaux ? Et que devient le festif sorti des maisons lorsqu'il est repris collectivement?

\section{Les rites annuels à l'extérieur de la maison : rôle des ritualités communautaires du groupe local}

Le " groupe local » désigne ici l'organisation autonome constituée par l'ensemble des maisons qui forment une communauté de vie incluse dans un périmètre topographiquement délimité. À Sasaguri, cette organisation autonome a pour unité de base le groupe dénommé kumi 組 (littéralement "ce qui est noué ensemble ") ou kumi.ai 組合62 (traduit ici par "section"), qui est composé de 10 à 50 maisons. $\mathrm{La}$ réunion de ces sections forme le "quartier» $(k u$ 区). Dans les 2I quartiers, on compte, en 2013, respectivement ro sections à Kido, 7 à Yamate, 5 à San.nō 山王, 9 à Kami-machi 上町, 12 à Naka-machi 中町, 17 à Shimo-machi 下町, 8 à Takata 高田, 7 à Kana.ide 金出, 4 à Haginoo 萩尾, 7 à Ôseto 大勢門, 8 à Shin-machi 新町, 23 à Shō 庄, 39 à Onaka 尾仲, II à Wakasugi 若杉, 26 à Oto.inu, 24 à Wada 和田, I2 à Tsubakuro, II à Tanaka 田中, Io à Meiji 明治, 2 à Ike-no-hata 池の端, I5 à Bentana Hiruzu ベンタナヒルズ ${ }^{63}$. Ces quartiers actuels de Sasaguri correspondent majoritairement aux anciennes unités villageoises (mura 村) qui, lors de la fusion communale de 1955 , ont été réunies pour donner naissance à la commune ${ }^{64}$. Aussi le sentiment de communauté et de solidarité locales est-il très développé chez les habitants de ces quartiers et sections. Les rites annuels communautaires analysés ici sont ceux de ces entités micro-locales des sections et quartiers. Ceux qui sont

62. Les sections d'un même quartier sont appelées par exemple sections I et 2 (ichi-kumi, ni-kumi 1 組, 2組), ou haute et basse (kami-gumi 上組, shimo-gumi 下組). Certaines d'entre elles sont elles-mêmes composées de "divisions " (ban 班). Les sections ont un budget indépendant de celui des quartiers, qui fait l'objet d'une collecte interne. Elles ont des comptables, des comités culturels et sportifs.

63. Pour une population de : 287 habitants à Kido, 216 à Yamate, 224 à San.nō, 715 à Kamimachi, 1786 à Naka-machi, 1622 à Shimo-machi, 862 à Takata, 475 à Kana.ide, 137 à Haginoo, 512 à Ōseto, 1463 à Shin-machi, 4310 à Shō, 4712 à Onaka, 94I à Wakasugi, 3084 à Oto.inu, 3122 à Wada, 2231 à Tsubakuro, 2075 à Tanaka, 490 à Meiji, 23I à Ike-no-hata, 2 IIo à Bentana hiruzu (chiffres de 2013).

64. Voir la présentation de ce volume par Anne Bouchy, "Sasaguri. Dedans, dehors : une approche ethnologique collective », p. I-26. 
organisés sous l'autorité de la commune et qui réunissent la population communale tout entière entrent dans la catégorie des rites extérieurs au groupe local ; ils ne seront donc pas abordés ici.

Ces rites communautaires du groupe local sont organisés soit par le quartier (ou la section), soit par un groupe d'âge ou par un groupe cultuel. Autrefois, des confréries de solidarité économique avaient elles aussi leurs rituels, mais ces groupes disparurent dans les années $1950^{65}$. Les associations féminines, qui furent particulièrement actives à partir des années de guerre, avaient également les leurs, mais elles furent remplacées par des groupes de bénévoles et furent dissoutes en mars 2002.

\section{Contenu et acteurs des rites communautaires locaux}

CONTENU DES FÊTES ET ÉVÉNEMENTS ANNUELS DU QUARTIER. -

Les représentants du quartier comme acteurs principaux. - Ceux qui dirigent les fêtes du quartier et des sections sont les responsables, les « chefs » (kuchō 区長, kumichō 組長) de ces derniers. Ils sont aussi les représentants de toutes les maisons dont les délégués sont majoritairement les maîtres de maison. Les fêtes des sections et celles du quartier sont distinctes. Au sein des premières a lieu seulement la réunion générale de la section (kumi.ai sökai 組合総会), organisée par le chef de section en exercice, et à laquelle participent les représentants de toutes les familles (principalement les maîtres de maison) ${ }^{66}$. Dans les quartiers, dont les responsables sont au nombre de trois, à savoir le chef de quartier, son second et le comptable, fêtes et événements sont placées sous la responsabilité de ces derniers. Y participent les chefs des sections du quartier et une partie des habitants. Le chef de quartier et son second cumulent aussi les fonctions de directeur et sous-directeur de la Maison citoyenne (köminkan 公民館), qu'on qualifie d'《 annexe " (kömin bunkan 公民分館) pour la distinguer de la Maison citoyenne communale dite " centrale 》 (chūō köminkan 中央公民館), qui relève de toute la commune de Sasaguri. Les fêtes et événements du quartier qui se déroulent dans cette Maison citoyenne annexe ont pour acteur principal son directeur, qui est aussi le chef de quartier. Les autres acteurs sont choisis sur recommandation des gens du quartier. Il faut remarquer ici que les responsables des maisons qui siègent aux assemblées du quartier et tous ces responsables sont majoritairement des hommes. Aussi les acteurs principaux des fêtes et événements communautaires sont-ils masculins. Ils sont chargés de l'organisation et des préparatifs des fêtes. Bien que ceux-ci soient réalisés suivant un

65. Les confréries économiques de Sasaguri tenaient leurs réunions en disant qu'elles “ faisaient confrérie " ( $k o ̄$ wo suru 講をする). La totalité de l'argent versé en parts égales par les membres faisait l'objet d'une adjudication chaque mois. À partir du mois suivant, l'adjudicataire devait ajouter les intérêts à la somme qu'il reversait. Dans certains cas, les non-adjudicataires recevaient à tour de rôle la totalité de la somme. Ou bien, l'argent était réparti entre ceux dont le nom avait été tiré au sort.

66. À Tsubakuro, après la réunion générale de section a lieu un repas au restaurant, organisé par le chef de section, auquel participent toutes les maisons de la section et qui est appelé banami 花見 (《admirer les fleurs 》). 
protocole fixe d'une année à l'autre, la charge en est assez lourde. Par exemple, pour la grande fête du sport du quartier qui se déroule en automne, à laquelle participait la quasi-totalité des familles jusque vers la fin des années 1990, il faut emprunter le stade de l'école. Aussi, en début d'automne, avant la saison des fêtes du sport, tous les quartiers sont-ils en concurrence pour la réservation des lieux. Dans ces années-là, on disait que pouvoir réserver le stade à la bonne date était une affaire relevant du talent personnel du chef de quartier qui en était responsable.

Événements communautaires et participants. - Je prendrai pour exemple concret le cas du quartier de Tsubakuro ${ }^{67}$ et classerai les fêtes et événements communautaires en catégories définies par leur orientation :

- Evénements pour la gestion collective du quartier : assemblées (de tout le quartier, de toutes les sections), assemblées des chefs de sections, assemblées à l'extérieur du quartier, nettoyage des fossés et canaux du quartier, grand nettoyage, activités des sapeurs-pompiers ${ }^{68}$;

- Fêtes et événements relationnels à caractère culturel : grande fête du sport, fête de la culture du quartier, participation aux fêtes du sport et de la culture extérieures au quartier, « salon-vitalité » (Iki-iki saron いきいきサロン), réunion des anciens, fête de l'été ;

- Rites religieux et ritualités agricoles : fêtes annuelles du sanctuaire tutélaire Goryō-gū 御霊宮, veille au sanctuaire (okomori), fête de l'été c'est-à-dire danse du bon pour la fête des morts (bon odori 盆踊り) ${ }^{69}$, veille du dieu «des Grains ${ }^{70}$ » (Gokoku-jin 御穀神), rite agraire.

On constate que sont appelés gyōi 行事 (《fête, rite, cérémonie, événement »), et entrent ainsi dans la liste des "rites annuels » gérés par les mêmes instances du quartier, des événements totalement laïcs et d'autres qui sont cultuels et religieux. Ce mélange contrevient au principe de laïcité de la constitution qui impose la séparation du religieux et du politique. Pourtant, au niveau micro-local, la question n'est généralement pas appréhendée sous cet angle ${ }^{71}$. Car les organisations locales

67. Voir le calendrier des fêtes et événements communautaires (quartier de Tsubakuro), pour l'année 2008 à la fin de cette contribution.

68. Les sapeurs-pompiers du quartier constituent une organisation autonome de prévention et sauvetage. Suite à la dissolution du groupe des jeunes (seinen-dan 青年団) après la seconde guerre mondiale, cette organisation, qui rassemble les jeunes hommes, perpétua le caractère de groupe d'âge. Mais aujourd'hui, ce caractère s'est affaibli car, à cause de la diminution de leur nombre, certains des membres ont la quarantaine.

69. La « fête de l'été » ayant le double caractère de fête relationnelle à caractère culturel et de rite religieux, elle entre dans ces deux catégories.

70. Les " grains" sont assimilés ici aux céréales cultivées; il s'agit d'un rite propitiatoire pour l'obtention de bonnes moissons. (On parle plus généralement du dieu des "Cinq grains ", Gokoku-jin 五款神).

7I. Lorsque des citoyens contestent la légalité de l'usage des deniers publics pour ce qu'ils considèrent comme des actes religieux et donc illégaux, l'affaire peut aller jusqu'au procès. Mais dans la plupart des cas, ils sont déboutés par le tribunal, qui reconnaît aux actes litigieux le statut de " pratiques coutumières » ne relevant donc pas de la « religion ». Ceci met en lumière l'ambiguïté de la définition de la religion et de la sphère du religieux dans la société japonaise, notamment depuis Meiji. (N.D.T.) 
actuelles et leurs autorités sont considérées par tous comme prolongeant aujourd'hui les activités des organisations anciennes, datant de l'époque Edo, qui géraient toutes ces facettes de la vie communautaire ${ }^{22}$. C'est à ce titre que rites, fêtes et événements communautaires, actuels et traditionnels, qu'elles organisent sont analysés ensemble ici.

Les participants à ces différents événements se répartissent comme suit. Pour la gestion collective, ce sont les représentants de chaque maison en la personne de l'un des leurs (un homme pour les assemblées de sections, un homme ou une femme pour le nettoyage des fossés et le grand nettoyage) ; et généralement les chefs de section pour l'assemblée du quartier (alors que la présence de tous les habitants y est autorisée). Tout le quartier participe aux fêtes et événements relationnels majeurs à caractère culturel que sont les fêtes du sport et de l'été. Cette dernière, qui correspond en fait à la danse de la fête des morts, est ainsi la grande réunion de tous les habitants. Les « salons-vitalité » mensuels (réunions autour d'un déjeuner) et la réunion annuelle des anciens ont pour seuls participants les personnes âgées qui y sont fêtées. Quant aux événements extérieurs au quartier, ce sont soit le chef de quartier soit les représentants élus du quartier qui s'y rendent au nom de tous.

Rites annuels traditionnels et participants. - D'une façon générale, on constate la tendance à l'affaiblissement de la dimension religieuse et cultuelle des rites anciens au profit de leur perception par les participants comme une occasion de réjouissance collective.

La fête annuelle du sanctuaire tutélaire est l'une des fêtes du quartier, parce que celui-ci correspond à l'ancien village d'avant la fusion communale de 1955, et que, jusqu'à cette époque, il y avait un sanctuaire tutélaire dans chaque village, dont les habitants constituaient le groupe cultuel. Les fêtes du sanctuaire ont pour objet des rites propitiatoires pour la sécurité et la prospérité du quartier. Les acteurs rituels sont, d'une part, les représentants auprès du sanctuaire des habitants (omiya sōdai お宮総代) résidant dans le périmètre de protection du dieu tutélaire (ujiko 氏子) ${ }^{73} \mathrm{et,}$ d'autre part, les responsables du quartier. L'officiant est le desservant du sanctuaire (sbinkan 神官, ou güji 宮司, prêtre). À Sasaguri, deux desservants se répartissent les services de tous les sanctuaires de la commune ${ }^{74}$.

Il y a chaque année deux fêtes, du printemps et de l'automne, dans le sanctuaire de chaque quartier, et celles-ci ont lieu à peu près au même moment. Depuis la fin des années 1990, les célébrations sont toutes concentrées sur les samedis et dimanches ;

72. Voir dans ce même volume Suzuki Masataka 鈴木正崇, «Continuités et transformations de la société locale : le fait coutumier dans le village de Wakasugi ", p. 27-II4 et Anne Bouchy, «Les rapports communautaires aux espaces forestiers entre politiques du dehors et stratégies du dedans : les montagnes-forêts de Sasaguri », p. 115-202.

73. Aujourd'hui, les ujiko sont plus des participants à l'entretien du sanctuaire que des " fidèles » à proprement parler. Ce groupe de soutien est parfois plus vaste que celui du quartier, comme c'est le cas pour le sanctuaire Suwa qui réunit les habitants de sept quartiers. Les représentants des ujiko sont élus parmi eux, et sont généralement des membres des maisons anciennes.

74. Habitant de Naka-machi, le prêtre U. du sanctuaire Suwa a aussi la charge des sanctuaires Suga 須賀神社, Takata Tenjjin 高田天神, Hōman 宝満宫, Hagio 秋尾神社, Taiso 太祖宮. Le prêtre F. du sanctuaire Oimatsu 老松神社 qui habite à Onaka a aussi celle des sanctuaires Tanaka Hachiman 田中八幡社, Wada Hachiman 和H八幡社, Goryō 御需神社. 
aussi les fêtes de plusieurs sanctuaires se déroulent-elles à la même date. Les représentants des habitants et les responsables des 21 quartiers de Sasaguri doivent donc convenir ensemble d'une grille horaire pour les services des prêtres. Ce sont eux aussi qui, le jour de la fête, vont le chercher et le conduisent au sanctuaire suivant.

La « veille au sanctuaire " (okomori), qui a lieu dans chaque quartier de Sasaguri, était originellement, comme son nom l'indique, une veillée de tous les habitants qui passaient la nuit dans le hall de prière devant le sanctuaire. Aujourd'hui, après le service religieux auquel participent le représentant des ujiko, les responsables $\mathrm{du}$ quartier et les chefs de sections, les habitants s'assemblent dans l'enceinte du sanctuaire où ils partagent un repas froid. Dans le quartier de Tsubakuro, l'okomori du sanctuaire se fait en juillet, indépendamment des rites du sanctuaire. Ceci est probablement dû au fait que, comme les dieux vénérés dans ce sanctuaire Goryō 御霊神社 sont les mêmes que les Goryō ${ }^{75}$ du sanctuaire de Gion à Kyōto, dont la célébration (Gion Goryō-e 祇園御霊会, fête de Gozu tennō 牛頭天王祭, dite aussi «fête de Gion », Gion matsuri 柢園祭) a lieu au mois de juillet, c'est ce même mois qui a été choisi pour cet événement.

La fête du dieu « des Grains » (Gokoku-jin) est un rite de demande de bonnes récoltes. Tant que l'économie était de type autarcique, toutes les maisons pratiquaient l'agriculture; aussi participaient-elles toutes à cette fête. Mais avec le passage à l'économie marchande, cette fête est aujourd'hui célébrée par les seules familles d'agriculteurs, ce qui suscite dans les quartiers une certaine résistance à utiliser les fonds collectifs dans ce but. Néanmoins, le rite est continué. Mais bien que toutes les familles soient invitées à y participer, seuls se rassemblent devant la stèle du Gokoku-jin celles des agriculteurs et les responsables du quartier pour la célébration, qui est suivie d'un repas commun. L'autre rite agraire, dit sanabori, a lieu après la fin du repiquage. À Onaka, il se déroulait devant la stèle du dieu Kōshin 庚申 située sur le bord des rizières. Tous s'y retrouvaient après le repiquage, célébraient le dieu Kōshin, puis partageaient un repas sur place. C'est pourquoi on disait faire la « veillée sur la digue»(dote tsüya 土手通夜). C'était la même chose dans les autres quartiers.

Aujourd'hui, pour les participants, le centre de ces fêtes annuelles des sanctuaires et de ces rites agraires est davantage le repas de fête collectif (naorai 直会) ${ }^{76}$, qui vient après le service du culte, que la célébration des divinités. Les rites au sanctuaire sont généralement suivis par les seuls responsables du quartier et les représentants des ujiko, alors que tous les habitants participent au repas festif ; certains d'entre eux peuvent même ignorer l'existence de la partie cultuelle.

75. Au nombre de ces «Âmes», se trouve celle de l'empereur Sudō 崇道天皇, c'est-à-dire le prince Sawara 早良親王 (750?-785), mort dans des circonstances dramatiques lors de luttes politiques. Sur le Goryō-e et l'identité de ces entités terribles, voir Anne Bouchy, "Du bon usage de la malemort. Traitement des "âmes rancuneuses" et rituels oraculaires dans la société japonaise ", dans Brigitte Baptandier, éd., De la malemort en quelques pays d'Asie, 2001, p. 201-234. (N.D.T.)

76. Repas collectif au cours duquel sont partagées les offrandes de nourriture et de sake (o-miki $お$ 神酒). Comme il vient après une purification comportant, entre autres, des interdits alimentaires, il a le sens de retour à la vie ordinaire, d'où ce nom « assemblée du retour (à l'ordinaire) ». 
Dans toute la commune, la danse de la fête des morts (bon odori) prit le nom de " fête de l'été » à partir de la fin des années 1980. Ce changement fut le résultat de la fusion de cet événement rituel avec la fête de la culture des quartiers qui avait lieu anciennement au mois de septembre. La danse du bon se déroule sur la place devant la Maison citoyenne, où sont exposées les plaquettes funéraires des morts de l'année de chaque maison, après que le moine du temple paroissial a récité les sūtra devant elles. Par là, il est clair que ce rite, qui correspond à un événement du cycle de la vie individuelle dans le cadre familial, et pour lequel l'ensemble des membres de la communauté locale s'associe aux familles, fait aussi partie des ritualités extérieures aux maisons ${ }^{77}$. Aujourd'hui, les participants à la fête de l'été ont tendance à oublier les plaquettes funéraires et l'aspect cultuel de cette fête, qu'ils regardent davantage comme l'occasion de danser et de se réjouir ensemble.

Jusqu'en 1945, existait à Sasaguri la coutume dite, littéralement, « du puisage au puits d'eau de mer » (oshioi-tori お潮井取り $)^{78}$ consistant à aller chercher du sable pour la purification sur la grève devant le sanctuaire Hakozaki de Fukuoka. Dans le quartier de Kana.ide, ce sont les chefs de sections qui, à tour de rôle, allaient le chercher chaque mois et le distribuaient au retour dans chaque maison. Il s'agit là d'un travail consistant à se déplacer pour rapporter un opérateur de purification d'un lieu saint extérieur au groupe local. Cette pratique entre dans la catégorie des fêtes et événements relationnels à caractère culturel. Or, bien que l'acte de purification soit fait indépendamment dans le cadre de chaque maison, par sa transformation en un rite des sections, on peut penser que cette pratique a pris le sens d'une purification collective des sections et des quartiers.

LES RITES ANNUELS DES GROUPES D'ÂGE. - Les groupes d'âge sont les associations des anciens (röjin kai 老人会), les amicales (tomodachi kai 友達会), les associations pour le pèlerinage à Ise (sangu $k a i$ 参宫会) et les associations enfantines (kodomo kai 子ぞ も会). Les événements des associations des anciens sont gérés au niveau communal et ne seront pas abordés ici puisqu'ils sont extérieurs au quartier.

Associations pour le pèlerinage d'Ise (sangū kai) et amicales. - Autrefois, ces associations de volontaires réunissaient les membres des groupes des jeunes (seinen-dan 青年団) une fois qu'ils étaient sortis de ceux-ci, et, dans certains cas, les mêmes se retrouvaient dans les deux à la fois.

77. Pour les rites du «premier bon », il est d'usage que tous les habitants du voisinage rendent visite à la maison qui le célèbre. Et c'est dans la cour de cette maison qu'à cette occasion, le groupe local organise, pour l'apaisement de l'âme du défunt récent (ara-mitama 荒御魂/新御整), des récitations ou des danses collectives, dites du nenbutsu 念仏. Mais cette tradition n'est pas rapportée à Sasaguri.

78. Les responsables allaient chercher du sable sur la plage de Hakozaki devant le sanctuaire Hakozaki 笘崎宮 de Hakata (Fukuoka), et en déposaient dans un petit panier (tebo テボ) à l'entrée de chaque maison. Chaque fois qu'un membre de la famille sortait pour se rendre quelque part, il en jetait un peu sur lui. - Originellement, c'était une pratique de purification faite en entrant dans la mer. Par extension, le pouvoir purificateur de l'eau est transféré au sable. Celui-ci est rapporté jusqu'au fond des montagnes par des délégués des communautés locales : tous les membres peuvent ainsi bénéficier de la protection de cette "purification "sans avoir à aller jusqu'à la mer. (N.D.T.) 
Exemple 9. - Habitant de Wada, A. S. (né en 1926) participa au pèlerinage d'Ise en 1955 avec un groupe de 19 hommes de son âge, dit «compagnons du pèlerinage au sanctuaire » (sangū dōgyó 参宮同行) ${ }^{79}$. Comme ceux de la même tranche d'âge qui n'avaient pu se joindre à eux le regrettaient, fut ensuite créée l'amicale « Association prospère 》 (minoru kai みの) る会), qui les intégra tous. Lui-même faisait partie des deux groupes.

Les associations pour le pèlerinage d'Ise sont pour partie de type religieux, mais comme leurs membres font l'expérience d'une sorte d'épreuve en se rendant à l'extérieur de leur localité, elles sont aussi une forme de groupe de rite de passage.

Exemple 10. - À Kana.ide, une amicale dite « causerie-thé » (sawa kai 茶話会) se réunit chaque mois dans l'une des maisons de ses membres, où ceux-ci conversent en buvant. La maison qui les reçoit assure les préparatifs et les frais. À l'origine, tous les membres faisaient partie du même groupe de jeunes, et c'est lorsqu'ils en sont sortis que douze d'entre eux ont formé cette amicale. «Tout ce que nous faisons, nous le faisons ensemble. », disent-ils. Ils apportent notamment leur aide lors des funérailles de leurs membres, en association avec le groupe d'entraide de leurs sections. Chaque mois, ils mettent de l'argent de côté pour faire ensemble des voyages. Lorsqu'ils ont atteint un certain âge, ils se sont mis à participer aux concertations pour le choix du chef de quartier. Et quatre ou cinq des épouses des membres de ce groupe ont constitué de leur côté une amicale du même type.

Axés sur l'entretien des relations amicales des gens du même âge, ces groupes ont aussi pour objectif la solidarité de ceux qui sont aux postes de responsabilité du quartier et des sections. Tous les membres à tour de rôle ont la charge d'organiser la réunion.

Avec douze amicales (dont certaines ont disparu aujourd'hui pour cause de maladies ou de décès de leurs membres) ${ }^{80}$, Kami-machi est le quartier où elles sont les plus nombreuses. Comme j'ai pu vérifier qu'elles sont également présentes dans ceux de Naka-machi, Shimo-machi, Haginoo, Kana.ide, Takata, Tsubakuro, Wada et Oto.inu, on peut penser qu'il en va de même dans tout le reste de la commune. À l'instar des rites annuels de la maison, ces réunions devraient avoir tendance à disparaître à cause de l'indisponibilité des hommes, de plus en plus pris par leur travail. Or ce n'est pas le cas. La raison en est peut-être que la charge des repas de ces rencontres ne revient pas aux hommes qui les organisent, mais à leurs épouses. Mais peut-être est-ce surtout parce que c'est là que s'échangent les informations internes au quartier, et que se fait le recrutement des futurs responsables de l'organisation autonome de celui-ci. Néanmoins, aucune de ces amicales ne compte de membres dont l'âge est inférieur à 40 ans. Aussi leur avenir est-il une inconnue.

Les associations enfantines. - Les rituels que celles-ci organisent sont faits en coordination avec les associations de parents (ikusei-kai 育成会), en majorité

79. Groupe d'hommes nés entre 1921 et 1930. Ils partirent de Sasaguri par le train, passèrent par des sources chaudes à Tottori 鳥取 et Fukui 福井 avant de gagner Ise. Le voyage dura deux semaines.

80. Shōwa-kai 昭和会 (année de naissance moyenne des membres : 1894), Shinwa-kai 親和会 (1912), Shin.yū-kai 親友会 (1916), Sen.yū-kai 選友会 (1923-1929), Yūshin-kai 友信会 (1927-1928), Gogatsu-kai 五月会 (1928), Shin.ei-kai 親栄会 (1938), Uzuki-kai 卯月会 (1938), Jōyū-kai 上友会 (1942), Hōyū-kai 朋友会 (1945-1951), Eiyū-kai 栄友会 (1945-1952), Shinsei-kai 新生会 (1945-1957). 
constituées de mères). Elles sont aidées pour cela de subventions du quartier et des sections. Ayant principalement pour objet la bonne croissance des enfants, les rites annuels traditionnels auxquels participent ces groupes sont nombreux et divers. À Tsubakuro, les associations d'enfants organisent ceux du bokkengyō, du sumō du bord de la rivière (kawabata zumō 川端相撲), de la fête de Kannon ${ }^{81}$; à Wada, celui du tir à la corde du bon (bon tsunabiki 盆綱引き) ; dans les quartiers de Kami-machi, Naka-machi et Shimo-machi, celui du char des enfants (yamagasa 山笠) pour la fête de Gion (Gion matsuri 祇園祭) du sanctuaire Suwa ; ou encore celui de la danse du lion de chaque quartier (shishi mai 獅子舞).

Exemple Ir. - Pour lc bokkengyō dc Kami-machi, toutcs lcs maisons, qu'il y ait ou non des enfants, déposent à leur porte la corde de paille du Nouvel An pour que les enfants la ramassent. Durant l'enfance de T. T. (né en 1924), les enfants de l'école primaire et du collège se faisaient aider par le groupe des jeunes pour aller couper des perches de bambous. Dans une rizière asséchée depuis la récolte de l'automne, ils en faisaient une structure pyramidale dont ils comblaient le centre avec de la paille. Pour éviter que quelqu'un n'y mette le feu, ils étaient obligés de passer la nuit à côté. Le 7 janvier au petit matin, ils l'allumaient et y jetaient toutes les cordes de paille et autres apparats festifs du Nouvel An qu'ils avaient ramassés. Dans les cendres chaudes, ils faisaient griller des morceaux de mochi, puis rapportaient chez eux des braises qu'ils mettaient dans le fourneau. Cuire le riz et faire bouillir l'eau du thé sur ce feu était considéré comme propitiatoire. Certains habitants venaient chercher des braises.

Exemple 12. - Selon I. O. de Tsubakuro (né en 1935), ce rite du bokkengyō n'existait pas dans son enfance. Mais dans les années 1975 , il fut créé " pour faire plaisir aux enfants ", à l'imitation de tous les autres quartiers. Ce feu se faisait sur la berge de rivière. Après une période d'interruption, il a été pratiqué de nouveau et existe encore aujourd'hui.

Ce rite du Nouvel An est un rite des enfants auquel prend part tout le quartier puisque l'apparat festif de chaque maison y est brûlé. Cette pratique communautaire marque la fin des festivités de la nouvelle année à l'intérieur de chaque maison.

Le sumō des enfants existe aussi dans chaque quartier, où il a la fonction d'éliminatoire avant le grand sumō du sanctuaire Taiso de Wakasugi. Le sumō est à l'origine un rite qui se déroule devant les dieux. À Tsubakuro, ce sumō a conservé un caractère rituel.

Exemple 13. - Selon I. O. né en 1935, à Tsubakuro, dans son enfance, le sumō dit " des berges de la rivière » se déroulait sur un banc de sable au milieu de la rivière Tatara 多々 良川. Mais il lui a été rapporté par un homme né en 1926 qu'auparavant, la lutte avait lieu dans la rivière elle-même. Selon lui, c'était un rituel pour protéger les enfants de la noyade. Il s'agissait de montrer aux esprits de la rivière (kappa 河童), dont on disait qu'ils entrainaient les enfants, que ceux-ci avaient de la force.

Le tir à la corde qui existait autrefois dans toute la commune, n'est plus organisé aujourd'hui qu’à Wada.

Exemple 14. - Le tir à la corde a lieu dans l'enceinte du sanctuaire Hachiman de Wada, le dernier jour du bon. Anciennement, la corde était en lianes tressées, et une fois le tir fini, on allait la jeter dans la rivière. Dès que le tir à la corde est terminé, les habitants

81. Voir l'exemple 17, ci-dessous, p. 508. 
de chaque maison du quartier, qui sont venus en spectateurs en apportant avec eux des bâtons d'encens allumés (supports des âmes des défunts), se rendent immédiatement sur les tombes.

Les enfants séparés en deux groupes tirent sur la corde, mais ce n'est pas un jeu où l'un des deux côtés gagne. Après qu'ils ont tiré trois fois, cette corde est coupée à l'aide d'une hachette. Cet acte rituel «tranche » à la fois le lien avec les âmes, qu'on renvoie dans l'au-delà, et celui avec toutes les causes de malheurs susceptibles de s'abattre sur la communauté locale. Originellement, la corde était faite de lianes que les enfants allaient couper dans la montagne, et qu'à la fin de la fête ils « jetaient » sur les berges ou dans la rivière. Assurer la bonne fortune du quartier est le rôle rituel des enfants. Mais aujourd'hui, les chemins de montagnes n'étant plus débroussaillés, on ne va plus y couper de lianes, si bien qu'on utilise la corde des fêtes du sport. Aussi cette corde n'est-elle plus ni tranchée, ni jetée à la rivière.

La danse du lion est une autre forme de ces rites assurés par les associations d'enfants de chaque quartier. Les enfants de l'association font du porte à porte dans tout le quartier en portant la tête de lion (shishi gashira 獅子頭) et en chantant des paroles propitiatoires, sans danser. On leur donne quelques sous qui constituent les fonds de leur association, en échange desquels ils donnent une branche de châtaignier à feuilles persistantes (sbii 椎) et du sable pour faire les purifications. Aujourd'hui, les mères de famille qui les assistent dans la logistique sont un peu réticentes à aller chercher elles-mêmes les branches de châtaignier et le sable, et dans certaines associations, celles-ci sont achetées au supermarché du coin. La plupart des rites annuels auxquels participent les enfants ont ainsi un fort aspect cultuel qu'ils sont parfois les seuls à perpétuer localement. Pourtant, la tendance générale est à l'effacement de ce caractère devant le seul objectif de la réunion enfantine elle-même.

LES RITES DES GROUPES CULTUELS. - Dans cette catégorie entrent les confréries de Kōshin (Kōshin-kō 庚申講) ${ }^{82}$, les confréries « du Grand Maître » (Daishi-kō 大師請, c'est-à-dire de Kōbō daishi-Kūkai 弘法大師空海 ${ }^{83}$ et les confréries de Kannon $(\text { Kannon-kó 観音講 })^{84}$. Ces dernières se réunissant le jour de la fête du bodhisattva Kannon qui a lieu le $17 \mathrm{du}$ mois, on appelle ces confréries « soir du 17 » (ojūbichi ya お十七夜), et celles du Grand Maître sont dites « le 20 (obatsuka お二十日), jour anniversaire de la mort de Kūkai et de leur réunion mensuelle. Les temples paroissiaux organisent aussi des rites rassemblant toutes les maisons de leurs paroissiens,

82. Pratique fondée sur la croyance (d'origine chinoise) en la mise en danger de la vie par trois " insectes » (sanshi 三尸) qui vivent dans le corps humain. D'après celle-ci, ces « insectes » montent au ciel la nuit du jour marqué du double signe calendaire kō-shin ou kanoe-saru 庚申 pour relater à l'empereur céleste (Tentei 天帝) les mauvaises actions commises par les hommes, ce qui peut causer la mort prématurée de la personne concernée. Pour les empêcher de sortir du corps, la confrérie se réunissait et veillait toute la nuit. De nos jours, la plupart des veillées se terminent vers minuit.

83. Groupe vénérant le Grand Maître, c'est-à-dire Kōbō daishi-Kūkai 弘法大師空海 (774-835), le fondateur de l'École Shingon 真言宗 du bouddhisme ésotérique japonais.

84. L'existence d'autres confréries comme celles de Yakushi 薬師講 ou d'Akiba 秋葉講 est mentionnée dans Sasagurichō bunkazai senmon iinkai 篗栗町文化財専門委員会, éd., Sasaguri chōshi. Minzoku-hen 策栗町誌:民俗篇, 1990, p. 279-290, mais n'a pu être confirmée par mon enquête. 
mais celles-ci sont réparties dans un périmètre qui dépasse le cadre du quartier et des sections.

À Sasaguri, ces groupes cultuels sont constitués à l'intérieur des sections et des quartiers; aussi ces organisations sont-elles subtilement entrelacées avec celles de la gestion autonome micro-locale. Les confréries de Kōshin sont composées de maisons d'agriculteurs d'un même quartier ; quant à celles de Daishi et de Kannon, tout en étant des groupes cultuels, elles réunissent les habitants d'une même section.

Exemple 15. - Les membres des confréries de Kōshin d'Onaka sont exclusivement les aînés des maisons qui existent depuis plus de cent ans. Mais aujourd'hui, le nombre des participants à la réunion mensuelle est inférieur à dix, et si le maître d'une maison est mort ou s'il n'est pas sur place, une femme peut le remplacer. Jusqu'il y a dix ans, seize maisons y participaient ; aujourd'hui (2010), ce sont les dix représentants des dix maisons membres de la confrérie. Selon les membres, cette confrérie de Kōshin était aussi " autrefois, le lieu et l'occasion de l'intégration dans la communauté villageoise ${ }^{85}$ ».

Les rites mensuels jouaient alors un rôle important dans la gestion collective locale. Mais avec l'éloignement des familles de l'activité agricole, la volonté de se réunir semble aujourd'hui moins forte. En outre, lorsque seule l'épouse reste à la suite du décès du maître de maison, ou que les moyens économiques d'une famille diminuent, ces maisons ont tendance à quitter la confrérie. Il en va de même dans les autres quartiers, où ce type de confrérie est également en perte de vitesse ou en voie de disparition.

Ces confréries cultuelles se caractérisent par la rigueur de leurs conditions exclusives et leur fermeture aux nouveaux habitants, dont l'intégration est généralement refusée.

Exemple 16. - Toutes les maîtresses de maison en titre des douze familles de la section 3 du quartier de Takata sont membres des confréries du Grand Maître et de Kannon de cette section (fig. 3). Comme ces confréries n'admettent aucune adhésion nouvelle, lorsque des familles viennent habiter dans le périmètre de cette section, les membres ne proposent pas aux femmes de les rejoindre. La seule exception a été l'intégration de deux femmes qui ont déménagé de la section 4 de Takata pour venir dans la section 3, et qui ont été invitées à devenir membres. La confrérie du Grand Maître de la section 3 est propriétaire de l'oratoire (fudasho 札所) $n^{\circ} 69$ du circuit des 88 lieux saints de Sasaguri ${ }^{86}$. Les rites mensuels de la confrérie se déroulent, non pas dans cet oratoire, mais à tour de rôle chez l'un de ses membres, le 17 du mois, en même temps que ceux de la confrérie de Kannon. C'est ce qui permet aux deux femmes nouvellement arrivées de la section 4 de participer aux rites des deux confréries. Mais en fait, le droit de propriété de l'oratoire est limité aux douze familles anciennes : celle-ci ne peuvent donc pas être membres de la confrérie du Grand Maître. Ainsi, en avril, elles ne peuvent pas prendre part au seul rite annuel de cette confrérie qui a lieu dans l'oratoire, où sont offertes boissons et friandises aux pèlerins qui font le circuit de pèlerinage (settai 接待).

85. Voir l'exemple ig ci-après, p. ऽı.

86. Sur ce pèlerinage, voir dans ce même volume Nakayama Kazuhisa 中山和久, « La dynamique de création, réplication et déclin des lieux de pèlerinage : le nouveau pèlerinage de Shikoku à Sasaguri », p. 269-350 - Fudasho, "lieu (où l'on dépose les) vignettes » (fuda [wo osameru] tokoro 札[を納める]所 abrégé en “ lieu des vignettes»), est l'oratoire ou le temple d'un circuit de pèlerinage dans lequel les pèlerins déposent des vignettes indiquant leur passage. Le fudasho $\mathrm{n}^{\circ} 69$ est le Takata Kannon-dō 高田観音堂. (N.D.T.) 


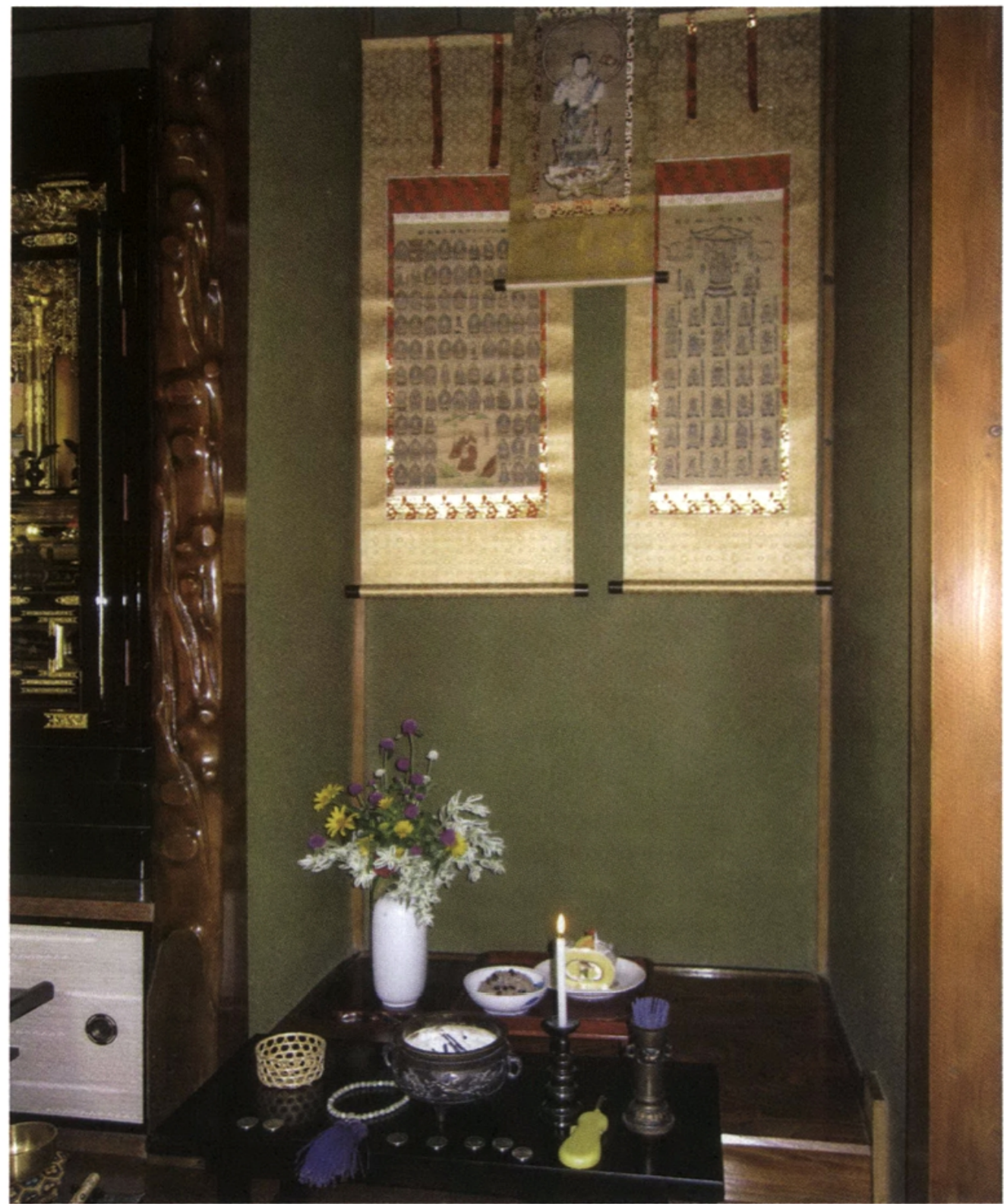

Fig. 3 : Rouleaux peints de la confrérie de Kannon et de celle du Grand Maître (Takata, section 3, 17 août 2010).

Les droits de propriété de l'oratoire sont sans doute à l'origine de ce refus de nouvelles entrées dans la confrérie. Mais il semble que ce soit là une tendance généralisée à Takata, où l'on dit communément : «On ne peut confier la charge de chef de quartier à un nouvel arrivant ou à un gendre. " Les sections 2 et 3 gèrent ensemble un même oratoire du circuit de pèlerinage, le fudasho $\mathrm{n}^{\circ} 32$, Takata Jū.ichimen Kannon-dō 高田十一面観音堂. Or elles aussi refusent les nouvelles intégrations.

Voyons comment, lorsque les membres des sections et des confréries sont les mêmes, s'opère la confusion entre les rites et les événements annuels des différentes organisations. 
Exemple 17. - Le "soir du 17 " (rite mensuel de la confrérie de Kannon) de la section 7 de San.nō rassemble les femmes de dix des douze maisons de cette même section. L'une des deux femmes qui n'en fait pas partie a quitté la confrérie parce qu'elle était trop âgée, et l'autre ne peut y entrer car c'est une nouvelle arrivée. Tous les $17 \mathrm{du}$ mois, les membres se réunissent chez l'une d'entre elles, où, après les pratiques cultuelles à Kannon, elles partagent un repas léger. La famille qui reçoit prépare les accompagnements salés, les friandises, le thé. Or, à cette occasion, celle qui tient le rôle de secrétaire de cette confrérie recueille le montant des économies que chacune veut placer à la coopérative agricole, où elle va ensuite les déposer ${ }^{87}$. Les intérêts étant versés en juillet et décembre, c'est aussi la secrétaire qui les apporte. Cette pratique remonte à ce qui se faisait lorsqu'existait une section féminine à la coopérative agricole.

Cette double appartenance des membres ne se constate pas seulement dans le cas de la coopérative. Tant qu'il y avait une association féminine dans chaque quartier, ses membres étaient également ceux des confréries de Kannon des sections. Aussi, lors des réunions cultuelles, devait-on parler également des affaires de tous ces autres groupes. De fait, à l'occasion du « 20 » (jour de réunion rituelle de la confrérie du Grand Maître), qui, dans la section 2 de Shimo-machi, se tient de 20 à 22 heures

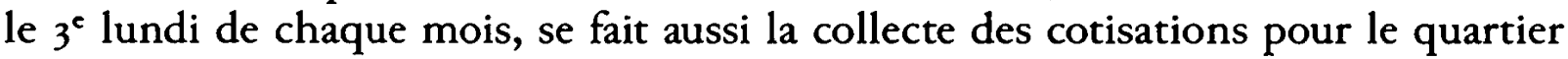
ou pour les sapeurs-pompiers, alors même que la confrérie n'a aucun rapport avec les affaires du quartier, mais parce que dans ces différents groupes se retrouvent les mêmes membres. De même, les femmes de la section I de Shimo-machi disent que les femmes du « groupe du 20 (obatsuka gumi お二十日組) » (c'est-à-dire la confrérie du Grand Maître) étaient membres de l'association féminine (jusqu'en 2002, date de la disparition de celle-ci) et qu'elles sont liées aujourd'hui encore par de vrais liens d'amitié. Être ensemble membres de plusieurs groupes renforce de fait ces réseaux. On voit ainsi comment les divers types d'activités de groupes différents s'entremêlent en raison de la présence d'acteurs qui leur sont communs.

Si la finalité affichée des groupes religieux est le culte d'une entité bouddhique ou d'une divinité, c'est bien la réunion de leurs membres autour de repas partagés, venant entretenir les liens amicaux, qui en est la véritable force d'attraction. L'attention est attirée en outre par le fait que l'organisation de la réunion mensuelle revient à tour de rôle à l'un des membres de la confrérie. Lorsque le rite a lieu chez celui-ci, c'est sa propre maison qui offre pour l'occasion l'espace rituel et est aussi chargée de l'apparat festif communautaire. Cette charge est lourde, puisqu'il faut fournir la pièce et le repas (avec tous les frais d'achat des produits et la préparation culinaire que cela comporte), assurer la garde de l'objet cultuel déposé depuis la réunion précédente et son culte quotidien. Nous reviendrons sur ces points dans la partie suivante, mais on peut déjà signaler ici que ces obligations sont l'une des causes de la tendance à la réduction et à la disparition des ritualités de ces groupes.

FONCTIONS ET TRANSFORMATIONS DES RITES COMMUNAUTAIRES LOCAUX. - Tous les exemples précédents montrent qu'il existe de nombreux rites mensuels qui n'ont rien à voir avec les organisations autonomes locales que sont le quartier et les sections, et que les maisons à l'intérieur d'une même section peuvent être membres de plusieurs

87. Les coopératives agricoles (nōgyō kyōdō kumi.ai 農業協同組合) sont aussi des organismes de crédit. 
groupes à la fois. Aussi les rites auxquels participe chaque maison peuvent-ils être fort différents les uns des autres. Par là, il n'est pas étonnant que les rites propres à chaque maison different également de l'une à l'autre. Si l'un ou l'autre des membres d'une maison appartient à une amicale, cette famille connaît le contenu des événements mensuels ou annuels de celle-ci, alors que ceux des maisons qui n'en font pas partie ignorent ce qui s'y passe, et parfois même jusqu'à l'existence de ces rites et pratiques. Seules les ritualités liées aux enfants sont pour la plupart organisées par l'ensemble de la communauté locale, et même les maisons où il n'y a pas d'enfants y participent (exemple iI). L'analyse précédente a cherché à mettre en évidence les différents types d'acteurs. Si l'on considère en outre les teneurs et finalités des rites et événements annuels, on pourrait penser que la communauté du quartier organise séparément les événements qui relèvent de sa seule gestion. Or il est clair que les groupes d'âge, par exemple, dont le moteur est le réseau amical de ses membres qui discutent entre autres des affaires concernant la gestion du quartier, sont en fait le support d'un certain nombre de rites ou événements du quartier tout entier. Le témoignage des membres de la confrérie de Kōshin à Onaka (exemple is) montre aussi clairement que, bien qu'un groupe cultuel ait une pratique religieuse pour centre affiché, l'appartenance à un tel groupe peut également être la preuve de l'intégration (ou non) et de la place de ses membres dans la communauté locale. Une confrérie cultuelle (comme le montre l'exemple 17) peut aussi assurer des tâches qui relèvent de la gestion communautaire du groupe local. Enfin, les célébrations du sanctuaire tutélaire du quartier et les rites des enfants ont une fonctionnalité religieuse à l'échelle du quartier. Mais, d'une façon générale, on constate une forte tendance à négliger cet aspect religieux et cultuel au profit du renforcement de l'aspect convivial de l'événement communautaire.

\section{Les lieux des rites communautaires locaux}

LES DIFFICULTÉS À ENTRETENIR LES BÂTIMENTS DE CULTE ET LES STÈLES. — Nous partirons de l'examen des lieux où se déroulent les ritualités de Tsubakuro tout en recourant à des comparaisons avec les autres quartiers.

La célébration des fêtes annuelles du printemps et de l'automne du sanctuaire tutélaire de Tsubakuro, le Goryō-gū 御霊宮, ainsi que la « veille au sanctuaire » (okomori) ont lieu dans l'enceinte du sanctuaire. Autrefois, pour la « veille ", les habitants devaient certainement passer la nuit dans le hall de prière (baiden 扯殿), mais aujourd'hui, quel que soit le quartier, on ne peut plus recueillir d'information sur cette pratique. Les gens du quartier se rassemblent seulement dans l'enceinte du sanctuaire où ils mangent tous ensemble les boîtes à repas qu'ils apportent. À Takata, de nombreux cerisiers ont été plantés dans l'enceinte du sanctuaire de Tenjin 天神社; aussi la " veille " communautaire est-elle doublée d'un banami 花見, cette pratique de réjouissances collectives sous les fleurs de cerisiers. S'il pleut ce jour-là, une fois terminé le service religieux dans le bâtiment du sanctuaire, tout le monde gagne la Maison citoyenne du quartier pour les festivités. Même en temps ordinaire, le sanctuaire et son enceinte sont des lieux considérés comme sacrés. La « veille au sanctuaire " après le service religieux avait originellement la signification du partage des offrandes faites au préalable aux divinités. Mais aujourd'hui, ce sens est plutôt estompé, voire oublié. Le fait de ne plus 
utiliser les bâtiments du sanctuaire en cas de pluie, mais ceux de la Maison citoyenne, témoigne de l'éloignement physique et mental d'une telle conception, alors même qu'est renforcée celle d'une festivité collective pour le plaisir d'être ensemble.

Le rite agraire de la célébration du dieu des Grains (Gokoku-jin) se déroule devant la stèle de pierre portant son nom. À Takata et à Wada, la stèle se dressait originellement au sommet d'une montagne du quartier. Vénérer l'âme des graines de céréales sur un sommet est à relier aux pratiques propitiatoires précédant les travaux agricoles printaniers pour demander la prospérité des récoltes au dieu de la montagne, au moment où il va devenir dieu des rizières ${ }^{88}$. Mais lorsque monter jusqu'à cet endroit a été ressenti comme quelque chose de pénible, partout dans la commune, les stèles du dieu des Cinq grains ont été descendues dans l'enceinte des sanctuaires tutélaires ou à proximité des villages. Aussi est-ce là que se déroulent aujourd'hui ces ritualités et le repas collectif qui les suit. Mais ainsi, personne ne va plus jusqu'à ce lieu sacré en haut des montagnes.

Dans tous les quartiers, j'ai pu recueillir des informations sur le congé, appelé sanabori, qui marque la fin des travaux de repiquage des plants dans les rizières. Il s'agissait là d'un simple repos collectif sans festivités particulières. Néanmoins, à Onaka, avait lieu un rituel et un repas devant la stèle de Kōshin (Kōshin-tō 庚申塔). Comme les rites des confréries de Kōshin, ces pratiques cultuelles devant la stèle de Kōshin devaient être organisées par le groupe des agriculteurs du quartier et ont disparu avec leur diminution.

On retrouve le même phénomène avec les rites dans les oratoires des bouddhas et des dieux.

Exemple I8. - Autrefois, le 17 de chaque mois, à Tsubakuro, on célébrait le jour du bodhisattva Kannon, “Vénéré Kannon 》(O-Kannon sama お観音様), devant l'oratoire de Kannon situé dans la section basse (shimo-gumi 下組). Cette fête était organisée par les enfants, qui allaient chercher du sable à la rivière pour l'étendre devant l'oratoire ainsi purifié, et déposaient des offrandes de gàteaux qu'après le rite ils se partageaient et mangeaient sur place. Les habitants de la section médiane se joignaient à ceux de la section basse, où les habitants de longue date étaient les plus nombreux. Cette fête a disparu il y a plus de 35 ans, et aujourd'hui, les habitants proches de l'oratoire ne font plus que la garde des lieux.

De telles ritualités en des endroits dédiés à des entités cultuelles, où se réunissaient ainsi les habitants du quartier pour le seul jour de la célébration, étaient nombreuses dans la commune de Sasaguri. Mais ces pratiques se sont réduites, et à l'heure actuelle, les lieux sont simplement gardés par les gens du voisinage.

À l'inverse, des oratoires compris dans le circuit de pèlerinage des 88 lieux saints de Sasaguri, comme le fudasho $\mathrm{n}^{\circ} 32$ géré par les sections I et 2 de Takata, ou le $\mathrm{n}^{\circ} 69$ géré par la section 3 du même quartier, continuent à être l'objet de soins attentifs.

88. Au début du printemps, le dieu de la montagne (d'où viennent les eaux d'irrigation) est appelé à descendre au pied des montagnes où il est célébré comme dieu des rizières, puis renvoyé dans la montagne à l'automne, après les moissons et les rites de remerciement. C'est ce que l'on appelle l'" alternance du dieu de la montagne et du dieu des rizières » (yama no kami ta no kami kōtai 山の神田の神交代), mise en lumière par l'ethnologie du Japon. (N.D.T.) 
Ici, la sacralité des lieux est reconnue par la venue des pèlerins de l'extérieur de la commune, ce qui en rehausse la valeur à l'intérieur de l'espace local.

D'une façon générale, dans chaque quartier, avec la diminution des ritualités dans les lieux cultuels, la gestion et l'entretien de ceux-ci posent aujourd'hui des problèmes, y compris pour les sanctuaires tutélaires. Pourtant, certains lieux et certains rituels bénéficient positivement de la stimulation du debors, comme c'est le cas pour les oratoires du circuit de pèlerinage, ou encore lorsqu'il y a une volonté d'imiter des pratiques inexistantes jusque-là mais qui ont cours dans les autres quartiers (cas de l'exemple 12).

LES LIEUX OUBLIÉS : RIVIÈRE, BERGES ET CARREFOURS. - Les ritualités liées auX enfants avaient un caractère religieux particulièrement marqué. En témoignent les lieux où celles-ci se déroulaient.

Ainsi, à Tsubakuro (exemple I2) et à Tanaka, c'est sur les berges de la rivière qu'était allumé le feu du bokkengyō. De même, le sumō du bord de la rivière à Tsubakuro (exemple 13) avait anciennement lieu sur un banc de sable au milieu de la rivière, dans l'eau ou sur les berges. La corde sur laquelle on tirait pour la fête des morts à Wada (exemple 14) était initialement jetée à la rivière. Jusque vers la fin des années I980, c'est également à la rivière que toutes les maisons jetaient les offrandes de l'autel de la fête des morts. Espace liminaire où ce monde et l'autre communiquent, la rivière est l'un des lieux d'où repartent les âmes des morts et où résident les divinités des eaux comme les kappa. Mais tous les rites qui se déroulaient sur les berges furent interdits dans l'ensemble du Japon pendant la seconde moitié des années I980 pour cause de pollution des rivières. Ceci contribua de façon déterminante à la transformation de leurs contenus et à leur disparition. C'est en effet à partir de ce moment-là que les offrandes de la fête des morts, au lieu d'être mises à l'eau, en vinrent à être jetées en tant qu'ordures par les habitants de Sasaguri.

La rizière, où l'on célèbre le dieu des rizières, était aussi l'endroit où, dans certains quartiers, les enfants brûlaient le bokkengyō avant la reprise des travaux agricoles. Mais ces feux furent interdits, suite à la sensibilisation pour la protection contre les incendies, et transférés dans la cour des jardins d'enfants, quittant ainsi leur lieu rituel traditionnel, la rizière d'où le dieu des rizières était renvoyé, pour un espace public. À Oto.inu, selon S. N. (née en 1925), il existe cette formule : « brûle le bokkengyō au carrefour. " Les carrefours sont eux aussi, à la fois, les limites entre le dedans et le dehors de l'espace communautaire local, et ils sont regardés comme un point de passage vers l'au-delà. Le fait de transférer les rites hors de tels espaces porteurs de significations religieuses a contribué à affaiblir leur valorisation cultuelle et à les transformer en simples divertissements ou compétitions.

TRANSFERT DES RITES LOCAUX DANS LES LIEUX PUBLICS COMMUNAUX. - En dehors des événements collectifs liés à des espaces spécifiques (comme les divers nettoyages par les habitants ou les activités des sapeurs-pompiers, ou encore les fêtes du sport qui se déroulent dans les stades scolaires), la majorité d'entre eux a lieu dans ou devant la Maison citoyenne du quartier. C'est le cas des assemblées de quartier, des expositions de peinture ou encore des réunions des personnes âgées, etc. Ce lieu cumule donc les caractères d'espace culturel, administratif et d'entraide. Mais c'est aussi là que, dans la plupart des quartiers, se déroule la danse de la fête des morts, 
généralement appelée aujourd'hui « fête de l'été ». Or les plaquettes funéraires des habitants qui sont morts durant l'année écoulée y sont transférées depuis leurs maisons respectives, et le moine du temple paroissial vient réciter les sütra devant elles avant la danse communautaire qui a lieu sur la place de la Maison citoyenne. Aussi ces lieux publics deviennent-ils également un espace de ritualités pour les morts.

Depuis une date récente, c'est là que beaucoup de confréries religieuses viennent organiser leurs réunions cultuelles. Par là, la Maison citoyenne devient l'espace des rites. Comme on l'a vu, une partie des rites communautaires locaux organisés par les groupes cultuels reste implantée à l'intérieur de l'espace domestique. Mais comme le montrent les exemples r à 8 (partie "Métamorphoses des rites à l'intérieur de la maison »), aujourd'hui la tendance est à maintenir de préférence l'intérieur de la maison comme un espace ordinaire et à en faire sortir le festif, ces deux mouvements se conjuguant pour faire de la Maison citoyenne et des lieux publics du quartier les lieux privilégiés des cultes et des rites.

Importation des rites communautaires locaux du debors vers le dedans des maisons

\section{Les acteurs des rites}

On a vu que les lieux où se déroulent les rites communautaires locaux - sanctuaire du dieu tutélaire, temples, oratoires et stèles, Maison citoyenne ou encore bord de la rivière - se situent à l'extérieur de l'habitation. Pourtant, à Sasaguri, nombreux sont aussi ceux qui font de l'intérieur de celle-ci un espace communautaire. C'est le cas avec les réunions des groupes d'âge et des confréries cultuelles - de Kōshin, du Grand Maître, de Kannon ${ }^{89}$ - qui ont lieu chez l'un de leurs membres selon un tour fixé à l'avance (ie mawari 家回り). Le groupe d'âge organise une réunion amicale mensuelle centrée sur le repas partagé (exemple ro).

La confrérie de Kōshin reflète bien la façon dont les acteurs organisent les groupes cultuels.

Exemple 19. - La confrérie de Kōshin d'Onaka (exemple is) se réunit six fois par an chez l'un de ses membres, lesquels assurent à tour de rôle la charge d'accueillir le groupe. Les membres, qui sont aussi les gens du voisinage immédiat, arrivent vers 19 heures, se lavent les mains dans l'entrée avant de gagner la pièce de réception, pour s'incliner devant le rouleau peint représentant la divinité Sarudahiko 猿田彦 suspendu dans le tokonoma. Ils allument deux bâtons d'encens, déposent chacun une offrande de cent yens sur un plateau et suivent le protocole du salut aux divinités (deux inclinations, deux frappements de

89. Autrefois, d'autres confréries comme celles de Kinoe-ne 甲子講 (les membres se réunissaient le jour du kinoe-ne pour rendre un culte à Daikoku-ten 大黒天) ou d'Akiba 秋葉講 (ils se réunissaient pour faire le pèlerinage au mont Akiba [Hamamatsu 浜松, département de Shizuoka 静岡県] où est vénéré Akiba gongen 秋葉権垷, célèbre pour son pouvoir de protection contre les incendies, ou à d'autres sanctuaires d'Akiba) ou encore les confréries économiques, organisaient aussi leurs réunions dans les maisons de leurs membres à tour de rôle, mais elles ont presque toutes disparu. À l'occasion de certaines fêtes, les confréries des enfants se réunissaient également dans chaque maison à tour de rôle jusque dans la seconde moitié du xxe siècle. 
mains, une inclination). Les offrandes sont faites de ces pièces de monnaie, d'un bol de riz agrémenté de poulet et de sake. Dans la boîte du rouleau peint est gardé le livret de caisse d'épargne sur le compte duquel sont versées les offrandes en espèces. Pour cuisiner le riz au poulet, le responsable de la séance du mois a fait préalablement le tour des maisons des autres membres pour recueillir le riz qui est appelé " riz de contribution " (kome kiri 米切り). Même pendant la guerre, les membres de la confrérie avaient pu continuer cette collecte de riz, en disant qu'au moins à leur réunion, ils pouvaient manger du riz à leur faim. Le repas commence à 19 heures 15 . Les plats servis sont toujours les mêmes dans toutes les maisons : riz au poulet, accompagnement de légumes aigres-doux, poisson cru en tranches, légumes en saumure, sake, bière. Durant le repas qui dure environ deux heures sont échangées les nouvelles familiales, celles du quartier. Tout le monde se sépare vers $2 r$ heures.

Alors que la confrérie est constituée autour du culte de Kōshin, celui-ci n'occupe qu'une fraction du temps, qui est majoritairement employé au partage du repas et aux échanges. Les frais et les préparatifs de ce repas sont assurés par la maison dont c'est le tour de recevoir ( $t o ̄ b a n$ 当番). Cuisine, préparatifs et disposition des plateaux individuels dans la pièce sont bien sûr à la charge de la maîtresse de maison. Il semble qu'après la guerre, alors que la vie alimentaire s'améliorait peu à peu, le nombre des plats servis dans les amicales et les confréries se soit mis à augmenter de façon exponentielle, ce qui ne fit qu'alourdir la tâche des femmes. Pourtant, lorsque le mari disait que «dans la maison une telle, le repas était vraiment fastueux ! », il n'était pas question pour l'épouse de ne pas montrer ses talents. Afin de stopper ce renchérissement croissant, les femmes de l'amicale de Yamate fixèrent la limite, d'un accord commun, à la formule « un seul mets par bol d'accompagnement » (bachi mori ippin 鉢盛り一品).

Ces rassemblements communautaires introduits dans les maisons étant très nombreux, lorsqu'on appartient à plusieurs groupes, le nombre de réunions mensuelles est assez élevé. Ainsi, lorsqu'on prend le cas d'I. F. (née en 1928) de la section I de Kana.ide, au calendrier des déplacements mensuels de cette femme dans les maisons qui en assurent la charge mensuelle, on trouve le « soir du i7 » (confrérie de Kannon), le « thé-causerie » de l'amicale de la fin du mois et, le 3 du mois, la réunion de l'Association Kōmyō (Kōmyō-kai 光明会) ${ }^{90}$ du temple paroissial Shurin-ji 珠林寺91. Quand c'est à son tour de recevoir, c'est elle qui assure les préparatifs.

Recevoir ainsi les membres d'un groupe local pour sa réunion mensuelle implique de pouvoir proposer une pièce où il est possible d'accueillir un grand nombre de personnes, un tokonoma où exposer le rouleau peint de l'entité vénérée et, plus que tout, l'aisance économique et morale qui permet cet accueil de nombreux voisins chez soi. Introduire les gens de la communauté locale à l'intérieur de la maison, c'est aussi perdre une partie de sa vie privée. Par là, en effet, la communauté locale connaît le dedans de toutes les maisons. On peut penser qu'ainsi, ce debors (sotoソト)

90. Kōmyō : nom d'un mantra shingon, le kōmyō shingon 光明真言.

91. L'Association féminine Kömyō fujin-kai 光明婦人会 réunit les paroissiennes du temple Shurin-ji de Kana.ide le 3 du mois chez l'une d'entre elles selon un tour fixe, pour une récitation de sūtra, une homélie du supérieur et un repas. Dans les autres quartiers, les paroissiens ont ce même genre de réunion au temple, le 14 du mois. 
qu'est le micro-local par rapport aux maisons devient une forme de dedans (ucbi ウチ). Un échange s'y effectue. Pour réaliser ses réunions cultuelles et amicales, la communauté locale demande à la maison d'offrir espace et force de travail. La maison attend des informations du debors, que lui procure le groupe local réuni. Tant que cet équilibre est maintenu, l'organisation du groupe perdure. Mais, comme nous l'avons vu dans la partie « Métamorphoses des rites à l'intérieur de la maison », alors que, parallèlement aux transformations des rites familiaux, augmente le nombre de familles qui refusent de faire entrer le festif chez elles, on peut se demander ce qu'il adviendra de ces rites communautaires introduits dans les maisons. Ceci est d'autant plus crucial que la relève des membres n'est plus assurée. Il arrive que la fille ou la belle-fille d'une femme âgée décide de quitter la confrérie sans même lui avoir demandé son avis. Ainsi, dans les confréries féminines, lorsque, trop âgée, la mâ̂tresse de maison en titre doit se retirer et qu'elle n'a ni belle-fille ni fille, ou lorsque celles-ci refusent de prendre sa place pour des raisons personnelles, et notamment parce que la tâche est trop lourde pour elles, la confrérie perd-elle non seulement un membre mais aussi un espace rituel, celui de la maison de cette femme qui la quitte. Bien entendu, c'est aussi la cause de frictions entre ces deux générations.

\section{Contenu des réunions des confréries cultuelles féminines}

Quasiment partout à Sasaguri, comme dans les communes avoisinantes, les confréries cultuelles exclusivement féminines, comme celles du Grand Maître et de Kannon, ont connu une grande vogue jusqu'à une date récente ${ }^{92}$. Selon les informations recueillies, on peut penser qu'on en comptait une trentaine dans la commune jusqu'à la fin des années I980. En 2010, sur l'ensemble de Sasaguri, quinze confréries continuent à organiser leurs rites mensuels.

Exemple 20. - La section I de Kana.ide organise le « soir du 17 » tous les mois de 19 à 22 heures chez l'une de ses membres à tour de rôle. Après s'être inclinées devant le rouleau peint représentant le bodhisattva Kannon, elles partagent le repas préparé par la maîtresse de maison. Celui-ci est en général composé de six plats : riz aux haricots noirs, bouillon, légumes au vinaigre doux, o-bira お平 ( $t o f u$ frit ou konnyaku 站够 [bardane] cuit dans un bouillon), légumes en saumure, friandises. Selon I. F. (née en 1928) qui en est membre, lorsqu'à son mariage elle arriva à Sasaguri, le repas était servi sur des plateaux individuels, qui furent ensuite remplacés par une table pour tout le monde. Personne ne voulait offrir quelque chose d'inférieur à ce que les autres avaient cuisiné ; aussi le nombre de plats se mit-il à augmenter. Mais il y a quelques années, le repas fut réduit à des friandises et des légumes en saumure. Si anciennement la réunion avait lieu le soir, aujourd'hui, c'est plutôt pour le déjeuner. Les femmes se regroupent autour du culte de Kannon qui protège les enfants. Autrefois, les occasions de divertissement étant rares, le rite mensuel de cette confrérie en offrait une. Dorénavant, ce sont plutôt des réunions de femmes âgées.

Outre cet exemple, on retrouve le « soir du 17 » célébré mensuellement à tour de rôle dans les six maisons de la confrérie de la section 3 de Haginoo à partir de 20 heures, ou encore dans sept maisons de la section basse de Wada à l'heure du

92. Parmi les 21 quartiers de Sasaguri, ce type de confréries n'existe pas dans les nouveaux quartiers, notamment ceux de Meiji, Ike-no-hata, Shin-machi, Shō et Ōseto. 
déjeuner. Les célébrations des confréries de Kannon et de celles du Grand Maître n'ont d'autre différence que celle de la figure cultuelle représentée sur le rouleau peint (Kannon ou le Grand Maître Kōbō). L’organisation séquentielle du rite luimême est identique :

- La responsable du mois dispose le rouleau peint, la statue vénérée et les offrandes, et prépare le repas.

- Les membres de la confrérie se réunissent chez la responsable le i7 ou le 20 de chaque mois.

- I a récitation des invocations et des sütra a lieu soit individuellement dans l'ordre des arrivées, soit en commun une fois que toutes sont présentes. Ou bien, se mettant en cercle, elles font tourner toutes ensemble le grand chapelet $^{93}$.

- Elles partagent le repas.

- Elles versent les frais de réunion et déposent leur offrande en espèces.

- La responsable suivante remporte chez elle le rouleau peint et la statue, ou bien la présente responsable va porter ces objets rituels chez celle qui assure la réunion suivante.

Ces rites se caractérisent donc par l'introduction d'objets sacrés dans la maison. Il en va de même pour les confréries de Kōshin, mais les membres de celles-ci sont des hommes, et les femmes y ont pour seul rôle celui des préparations culinaires. Or ces confréries féminines ont offert aux maîtresses de maison l'occasion, d'une part, de sortir pour partager un repas entre elles sans avoir à se justifier auprès de leur famille (mari, belle-fille, enfants, etc.) et, d'autre part, pour celle dont c'est le tour d'assurer la réunion, de démontrer à sa propre famille qu'elle est reconnue par la communauté locale comme maîtresse de la maison (sa représentante) et comme l'un des membres de cette même communauté. Il semble que les membres de la famille ignorent ce qui se passe dans ces réunions cultuelles, même si celles-ci se déroulent sous leur toit. Quant au mari, il n'a jamais eu son mot à dire sur la question. La belle-fille - c'està-dire la maîtresse de maison de la génération suivante - aide à préparer le repas, mais n'y participe pas. Ces confréries et leurs activités cultuelles peuvent ainsi être vues comme l'un des espaces où la maîtresse de maison prend et fait prendre conscience de son identité et de sa place sociale. Mais c'est là une situation déjà un peu ancienne.

\section{Mesures pour perpétuer les confréries}

Avec les bouleversements qui ont touché la maison, la famille et la société, les femmes ont désormais à leur disposition beaucoup d'autres espaces de prise de conscience et d'affirmation de leur identité. L'émergence d'un rejet face à l'intrusion du debors à l'intérieur de la maison en arrive à faire contrepoids à l'attachement aux pratiques cultuelles. Si la balance penche du côté du premier, alors la survie des confréries se trouve mise en jeu. La relève des membres des confréries s'est toujours faite de maîtresse de maison en titre à sa belle-fille ou à sa fille (celle-ci devenant la maîtresse de maison suivante). Mais aujourd'hui, ces continuatrices potentielles n'intègrent pas les

93. Grand chapelet de bois faisant un cercle d'environ deux mètres de diamètre (fig. 5). 
confréries, et nombre de ces dernières ont dû arrêter leurs activités à cause de l'âge avancé de leurs membres, et faute de reprise par les jeunes générations. Ainsi, même des confréries comme celles de Kannon et du Grand Maître de la section 3 de Takata (exemple 26 ci-après, p. 518), qui ont vu une intense relève de générations dans les années 1965-1975, ne comptent plus aujourd'hui comme membres qu'un petit nombre de maitresses de maisons ayant pris la suite de leur belle-mère ou de leur mère.

Pourtant, forte est la volonté d'assurer la continuité à tout prix. L'un des moyens choisi peut être de réduire le nombre de réunions ou de changer de jour : par exemple, pour les confréries qui se réunissaient chaque mois, réduire à une fois tous les deux mois (comme la section $x$ de Yamate), ou à quelques fois par an (comme la section 3 de Shimo-machi); ou encore, comme les six maisons de la confrérie du Grand Maître de la section 3 de Sannō, qui célèbrent « le 20 » chaque mois, choisir une date proche du 20 en dehors du vendredi, samedi et dimanche, qui convienne à celle qui doit l'assurer. Ici la priorité est donnée à la famille, qui, tous les autres jours de la semaine, est à l'extérieur de la maison pour le travail ou l'école. Il y a aussi le cas des cinq maisons des membres de la confrérie de Kannon de la section médiane de Wada, où, pour le "soir du 17 " célébré à tour de rôle, le choix s'est porté sur le samedi ou dimanche midi précédant le 17 de chaque mois.

Un second moyen est d'alléger la charge de la responsable du rite mensuel en remplaçant le repas par une simple collation ou par des boissons accompagnées de friandises. C'est par exemple le cas de la confrérie de Kana.ide (exemple 20), qui a limité le repas à un bol de riz accompagné de légumes en saumure pour juguler la surenchère des plats.

Le troisième moyen consiste à sortir la réunion cultuelle à l'extérieur de la maison. Lorsqu'il y a dans le voisinage un oratoire où est vénéré Kannon ou le Grand Maître Kōbō, elle y est déplacée ; s'il n'y en a pas, on utilise un espace communautaire du quartier. C'est le cas de la confrérie du Grand Maître de la section I de Shimo-machi (fig. 4).

Exemple 2I. - Cette confrérie célèbre « le 20 » de chaque mois dans la Maison citoyenne du quartier 94 . H. (née en 1928) qui en était membre, y participa à partir de janvier 1971, à la suite de sa belle-mère dont elle prit la relève. A cette époque, la maison de chaque membre accueillait la confrérie à tour de rôle. Après avoir pris chez elles le repas du soir à 20 heures, toutes s'y rassemblaient et, après la partie cultuelle, partageaient des assortiments de légumes, de fruits et de friandises. C'est à partir de 1989 qu'elles

94. Le jour de la réunion, la responsable se rend vers 19 heures à la Maison citoyenne pour faire les préparatifs : elle suspend le rouleau peint représentant le Grand Maître Kōbō, place devant lui sa statue et des offraindes de fleurs et de thé. À 20 heures, les autres membres arrivent. Chacune s'incline devant le rouleau peint en déposant une obole en espèces. Toutes récitent ensemble l'invocation au Grand Maître (Namu daishi Henjō kongō 南無大師遍照金剛). Ensuite, elles passent une heure à causer tout en partageant les gâteaux et les boissons préparées par la responsable du mois. À 2r heures, elles se séparent, et la responsable du mois suivant emporte avec elle le rouleau et la statue qu'elle installe chez elle dans le tokonoma. En mars, « le 20 » est jumelé à la réunion générale de la section : ainsi, des participants extérieurs à la confrérie viennent et déposent leurs offrandes. Ces offrandes et la cotisation mensuelle de mille yens constituent les fonds de la confrérie, avec lesquels ses membres font un repas au restaurant ou un voyage de deux jours. 


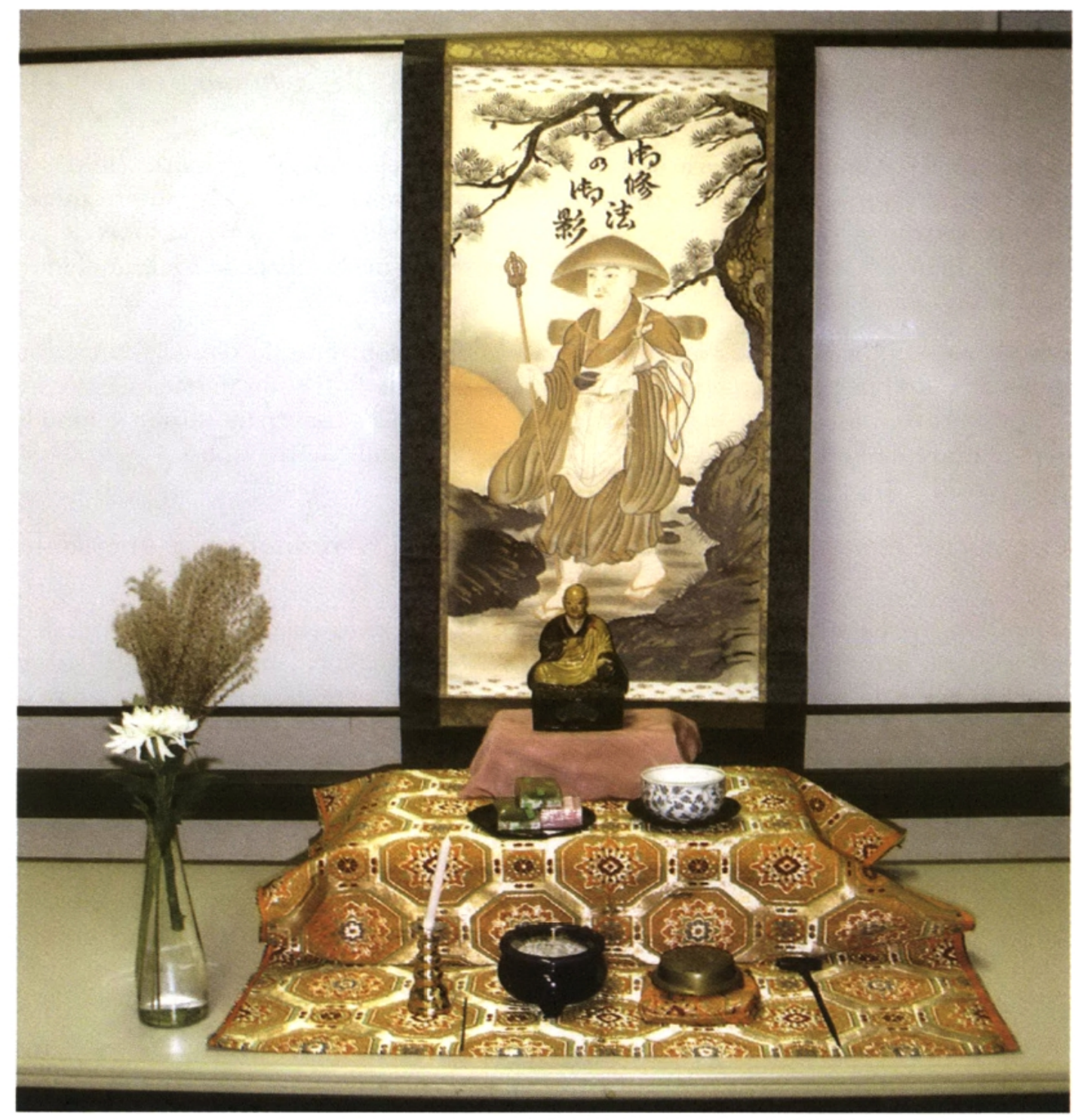

Fig. 4 : Rouleau peint et statue du Grand Mâitre Kōbō (Confrérie du Grand Maître, Daishi-kō, Shimo-machi, section I, Maison citoyenne, 25 octobre 2010).

utilisèrent la Maison citoyenne. H. K. a quitté la confrérie en 2009 à cause de son âge, mais comme son fils n'est pas marié, personne n'a pris sa place. À l'origine, la confrérie comptait vingt maisons, c'est-à-dire vingt maîtresses de maison. Mais soit à cause de leur départ pour des questions d'âge, soit parce qu'elles n'ont pas de remplaçante, soit parce que celle-ci n'habite pas avec elles, c'est aujourd'hui avec les seules représentantes de neuf maisons que se font les réunions cultuelles.

Exemple 22. - Depuis 2005, la confrérie du Grand Maître des sections médiane et basse de Wada se réunit chaque troisième lundi du mois dans la Maison citoyenne du quartier à partir de 14 heures. Depuis ce changement, les membres ont eu plutôt tendance à 
augmenter. À l'inverse, la confrérie de Kannon continue à se réunir chez ses membres, mais celles-ci étant devenues âgées, plusieurs d'entre elles ne peuvent plus assumer cette tâche et en sont sorties.

Mais dans plusieurs cas, le déplacement au-debors des maisons s'est fait vers les oratoires du quartier.

Exemple 23. - Ainsi, la confrérie du Grand Maître de la section Kyūtoku 久徳組 d'Oto. inu (à l'heure actuelle, sept maisons), dont les réunions se faisaient après-guerre suivant le tour des maisons, célèbre aujourd'hui « le Grand Maître » tous les 20 du mois de 14 à is heures, dans l'oratoire de Kannon où sont déposés en permanence le rouleau peint et la statue du Grand Maître Kōbō.

Exemple 24. - On peut citer aussi les membres de la confrérie du Grand Maître (qui compte aujourd'hui cinq maisons) de la section Tsukurude 作出組 du même quartier qui se réunissent un mois sur deux, dans la journée, à une date convenant à tout le monde, dans l'oratoire de Fudō où est conservée la statue du Grand Maître Kōbō.

Cette sortie des maisons peut s'accompagner de la réduction à une seule fête annuelle.

Exemple 25. - Le "soir du 17 " avait lieu à tour de rôle dans chacune des maisons de la confrérie de la seconde section de l'est de Hegi 辺木 à Tsubakuro, entre lesquelles passait le rouleau peint de Kannon. Mais depuis 1989, ce dernier a été déposé dans l'oratoire de Kannon, où cette célébration se déroule désormais une fois par an, le 17 juillet.

Cet exemple peut faire penser qu'en sortant des maisons ses rites mensuels, la confrérie a simplement réduit leur nombre. Mais comme le montre le cas de la confrérie de la section 3 de Haginoo, qui continue à pratiquer le tour des maisons pour le «soir du 17 », et participe également à la fête de Kannon qui a lieu chaque année le 17 juillet dans l'oratoire de Kannon du quartier, rite mensuel et fête annuelle sont en fait deux événements différents. Aussi le cas de la seconde section de l'est de Hegi (exemple 25) signifie-t-il en réalité la disparition de la confrérie de Kannon.

Enfin, une autre possibilité est celle de la célébration conjointe des rites des confréries de Kannon et du Grand Maître.

Exemple 26. - Jusque dans les années 1970, la confrérie de Kannon et celle du Grand Maître de la section 3 de Takata célébraient tous les mois de façon distincte le "soir du 17 » et « le 20 » chez l'une de leurs membres. Mais la charge des préparatifs et le fait que, pour les mêmes personnes, deux réunions se suivaient à trois jours d'écart, ont décidé celles-ci à combiner ces deux rendez-vous rituels en un seul. Aussi, dans le tokonoma, trois rouleaux peints sont-ils exposés (les 33 corps de Kannon, Sanjū-san Kannon zō 三十 三観音像, Shō Kannon 聖観音像 et le Grand Maître Kōbō en pèlerin, Hachijū hakka-sho Daishi zō 八十八所大師像). Ceci revient à la fusion de ces deux confréries. Or, comme celle du Grand Maître est propriétaire et gestionnaire de l'oratoire $n^{\circ} 69$ du circuit de pèlerinage de Sasaguri, c'est là qu'a lieu la célébration des mois d'avril et de juillet, où tous font le "million de tours" (byakumanben meguri 百万遍巡り), qui consiste à réciter des invocations et des sütra tout en faisant tourner le grand chapelet de mains en mains entre les participants assis en cercle sur les tatamis (voir exemple 16 et fig. 5 ). 


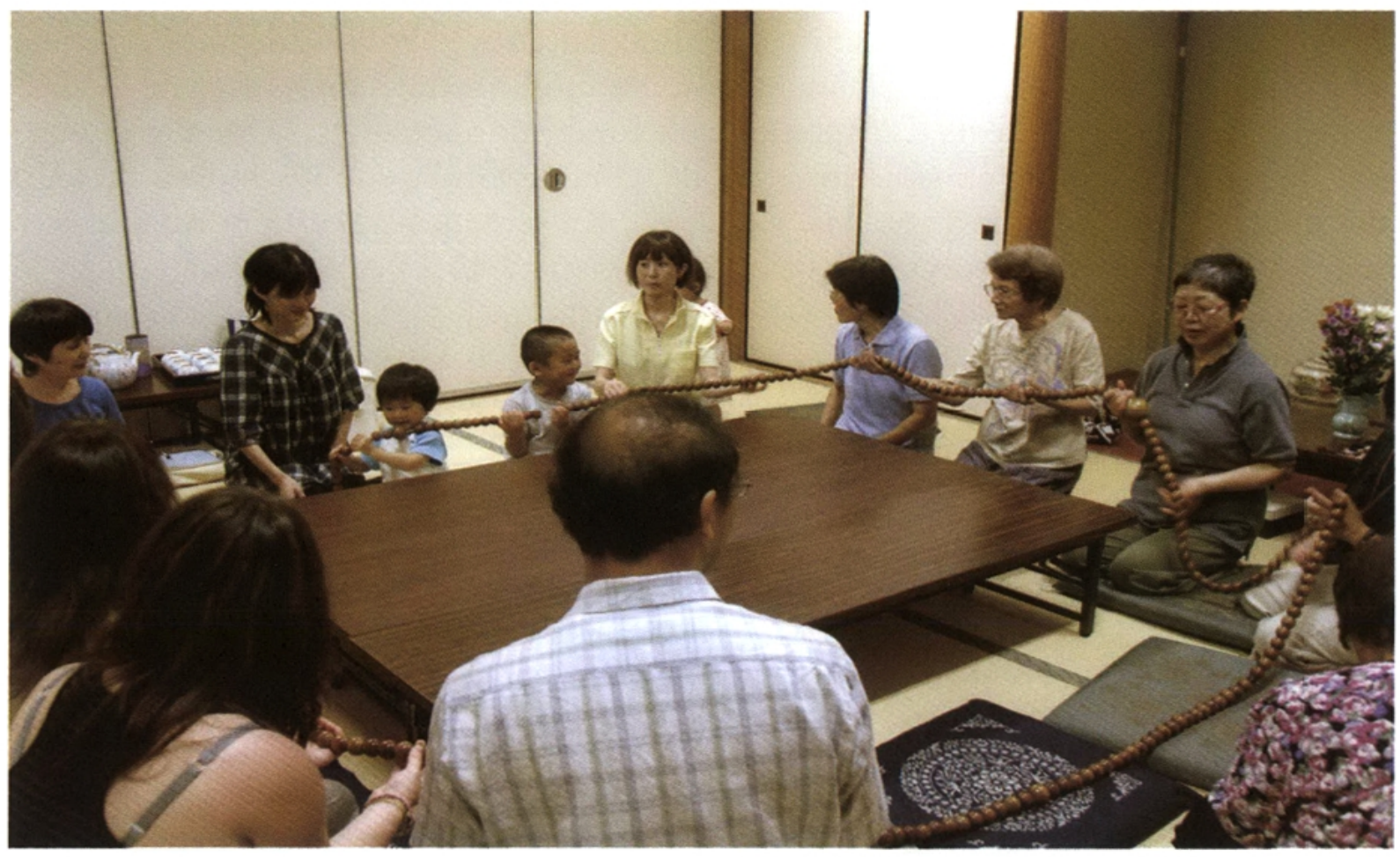

Fig. 5 : Le tour du grand chapelet pour « le 20 " (obatsuka) du Daishi-kō, la confrérie du Grand Maître (Shimo-machi, 17 août 2009) :

la confrérie est féminine; l'homme au premier plan est un des membres de l'équipe de recherche franco-japonaise.

\section{Transformations des finalités rituelles}

Comme les exemples précédents le montrent, plus que les pratiques cultuelles, qui sont originellement le mobile premier de la réunion des confréries, c'est aujourd'hui le côté relationnel et convivial qui est valorisé par leurs membres. Aussi certaines confréries ont-elles limité leurs réunions à cet aspect.

Exemple 27. - Alors que jusque-là, la confrérie de Kannon de la section Tsukurude d'Oto. inu se réunissait chaque mois dans la maison de l'une de ses membres, à partir des années 1990, toutes décidèrent ensemble de déposer définitivement le rouleau peint de Kannon à l'oratoire de Fudō 不動堂 de la cascade de Yōrō 養老ノ滝. Néanmoins, elles continuent à se réunir dans ce lieu tous les deux mois pour aller ensuite partager ensemble un repas dans un restaurant à l'extérieur.

Un tel stade représente la disparition de la confrérie en tant que groupe centré sur le tour des maisons pour son rite mensuel. Aussi l'appellation de confrérie cultuelle peut-elle être remise en question. Pourtant, comme ces activités ludiques sont toujours précédées d'une vénération du rouleau peint, on peut dire qu'elles restent malgré tout aux confins de cette catégorie. Pour assurer leur continuité, les confréries de femmes ont ainsi connu toute une série de transformations allant jusqu’à menacer leur identité. Parallèlement aux changements survenus dans les ritualités de 
l'intérieur de la maison, les fêtes et rites communautaires introduits depuis l'extérieur à l'intérieur de celles-ci ont également subi des modifications de sens et de finalité.

Mais malgré ces efforts d'adaptation aux conditions actuelles, la vie des confréries de femmes semble en situation difficile, comme l'indique l'âge moyen de leurs membres qui est de plus de 60 ans. Celles qui conservent une certaine vitalité sont celles qui pratiquent le service de collation (o-settai お接待) aux pèlerins.

Exemple 28. - Chaque année, le premier dimanche de mars, la confrérie du Grand Maître de la section I de Shimo-machi, dite "confrérie du 20 ", offre des collations à ceux qui font le circuit des 88 lieux saints de Sasaguri. Installant une table sur le bord des chemins et dans les squares sur le passage de ces derniers, ses membres y posent une image du Grand Maître Kōbō, des biscuits portant son nom (o-daishi sama お大 師样) et du thé. Lorsque tout est terminé, elles vont prendre ensemble un repas dans un restaurant. Les frais des collations offertes sont pris sur les cotisations de la confrérie, et la section de Shimo-machi fait aussi un don de dix mille yens. Lorsque le pèlerinage se faisait à pied, les pèlerins manifestaient leur reconnaissance pour ce service de collation reçu directement de la main de ces femmes. Mais aujourd'hui, comme le circuit se fait le plus souvent en voiture, les membres de la confrérie doivent passer thé et biscuits par la fenêtre ou même monter à bord du car des groupes. Ces femmes n'attendent pas de marque de reconnaissance pour elles de la part des pèlerins, mais elles souhaiteraient qu'au moins ils descendent pour s'incliner devant l'image du Grand Maître.

Elles pointent ainsi du doigt le déséquilibre actuel entre les deux facettes de ce « service » rituel. D'un côté, elles se sentent valorisées du fait même de rendre service aux pèlerins. Mais en même temps, elles éprouvent de l'insatisfaction devant l'attitude de ceux-ci, sans doute parce que, pour ces femmes, ce service de collation est l'occasion d'être reconnues comme membres d'une confrérie du Grand Maître et agents actifs du culte de ce dernier. Ici, la vénération par les pèlerins de cette figure au centre de leurs propres pratiques correspondrait donc pour elles à une reconnaissance externe de cette même identité.

Mais il faut ici préciser quelle est l'attitude des membres d'une confrérie par rapport à l'objet de culte. En avril 20Io, au cours d'un entretien avec la responsable du mois de la confrérie du Grand Maître de la section I de Shimo-machi, celle-ci me conduisit dans la pièce où a lieu la réunion et y installa un rouleau peint ainsi qu'une statue représentant le Grand Maître Kōbō. Or ce qui me frappa, c'est la façon dont cette femme manipula ces représentations du Grand Maître Kōbō, non pas comme des objets de culte, mais bien plutôt comme des pièces de collection. On avait l'impression d'être dans une exposition de statues bouddhiques classées trésors nationaux. S’il est vrai, comme le signale Fujii Tomoaki 藤井知昭, que nous sommes aujourd'hui dans l'âge d'or des petits groupes de style club"s, il n'en est pas moins certain qu'à la différence des groupes réunis par un même intérêt profane, ces confréries ont pour centre un objet de culte. Ce ne sont pas seulement les liens entre les personnes, mais les liens entre les membres et le bodhisattva Kannon ou le Grand Maître qui prévalent au sein de ces groupes. Les relations entre les gens

95. D’après Fujii Tomoaki 藤井知昭, «Kurabu-gata shakai no kanōsei » クラブ型社会の川能性, dans Kurita Yasuyuki 栗田靖之, éd., Nibonjin no ningen kankei 日本人の人間関係, Gendai Nibon bunka ni okeru dentō to benyō 現代日本文化に扔ける伀統と変享, vol. 3, 1987, p. 184-194. 
ont ici un intermédiaire qui est l'entité bouddhique. C'est un tampon qui permet, en cas de frictions humaines, de faire évoluer la situation favorablement. Or le culte en question semble assez superficiel. La statue ou le rouleau peint étant maniés plus comme des objets culturels que comme des objets cultuels, la réunion dont ils sont le centre est elle-même informelle, et le groupe peut ainsi se focaliser sur ses participants. En outre, on peut penser que cette simplicité contient en elle la souplesse qui en rend possible la pérennité. Ainsi, comme le dit Fujii, si la multiplication des clubs fait suite à la diversification actuelle des valeurs et si cette variable est elle-même introduite à l'intérieur de ces groupes (par exemple, sous la forme d'une chorale associant à ses activités musicales des activités de tennis et de voyage, créant ainsi des sous-groupes en son sein), le fait que les confréries de Sasaguri ajoutent à leurs activités cultuelles des réunions pour des repas ou des voyages en groupe, peut précisément apparaître comme ce qui permet aux confréries et à leurs rites mensuels de perdurer. Pourtant, il est évident qu'à toutes les époques antérieures, les repas collectifs ont toujours fait partie des réjouissances hautement appréciées par les membres des confréries. C'était notamment le cas pour les femmes, qui avaient peu l'occasion de sortir de la maison pour participer à des banquets, ou après la tombée de la nuit, et qui attendaient ces festivités extérieures avec impatience. Mais à compter de la période de haute croissance économique, les femmes ont progressivement pu accéder à un nombre croissant de distractions extérieures. Aujourd'hui, point n'est besoin d'être membre d'une confrérie pour pouvoir prendre un repas en dehors de chez soi ou faire un voyage en groupe. Aussi ce caractère ludique n'est-il plus nécessairement lié à la pérennité des confréries.

À l'inverse, comme on l'a vu précédemment, ce sont plutôt le contenu cultuel, le lien à l'entité bouddhique qui sont importants. Il semble bien que ce soit l'existence de l'objet de culte qui entretient et stimule la volonté de continuer les rites mensuels. À ceci vient s'ajouter le fait que, par le biais de cette pratique locale qu'est le service de collation aux pèlerins, le pèlerinage de Sasaguri offre aux confréries la possibilité d'affirmer leur propre existence par rapport au debors. Quant aux confréries qui ne pratiquent pas cette offre de collation aux pèlerins, elles cherchent à se perpétuer grâce à d'autres moyens. Ainsi, une femme qui participe depuis 2010 au " 20 " de la confrérie de Wakasugi explique qu'elle y apprend non seulement à chanter les hymnes des 88 lieux du pèlerinage mais aussi, plus généralement, « la vie ». Le culte n'est donc pas l'unique attrait de ces confréries. Elles semblent offrir à leurs membres une expérience qui ne peut pas être acquise ailleurs. 


\section{Bilan et perspectives}

Cette enquête a mis en lumière les caractères des modifications actuelles concernant le lieu, les acteurs et les finalités des rites internes et externes à la maison dans la commune de Sasaguri.

Tout d'abord, concernant le lieu, on a vu que les dispositifs transformant la maison, cœur de la vie ordinaire, en un espace-temps festif ont subi des transformations drastiques, parallèlement aux changements de la vie matérielle. En effet, avec la diffusion de l'architecture, de l'aménagement intérieur et du style de vie occidentaux, offrandes, instruments, aliments, qui constituaient la base de l'apparat rituel hérité des générations précédentes, sont devenus des objets soit décoratifs, soit accessibles quotidiennement, ce qui a amoindri considérablement la capacité à opérer cette permutation festive des lieux pour l'organisation des rites religieux. L'intérieur de la maison est ainsi devenu le lieu du maintien de l'ordinaire. Poursuivre cette enquête sur le long terme à Sasaguri, comme je l'ai fait ailleurs ${ }^{96}$, permettrait certainement d'affiner l'analyse sur les liens entre les aléas des rites familiaux et les transformations des modes de vie et de l'appareillage domestique. En outre, considérés sous l'angle du dedans et du debors, il est clair que parmi les rites de la maison, ceux du Jour de l'an sont fortement marqués par leur caractère de ritualités internes à la maison et à l'habitation, tandis que les rites de la fête des morts (obon) de Sasaguri sont inscrits, quant à eux, dans une dynamique reliant l'intérieur (maison) et l'extérieur (communauté micro-locale). Cette même dynamique existe dans un autre sens pour les rituels des confréries, qui, comme on l'a vu, après avoir été introduits dans les maisons de leurs membres, ont aujourd'hui tendance à en être sortis et à être déplacés vers des lieux publics communaux. À l'origine, ces rituels étaient communautaires ; aussi cela semble-t-il conforme à leur logique. Néanmoins, l'une des conséquences de ce changement est la disparition du «tour des maisons » mensuel qui associait le transport des objets cultuels et le passage de tous les membres d'une maison à l'autre. Or ce circuit rituel consolidait le groupe en tant que corps social. La question est de savoir si les lieux publics où les réunions se déroulent désormais permettront également la continuité des solidarités cultuelles et la pérennité des rites. Par ailleurs, on a vu que dans la gestion des lieux de culte sont mélangées les dimensions sacrées et profanes, puisque les acteurs des différentes organisations cultuelles et publiques sont les mêmes. Ceci, conjugé au transfert de rites religieux dans ces lieux communautaires publics, a aussi pour conséquence l'insatisfaction de certains habitants qui sont réticents à accepter l'aspect religieux des cultes, et ne participent plus aux rites et événements du quartier ou des sections. Cela conduit à

96. À Kami-Yahagi (département de Gifu), commune où j'ai mené une enquête, entre 2005 et 2006, dans les maisons où l'on puisait anciennement l'eau à la main dans le puits, fut d'abord installée une pompe manuelle, puis une pompe électrique, qui furent finalement remplacées par une conduite d'eau. Avec ce changement, le "puisage de l'eau nouvelle » (wakamizu kumi) au Nouvel An est passé de la main du maître de maison à celle de la maîtresse de maison. Le rite a perduré même après l'installation de la conduite d'eau, mais il a fini par s'éteindre. 
s'interroger sur la possibilité de la gestion des rites par les organisations publiques en de tels lieux à l'avenir et, par là, sur celle de la continuité des rites eux-mêmes.

En ce qui concerne contenus, finalités et acteurs des rites, étant donné que, jusqu'à une période récente, tous les rites et fêtes annuels des maisons ou des communautés locales associaient célébration du culte et repas communautaire (naorai), on peut penser que le plaisir de ce dernier a toujours constitué une part importante de l'attractivité de l'événement. Mais l'affaiblissement contemporain de l'intérêt pour les divinités de la maison ou celles du sanctuaire a entrainé une focalisation sur la réunion du groupe concerné, ainsi qu'une perte du caractère religieux des ritualités, de plus en plus centrées exclusivement sur la convivialité et les repas festifs. L'habitation n'étant plus l'espace où sont invités à venir les dieux ou les âmes des morts, plus que les règles rituelles héritées, ce sont les goûts des participants qui ont tendance à commander le contenu des mets festifs ; en outre, les rites annuels deviennent plutôt l'occasion de réunir les membres de la famille qui sont loin de la maison en temps ordinaire, et aussi celle d'accueillir des invités qui ne s'y assemblent qu'en ces moments particuliers. À ce titre, même si c'est dans un sens différent, les rites sont orientés vers la continuité. Mais une telle transformation des contenus contribue également à faire en sorte que soient privilégiées les "nouvelles fêtes ", comme la fête des Pères, des Mères, les anniversaires, etc., au détriment des ritualités traditionnelles qui associent le couple «célébration du culte et repas communautaire ». Enfin, les transformations de l'économie de subsistance ont elles aussi concouru à ces bouleversements. Autrefois fondés en grande partie sur le calendrier agraire de maisons dont l'habitation était aussi le lieu du travail communautaire, les rythmes calendaires rituels sont aujourd'hui soumis aux exigences de l'économie de marché et du travail à l'extérieur, qui a fait sortir une grande partie des membres des familles hors de l'activité agricole et de l'habitation-lieu de travail. Ricn de tout ceci n'est propre à la commune de Sasaguri. On peut penser qu'à l'heure actuelle, dans tout le Japon, les rites annuels des maisons ont subi une forte uniformisation. Les données recueillies à Sasaguri constituent à ce titre une base de référence à confronter à celles d'autres localités : ceci permettrait d'avoir un aperçu général de la question.

Ensuite, la pérennité des rites se révèle fortement liée à la personne de leurs acteurs. Le fait que les rites de la maison aient eu pour centre le maitre de maison, qui en est à la fois l'officiant principal et le transmetteur, est à mettre en relation avec le patriarcat. La notion de patriarcat telle qu'elle est conçue à l'intérieur des maisons diffère probablement de l'une à l'autre. À ce sujet, on peut se demander si, dans la commune de Sasaguri, le nombre des maisons restant organisées par une tradition patriarcale est similaire ou differre de celui d'autres localités et d'autres régions. De même, d'autres enquêtes seraient nécessaires pour savoir plus précisément dans quelle mesure et en quoi la transformation de la famille est à rapprocher de celle du patriarcat. Les raisons économiques qui ont conduit les hommes à travailler à l'extérieur de la famille ont aussi contribué à faire passer la responsabilité des rites familiaux aux mains des femmes. Même dans des cas extrêmes (comme celui de la confrérie de Kōshin de l'exemple is), où les ritualités communautaires limitaient la participation aux seuls maîtres de maisons ayant une histoire de plus de cent ans, on voit aujourd'hui qu'est acceptée la présence féminine. Ceci vaut plus généralement 
pour l'ensemble des rites de la maison et de la communauté locale, puisqu'ils sont accompagnés d'un repas et impliquent, par là, l'importance du rôle des femmes. Les recherches sur la place des femmes dans le cadre des ritualités se sont surtout focalisées sur le cas de celles qui sont officiantes, acteurs principaux des rites, mais très peu de travaux ont cherché à mettre en lumière la place et le rôle des femmes à l'intérieur des ritualités centrées sur les hommes. C'est là un point qui mérite d'autres investigations, tant au niveau des rites de la maison qu'à celui des communautés locales. Ceci n'est pas dissociable d'un approfondissement de ce qui n'a été abordé ici que brièvement, à savoir la conscience qu'ont les femmes de ces ritualités, de leur rôle, de leur propre identité de maîtresse de maison et d'officiante, de l'occasion que ces rites leur offrent, ou non, de s'affirmer comme telles aujourd'hui, tant à l'intérieur qu'à l'extérieur de leur famille et de la société locale. C'est aussi inséparable d'une approche de la conscience identitaire et collective d'un groupe cultuel organisé par les femmes. Les occasions pour celles-ci d'affirmer leur identité devenant plus fréquentes, la nécessité des confréries semble diminuer. Mais à Sasaguri, où les membres des confréries ont des contacts avec le debors par le biais des services de settai qu'elles rendent aux pèlerins, les organisations féminines peuvent leur fournir des opportunités de reconnaissance identitaire. Par ailleurs, Sakurai Tokutarō signale que les ritualités de la communauté villageoise durent et se perpétuent davantage que celles des maisons ${ }^{97}$. Ceci exigerait d'autres investigations, mais si l'on replace ceci dans le cadre d'analyse du dedans et du debors de la maison, et comme le suggèrent les cas rencontrés à Sasaguri, on peut dire qu'à partir du moment où ils ont un lien avec l'extérieur de la maison, les rites familiaux eux-mêmes ont beaucoup plus de chances de perdurer.

Enfin, se pose la question de ce qui est transmis dans les rites et de la façon dont on veut le transmettre. Si la transmission et l'héritage rituels sont définis comme le fait d'accomplir les mêmes offrandes et gestes rituels au même endroit et de partager la même nourriture que les ancêtres, c'est-à-dire de reproduire ce qu'ont fait les générations qui ont précédé, alors on peut dire qu'aujourd'hui, aucun rite traditionnel ne fait l'objet d'une transmission. La continuité des ritualités du Nouvel An en tant qu'« accueil du dieu de l'An par tous les membres de la famille réunis » est de nos jours tout à fait sujette à caution. Mais si " passer le Jour de l'an avec tous les membres de la famille réunis » est également considéré comme une ritualité du Nouvel An, alors il y a bel et bien transmission aujourd'hui. À ce titre, les modifications du calendrier rituel tendant à accorder celui-ci aux horaires et disponibilités des acteurs peuvent aussi être considérées comme des moyens de transmettre les rites. Telle est en tout cas la conscience qu'en ont les acteurs eux-mêmes. Nous sommes donc amenés à penser de façon souple le cadre rituel lorsque nous examinons cette question de la transmission. C'est ainsi que, lorsqu'à la finalité religieuse se sont ajoutés d'autres aspects attractifs pour les générations actuelles, la possibilité de la transmission aux jeunes, et même le renouvellement des rites des communautés locales s'en trouvent d'autant plus renforcés. C'est le

97. Voir plus haut, p. $480-497$ et note 21 . 
cas, par exemple, des rites des confréries qui, sans cela, risquent de disparaître par manque de relève. C'est aussi celui de fêtes communautaires rassemblant toute la population d'un quartier, lorsqu'elles sont associées à d'autres événements, comme par exemple la « fête de l'été » qui, dans certains cas, est la combinaison de la danse collective de la fête des morts et de la fête de la culture. Dans le quartier Meiji en août 2009, cette "fête de l'été " cumula rites religieux, danse de la fête des morts, démonstration de danses hawaïennes devant la Maison citoyenne, où étaient exposées des peintures et des réalisations artistiques diverses des habitants, tandis que les associations de parents tenaient des échoppes de jeux et de nourriture. C'est ce fusionnement qui semble bien l'une des clés de la transmission.

Un dernier point important, qui n'a été que peu abordé ici et qui nécessite une recherche plus approfondie, est celui de l'aspect économique des rites. Dans le rapport à l'extérieur, nous avons vu qu'à Sasaguri, les rituels des oratoires du pèlerinage des 88 lieux saints bénéficiaient d'une transmission active. L'une des raisons en est que le cadre de ce pèlerinage leur permet d'avoir comme support économique les dons des pèlerins et les frais de gestion versés par la communauté locale. Mais il ne faut pas oublier non plus, sous l'angle du rapport à l'intérieur des maisons et des communautés locales, la masse économique considérable que représente le flux des échanges suscités par chaque occasion rituelle : offrandes aux autels familiaux, cadeaux échangés entre les membres des familles et dans les communautés locales, offrandes aux temples et sanctuaires et rémunération des services de leurs desservants, autant d'échanges qui soutiennent toute une part de l'activité commerçante locale. Et alors même que la tendance est à l'évincement de l'aspect religieux des rites de la maison, il n'est sans doute pas anodin qu'une propriétaire d'auberge, M. R., qui vit de la venue des pèlerins, insiste sur l'importance de la transmission des rites cultuels chez elle, bien que son style de vie soit tout à fait moderne. Ici, la différence tient sans doute pour une part au lieu de l'activité professionnelle. Si les foyers de salariés cherchent plutôt à évacuer le festif à l'extérieur, la maison dont l'habitation est aussi le lieu de travail constitue encore aujourd'hui une communauté économique et, par là, ressent sans doute davantage la nécessité de perpétuer les rites relatifs à son activité de subsistance. Mais est-ce généralement vrai pour l'ensemble du groupe professionnel des auberges de pèlerinage ? Cela concerne-t-il toutes les maisons exerçant leur profession sur leur lieu de vie ? Qu'en est-il hors de la commune de Sasaguri ? De telles questions appellent davantage d'investigations sur les relations entre rites familiaux et fondements économiques des différents types professionnels.

Par ailleurs, s'il est vrai qu'on constate chez les salariés un affaiblissement général des dispositifs de transformation de l'habitat ordinaire en un lieu festif, des jeunes ayant aujourd'hui la trentaine ou la quarantaine (nés entre 1972 et 1982) disent qu'ils éprouvent une réticence à « jeter la corde de paille du Nouvel An au même titre que les ordures ». Ils ont donc bien conscience de son caractère sacré. C'est surtout entre les années 1985 et 2000 que s'est accentué le déclin des rituels. C'est probablement pour cette raison que diminuèrent les occasions de parler de la sacralité de l'apparat festif en tant que dispositif de transformation de l'espace ordinaire. Là encore, il faudrait s'enquérir auprès des générations nées après 1990 de ce qu'elles ont entendu dire sur les traditions rituelles. 
À propos de la danse du lion (shishi mai 獅子舞) des enfants, une femme de Takata me confia : «Autrefois, les enfants visitaient chaque maison avec la tête de lion en chantant "Félicitations et bonheur !" [Iwai medetano 祝いめでたの]. Aujourd'hui, les enfants sont peu nombreux à le faire et ils appuient seulement sur la sonnette. Il faudrait mieux leur expliquer que la danse du lion est un rite d'expulsion des forces néfastes pour l'été. » Les ritualités ne sont plus l'occasion de parler des divinités ou de la sacralité des objets rituels, alors qu'elles l'avaient été jusque-là. Or si les rites cessent d'exister, les transmissions orales les concernant disparaîtront elles aussi à tout jamais. Perpétuer les rites annuels de la maison ou de la communauté locale, sous une forme ou une autre, c'est aussi entretenir ce que l'on en dit et ce que l'on en sait. Lorsque j'ai questionné les jeunes femmes sur la continuation des rites de la maison, la réponse a généralement été unanime : "Je ne pourrai pas le faire aussi méticuleusement et rigoureusement que ma mère ou ma belle-mère, mais je voudrais en continuer au moins un certain nombre. "Quel impact aura le souhait de ces jeunes femmes sur la transmission des rites annuels, c'est là une question à suivre. 


\section{Bibliographie}

Bouchy, Anne

2001 "Du bon usage de la malemort. Traitement des "âmes rancuneuses" et rituels oraculaires dans la société japonaise », dans Brigitte Baptandier, éd., De la malemort en quelques pays d'Asie, Éditions Karthala, p. 201-234.

CAIllet, Laurence, FEAT, Gabriel et al., éd.

1980 Fêtes et rites des quatre saisons au Japon, coll. « La bibliothèque japonaise », Aurillac, Presses orientalistes de Francc.

Fleury, Elizabeth, éd.

1987 «Habiter la maison », Terrain $\mathrm{n}^{\circ}$ 9, numéro spécial (téléchargeable à l'adresse $<$ http://terrain.revues.org/2r4>).

FuJII Tomoaki 藤井知昭

1987 《Kurabu-gata shakai no kanōsei »クラブ型社会の可能性, dans Kurita Yasuyuki 栗田靖之, éd., Nibonjin no ningen kankei 日本人の人間関係, Gendai Nibon bunka ni okeru dentō to henyō 現代日本文化における伝統と変容, vol. 3, Tōkyō, Domensu shuppan ドメス出版, p. 184-194.

Fujiwara Osamu 藤原修

1998 «Ie no gyōji, mura no gyōji » 家の行事・ムラの行事, dans Jikan no minzoku 時間の民俗, Kōza. Nibon no Minzokugaku 講座:日本の民俗学, vol. 6, Tōkyō, Yūzankaku shuppan 雄山閣出版, p. 137-152.

GōDa (Tsubor) Hirofumi 鄉田(坪井)洋文

1957 《Nenjū gyōji no shakaisei to chiikisei » 年中行事の社会性と地域性, dans Seikatsu to minzoku 生活と民俗, vol. 2 [Nibon minzokugaku taikei 月本民 俗学大系, vol. 7], Tōkyō, Heibonsha 平凡社, p. I67-238.

IMADA Setsuko 今田節子

2001 《Chiiki ni okeru shoku no denshō »地域における食の伝承, dans Ehara Ayako 江原絢子, éd., Shoku to kyōiku 食と教育, Shoku no bunka föramu 食の文化フォーラム, vol. 19, Tōkyō, Domensu shuppan ドメス出版, p. 70-92.

IsHIKAWA Toshiko 石川稔子

2004 《Nenjū gyōji » 年中行事, dans Uno Yūsuke 鶇野祐介, Ōhashi Waka 大橋 和華 et Ishikawa Toshiko 石川稔子, éd., Higashi Mino no minwa, uta, asobi to nenjū gyōji 東美濃の民話·唄·遊びと年中行事, Okayama 岡山, Techōsha 手帖舎, p. $285-337$.

KURA.ISHI Tadahiko 倉石忠彦

1998 《Nenjū gyōji no kōsei » 年中行事の構成, dans Jikan no minzoku 時間の 民俗, Kōza. Nibon no Minzokugaku. 講座:日本の民俗学, vol. 6, Tōkyō, Yūzankaku shuppan 雄山閣出版, p. 121-136.

LÉvi-Strauss, Claude

1982 The Way of the Masks, translated from the French by Sylvia Modelski, Seattle, University of Washington Press.

1984 Paroles données, Paris, Plon. 
MiYamoto Tsune.ichi 宮本常一

1978 Minkan-reki 民間暦, Miyamoto Tsune.ichi chosakusbū 宮本常一著作集, vol. 9, Tōkyō, Mirai-sha 未来社 ( $\mathrm{r}^{\mathrm{re}}$ éd., 1942).

MuRAsaki Kazuko むらさき数子

1998 《Shoku bunka no henyō 》 食文化の変容, dans Minzoku no shisō 民俗 の思想, Gendai minzokugaku no shiten 現代民俗学の視点, vol. 3, Tōkyō, Asakura shoten 朝倉書店, p. 74-84.

NisHimURA Junko 西村純子

2004 《Kindai kazoku no naka no josei » 近代家族の中の女性, dans Shimizu Hiroaki 清水浩昭 et al., éd., Kazoku kakumei 家族革命, Tōkyō, Kōbundō 弘文堂, p. 6I-67.

ORIKUCHI Shinobu 折口信夫

1996 《Nenjū gyōji. Minkan gyōji denshō no kenkyū » 年中行事——民間行事 伝承の研觉, dans Orikuchi Shinobu zenshū 折口信夫全集, vol. 17, Tōkyō, Chūō Kōronsha 中央公論社, p. 13-84 ( ${ }^{\mathrm{re}}$ éd., 1930-1932).

SAKURAI Tokutarō 桜井徳太郎

1968 《Shūzoku henka no katei to yō.in 》 習俗変化の過程と要因, dans Sakurai Tokutarō, Shinbutsu kōshōshi kenkyū 神仏交涉史研究, Tōkyō, Yoshikawa Kōbunkan 吉川弘文館, p. 415-500.

TAKEDA Michi 竹田美知

2010 《Katei seikatsu no kobetsuka 》家庭生活の個別化, dans Kanbara Fumiko 神原文子 et al., éd., Yoku wakaru gendai kazoku よくわかる現代家族, Kyōto, Mineruva shobō ミネルヴア書房, p. 70-71.

TANAKa Sen.ichi 田中宣一

$1992 N e n j \bar{u}$ gyōji no kenkyū 年中行事の研究, Tōkyō, Ōfūsha 桜楓社.

WAKAMORI Tarō 和歌森太郎

$1957 N e n j \bar{u}$ gyojii 年中行事, Tōkyō, Shibundō 至文堂.

YANAGITA Kunio 柳田国男

1971 《Minkan reki shōkō" 民間暦小考, dans Teibon Yanigita Kunio shū 定本 柳田国男集, vol. 13, Tōkyō, Chikuma shobō 筑摩書房, p. 275-29I (Ire èd., 1931).

YANAGITA Kunio 柳田国男 et SEKI Keigo 関敬吾

1998 Shinpan Nibon minzokugaku nyūmon 新版:日本民俗学入門, Tōkyō, Meicho shuppan 名著出版 ( ${ }^{\mathrm{rc}}$ éd., 1942).

Monographies, bistoriographies locales, dictionnaires

Bunka-chō 文化庁, éd.

1969-1971 Nenjū gyōji 年中行事, vol. I et 2 de la série Nibon minzoku chizu 日本民俗 地図 (9 vol., 1969-2003), Tōkyō, Kokudo chiri kyōkai 国土地理協会. 
Fuxuta Ajio 福田アジオ et al., éd.

1999-2000 Nihon minzoku daijiten 日本民俗大辞典, 2 vol., Tōkyō, Yoshikawa Kōbunkan 吉川弘文館.

Kadokawa chimei daijiten hensan iinkai 角川日本地名大辞典編策委員会, éd.

1991 《Fukuokaken nenjū gyōji, II, Minzoku »福岡県年中行事, II, 民俗, dans Kadokawa Nihon chimei daijiten 角川旧本地名大辞典, Fukuoka-ken 福岡県, vol. 40, Tōkyō, Kadokawa shoten 角川書店, p. 1996-2002.

Kami-Yahagi chōshi hensan iinkai 上矢作町史編策委員会, éd.

2008 Kami-Yabagi chōshi. Minzokuben 上矢作町史:民俗編, Ena 恵那 (Gifu-ken 岐阜県), Ena-shi kyōiku iin-kai 恵那市教育委員会.

Sasagurichō bunkazai senmon iinkai 篠栗町文化財専門委員会, éd.

1990 Sasaguri chōshi. Minzoku-ben 箫栗町誌:民俗篇, Sasaguri, Sasaguri-chō 策栗町. 
Documents annexes :

I - Tableau des rites annuels de la maison à Sasaguri

\begin{tabular}{|c|c|c|c|c|c|c|c|c|c|c|c|c|c|c|}
\hline Lieu & & Oto.inu & & Shimo-machi & & Kana.ide & & Wada & & Tsubakuro & & Tsubakuro & & $\begin{array}{l}\text { Shingü (commune } \\
\text { au nord-ouest de } \\
\text { Sasaguri) }\end{array}$ \\
\hline \multirow[t]{3}{*}{$\begin{array}{l}\text { Inter- } \\
\text { locuteur }\end{array}$} & & $\begin{array}{c}\text { S. N. } \\
\text { (née en 1925) }\end{array}$ & & $\begin{array}{c}\text { M. R. } \\
\text { (née en 1962) }\end{array}$ & & $\begin{array}{c}\text { I. F. } \\
\text { (née en 1928) }\end{array}$ & & $\begin{array}{c}\text { A. S. } \\
\text { (né en 1926) }\end{array}$ & & $\begin{array}{c}\text { I. O. } \\
\text { (né en 1935) }\end{array}$ & & $\begin{array}{c}\text { K. S. } \\
\text { (né en 1947) }\end{array}$ & & $\begin{array}{l}\text { N. Y. (fille de K. S.) } \\
\text { (née en 1976) }\end{array}$ \\
\hline & Jour & & Jour & & Jour & & Jour & & Jour & & Jour & & Jour & \\
\hline & & & & Grand nettoyage & & Grand nettoyage & & & $\begin{array}{c}\text { À partir } \\
\text { du } 20\end{array}$ & Grand nettoyage & $\begin{array}{c}\text { Milieu du } \\
\text { mois }\end{array}$ & Grand nettoyage & & $\begin{array}{l}\text { Ménage plus à fond } \\
\text { que d'habitude. } \\
\text { Ni mochi, ni corde } \\
\text { de paille }\end{array}$ \\
\hline \multirow[t]{3}{*}{$\begin{array}{l}\text { Décembre } \\
\text { (12 } 2^{2} \text { mois) }\end{array}$} & & & 28 & Pilage du mochi & 28 & Pilage du mochi & & & 28 & $\begin{array}{l}\text { Pilage du mochi } \\
\text { (avant, on le } \\
\text { faisait le 30) }\end{array}$ & & & & \\
\hline & & & & & & & 29 & $\begin{array}{c}\text { "Nettoyage de } \\
\text { la suie » (grand } \\
\text { nettoyage). } \\
\text { Préparation du } \\
\text { mochi (actuelle- } \\
\text { ment apporté par } \\
\text { sa fille) }\end{array}$ & & & & & & \\
\hline & 30 & $\begin{array}{c}\text { Grand nettoyage } \\
\text { (« Nettoyage de } \\
\text { la suie } ») . \\
\text { Pilage du mochi. } \\
\text { Pose de l'apparat } \\
\text { festif : sbimenawa } \\
\text { (corde de paille), } \\
\text { mocbi-miroir }\end{array}$ & 30 & $\begin{array}{c}\text { Pose de l'apparat } \\
\text { festif : rouleau } \\
\text { peint de Taka- } \\
\text { sago 高砂の掛 } \\
\text { け軸, shimenawa, } \\
\text { mocbi-miroir. } \\
\text { Fabrication } \\
\text { des « baguettes } \\
\text { yari kuri » } \\
\text { (yarikuri=bashi } \\
\text { やり栗箸) }\end{array}$ & 30 & $\begin{array}{c}\text { Pose de l'apparat } \\
\text { festif: } \\
\text { shimenawa, } \\
\text { mochi-miroir. } \\
\text { Préparatifs des } \\
\text { mets du Jour } \\
\text { de l'an }\end{array}$ & 30 & $\begin{array}{c}\text { Pose de } \\
\text { l'apparat festif: } \\
\text { shimenawa, } \\
\text { mochi-miroir. } \\
\text { Nettoyage du } \\
\text { columbarium } \\
\text { collectif (3 pers. } \\
\text { par section) }\end{array}$ & 30 & $\begin{array}{c}\text { Mochi-miroir } \\
\text { (pas d'autre } \\
\text { apparat festif, } \\
\text { car la famille est } \\
\text { affiliée au Jödo } \\
\text { Shin-shū 浄土 } \\
\text { 真宗 — néan- } \\
\text { moins, i2 mocbi- } \\
\text { miroirs dans le } \\
\text { toko-no-ma). } \\
\text { Préparation des } \\
\text { mets festifs }\end{array}$ & 30 & $\begin{array}{c}\text { Achat du mochi } \\
\text { et de la corde } \\
\text { de paille posés } \\
\text { comme apparat } \\
\text { festif. } \\
\text { Décoration de } \\
\text { fleurs avec pin, } \\
\text { bambou, fleurs } \\
\text { de prunier } \\
\text { (maison et autel } \\
\text { domestique). } \\
\text { Fait le grand } \\
\text { nettoyage chez } \\
\text { ses parents }\end{array}$ & & \\
\hline
\end{tabular}




\begin{tabular}{|c|c|c|c|c|c|c|c|c|c|c|c|c|c|c|}
\hline & 31 & $\begin{array}{l}\text { Préparatifs des } \\
\text { mets du Jour } \\
\text { de l'an. } \\
\text { Repas de fête de } \\
\text { la veille du Ir } \\
\text { de l'an. } \\
\text { Nouilles de } \\
\text { sarrasin du } \\
\text { passage de l'An } \\
\text { («nouilles de } \\
\text { sarrasin de la } \\
\text { chance ») }\end{array}$ & 31 & $\begin{array}{c}\text { Fête du dieu de } \\
\text { l'An («Toshi } \\
\text { koshi sama » } \\
\text { 年越し様). } \\
\text { Pèlerinage au } \\
\text { sanctuaire Yaku } \\
\text { Hachiman } \\
\text { 厄八幡 } \\
\text { (Hakata). } \\
\text { Visites au } \\
\text { sanctuaire Suwa, } \\
\text { aux temples } \\
\text { Myōfuku-ji } \\
\text { 妙福寺, Nanzō- } \\
\text { in 南藏院, } \\
\text { Fudaraku-ji 補陶 } \\
\text { 落寺 (Sasaguri) } \\
\end{array}$ & 31 & $\begin{array}{l}\text { « Nouilles de } \\
\text { sarrasin de la } \\
\text { chance ». } \\
\text { Bain, linge } \\
\text { nouveau. } \\
\text { Sanctuaire } \\
\text { Hōman : offre } \\
\text { de sake par les } \\
\text { hommes « dâge } \\
\text { néfaste ». } \\
\text { Fête de la nuit } \\
\text { du passage } \\
\text { de l'An au } \\
\text { sanctuaire } \\
\text { Hōman (avec } \\
\text { le groupe de la } \\
\text { section) }\end{array}$ & 31 & $\begin{array}{c}\text { Exposition } \\
\text { de peintures } \\
\text { (sections) }\end{array}$ & 31 & $\begin{array}{c}\text { Nouilles de } \\
\text { sarrasin } \\
\text { Visite au Shinkō- } \\
\text { ji 真光寺. } \\
\text { On reçoit la } \\
\text { "première bou- } \\
\text { gie » (rouge). } \\
\text { Frappement de } \\
\text { la cloche de la } \\
\text { nuit du passage } \\
\text { de l'An. } \\
\text { Actuellement, } \\
\text { également visite } \\
\text { au sanctuaire } \\
\text { tutélaire Goryō- } \\
\text { gū 御霊宮 }\end{array}$ & 31 & $\begin{array}{l}\text { Préparation des } \\
\text { mets festifs chez } \\
\text { les parents. } \\
\text { Nouilles de sar- } \\
\text { rasin du passage } \\
\text { de l'An. } \\
\text { Premier pèle- } \\
\text { rinage au sanc- } \\
\text { tuaire tutélaire } \\
\text { Goryō-gū }\end{array}$ & 31 & $\begin{array}{l}\text { Nouilles (de blé) du } \\
\text { passage de l'An. } \\
\text { Concours de chant } \\
\text { télévisé « Rouge- } \\
\text { blanc » et "L'an passé, } \\
\text { l'année à venir " }\end{array}$ \\
\hline $\begin{array}{c}\text { Janvier } \\
\left(\mathrm{I}^{\mathrm{It}} \mathrm{mois}\right)\end{array}$ & $\mathrm{I}^{\mathrm{er}}$ & $\begin{array}{c}\text { Puisage de l'eau } \\
\text { nouvelle. } \\
\text { Offrande du sake } \\
\text { (dit «o-batsu wo } \\
\text { ageru » お初を上 } \\
\text { げる) aux dieux. } \\
\text { Repas du Jour } \\
\text { de l'an (thé, } \\
\text { o-toso, zöni, mets } \\
\text { festifs). } \\
\text { Visit au sanc- } \\
\text { tuaire tutélaire } \\
\text { (ujigami) }\end{array}$ & I & $\begin{array}{c}\text { Puisage de l'eau } \\
\text { nouvelle (puits). } \\
\text { O-toso, zōni, } \\
\text { mets festifs }\end{array}$ & I & $\begin{array}{c}\text { Omiki (sake) bu } \\
\text { en famille ; zöni, } \\
\text { mets festifs. } \\
\text { Visite au sanc- } \\
\text { tuaire Höman. } \\
\text { Tour des trois } \\
\text { sanctuaires } \\
\text { (aussi à Suga-sha } \\
\text { 㖽賀社 et Ino- } \\
\text { sha イノ社 de } \\
\text { Kubara 久原) }\end{array}$ & I & $\begin{array}{l}\text { O-toso, zōni. } \\
\text { Mets festifs. } \\
\text { Visite chez ses } \\
\text { parents }\end{array}$ & I & $\begin{array}{l}\text { Le maitre de } \\
\text { maison offre du } \\
\text { sake sur l'étagère } \\
\text { des dieux. } \\
\text { O-toso, zöni de } \\
\text { Hakata, avec des } \\
\text { brochettes de } \\
\text { mets d'accompa- } \\
\text { gnement. } \\
\text { Mets festifs }\end{array}$ & I & $\begin{array}{l}\text { Thé. } \\
\text { Ctoso. } \\
\text { Sushi et mets } \\
\text { festifs. } \\
\text { Zöni }\end{array}$ & I & $\begin{array}{l}\text { (Avec les gens du } \\
\text { quartier résidentiel, } \\
\text { montée sur une colline } \\
\text { pour voir le I' lever } \\
\text { de soleil). } \\
\text { Après un petit } \\
\text { déjeuner léger, départ } \\
\text { pour la maison de ses } \\
\text { parents. } \\
\text { En chemin, visite au } \\
\text { sanctuaire Rokusho- } \\
\text { gū 六所宮. } \\
\text { On emporte une boitte } \\
\text { à repas et on rapporte } \\
\text { les mets festifs du Jour } \\
\text { de l'an de la maison } \\
\text { des parents. }\end{array}$ \\
\hline
\end{tabular}




\begin{tabular}{|c|c|c|c|c|c|c|c|c|c|c|c|c|c|}
\hline 2 & $\begin{array}{l}\text { Tour du début de } \\
\text { l'année (visite des } \\
\text { voisins). } \\
\text { Premier rêve }\end{array}$ & & & 2 & $\begin{array}{l}\text { Visite chez } \\
\text { ses parents } \\
\text { (sato-gaeri } \\
\text { 里帰り) }\end{array}$ & 2 & $\begin{array}{l}\text { Visiteurs (enfants } \\
\text { et leur famille) }\end{array}$ & & & 2 & $\begin{array}{c}\text { Visite aux } \\
\text { parents (de } \\
\text { l'épouse). } \\
\text { Visite au sanc- } \\
\text { tuaire tutélaire } \\
\text { de la maison de } \\
\text { l'épouse et au } \\
\text { sanctuaire Taga } \\
\text { 多賀社 }\end{array}$ & 2 & Repos chez soi \\
\hline 3 & $\begin{array}{c}\text { Visite chez ses } \\
\text { parents (sato } \\
\text { aruki 里歩き) }\end{array}$ & & & & & 3 & $\begin{array}{c}\text { Célébration } \\
\text { au sanctuaire } \\
\text { (et réception : } \\
\text { anciennement } \\
\text { chez le respon- } \\
\text { sable du quartier, } \\
\text { actuellement } \\
\text { à la Maison } \\
\text { citoyenne) }\end{array}$ & & & & & 3 & $\begin{array}{c}\text { Visite au sanctuaire de } \\
\text { Munakata et autres. } \\
\text { Visite aux parents de } \\
\text { l'époux chez qui l'on } \\
\text { partage un repas à la } \\
\text { marmite }\end{array}$ \\
\hline 4 & $\begin{array}{c}\text { «Riz en bouillon } \\
\text { de la fortune » } \\
\text { (fuku-iri zoosui } \\
\text { 福入り雑炊) }\end{array}$ & & & & & & & & & & & & \\
\hline 7 & $\begin{array}{l}\text { Jour de l'an du } 7 \\
\text { (bouillon des } \\
7 \text { herbes). } \\
\text { Enlèvement de } \\
\text { l'apparat festif. } \\
\text { Feu rituel } \\
\text { (bokkengyō) }\end{array}$ & & & 7 & $\begin{array}{c}\text { Bouillon des } \\
7 \text { herbes (récent) }\end{array}$ & & & 7 & $\begin{array}{l}\text { Jour de l'an du } 7 \\
\text { (anciennement } \\
\text { sans aucun rite ; } \\
\text { aujourd'hui, } \\
\text { bouillon des } \\
7 \text { herbes) }\end{array}$ & 7 & $\begin{array}{c}\text { Bouillon des } \\
7 \text { herbes }\end{array}$ & 7 & $\begin{array}{c}\text { Bouillon des } 7 \text { herbes } \\
\text { (soir) }\end{array}$ \\
\hline & & 9 & $\begin{array}{l}\text { Veille d'Ebisu } \\
\text { (Yoi-Ebisu } \\
\text { 肖戎) : } \\
\text { pèlerinage au } \\
\text { sanctuaire Ebisu } \\
\text { (Hakata) }\end{array}$ & & & & & & & & & & \\
\hline
\end{tabular}




\begin{tabular}{|c|c|c|c|c|c|c|c|c|c|c|c|c|c|c|}
\hline & & & 10 & $\begin{array}{l}\text { «Ebisu du io } \\
\text { 十日戎. } \\
\text { Pèlerinage au } \\
\text { sanctuaire Ebisu } \\
\text { (enceinte du } \\
\text { sanctuaire Suwa, } \\
\text { Sasaguri) }\end{array}$ & 10 & $\begin{array}{c}\text { Premier Ebisu. } \\
\text { Loterie }\end{array}$ & & & & & & & Vers le 1o & $\begin{array}{c}\text { Ouverture } \\
\text { du mochi-miroir (dans } \\
\text { la Maison citoyenne } \\
\text { du quartier) }\end{array}$ \\
\hline & & & II & $\begin{array}{l}\text { «Ebisu restant » } \\
\text { 残り戎: pèleri- } \\
\text { nage à Daikoku } \\
\text { (Henshō-in } \\
\text { 遍照院). } \\
\text { Loterie. } \\
\text { Offrandes à la } \\
\text { statue d'Ebisu } \\
\text { dans le tokonoma }\end{array}$ & II & $\begin{array}{l}\text { Ouverture du } \\
\text { mochi-miroir. } \\
\text { Grand feu } \\
\text { «dondo yaki } \\
\text { (brûlage de } \\
\text { l'apparat festif) }\end{array}$ & & & & & II & $\begin{array}{l}\text { Ouverture du } \\
\text { mochi-miroir. } \\
\text { Hokkengyö (feu } \\
\text { pour brûler } \\
\text { l'apparat festif) }\end{array}$ & & \\
\hline & 15 & $\begin{array}{l}\text { "Petit Nouvel } \\
\text { An ( (riz aux } \\
\text { haricots rouges) }\end{array}$ & & & I5 & $\begin{array}{c}\text { Dondo yaki } \\
\text { au Köshō-in } \\
\text { 弘照院 }\end{array}$ & 15 & Riz aux haricots & 15 & $\begin{array}{c}\text { Dondo yaki } \\
\text { (récent). } \\
\text { Purification pour } \\
\text { les jeunes attei- } \\
\text { gnant la majorité } \\
\text { (20 ans) au sanc- } \\
\text { tuaire tutélaire } \\
\text { Goryō-gū }\end{array}$ & & & & \\
\hline & & & & & & & & $\begin{array}{l}\text { Premier Köshin } \\
\text { (confrérie de } \\
\text { Kōshin 庚申講) }\end{array}$ & & & & & & \\
\hline & $\begin{array}{c}\text { Ancien } \\
\text { Calen- } \\
\text { drier }\end{array}$ & $\begin{array}{c}\text { Ancien } \\
\text { Nouvel an } \\
\text { (reprise d'un an) }\end{array}$ & & & & & & & & & & & & \\
\hline Février & 3 & $\begin{array}{l}\text { Setsubun : jet de } \\
\text { haricots (récent) }\end{array}$ & 3 & $\begin{array}{l}\text { Setsubun : jet de } \\
\text { haricots (enfants) } \\
\text { (récent) }\end{array}$ & 3 & $\begin{array}{l}\text { Setsubun : jet de } \\
\text { haricots (enfants) } \\
\text { (récent) }\end{array}$ & 3 & $\begin{array}{l}\text { Setsubun : jet de } \\
\text { haricots. } \\
\text { On jette à la } \\
\text { rivière, dans } \\
\text { un papier, des } \\
\text { haricots en } \\
\text { nombre égal à } \\
\text { celui de son âge } \\
\text { de l'année }\end{array}$ & 3 & $\begin{array}{l}\text { Setsubun (ancien- } \\
\text { nement, aucun } \\
\text { rite ; maintenant, } \\
\text { jet de haricots) }\end{array}$ & 3 & $\begin{array}{l}\text { Setsubun : jet de } \\
\text { haricots }\end{array}$ & 3 & $\begin{array}{c}\text { Setsubun : jet de } \\
\text { haricots. } \\
\text { On mange autant } \\
\text { de haricots que l'on } \\
\text { compte d'années d'âge }\end{array}$ \\
\hline
\end{tabular}




\begin{tabular}{|c|c|c|c|c|c|c|c|c|c|c|c|c|c|c|}
\hline & & & & & & & & & & & & & 14 & $\begin{array}{c}\text { St Valentin. } \\
\text { Cadeau à son mari et à } \\
\text { son père }\end{array}$ \\
\hline \multirow[t]{4}{*}{ Mars } & & & $\begin{array}{l}\text { Ancien } \\
\text { calen- } \\
\text { drier }\end{array}$ & 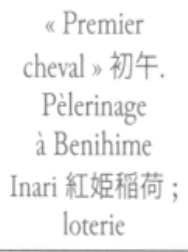 & & & & & & & & & & \\
\hline & & & & & & & & & & & 3 & $\begin{array}{c}\text { Fête des poupées } \\
\text { pour les filles } \\
\text { (tant que les } \\
\text { enfants sont } \\
\text { petits) }\end{array}$ & 3 & Fête des poupées \\
\hline & $\begin{array}{l}\text { Higan: } \\
\text { équi- } \\
\text { noxe } \\
\text { du } \\
\text { prin- } \\
\text { temps }\end{array}$ & $\begin{array}{l}\text { Higan (visite } \\
\text { aux tombes, } \\
\text { nettoyage } \\
\text { des tombes, } \\
\text { offrandes) }\end{array}$ & Higan & $\begin{array}{l}\text { Higan (visite } \\
\text { aux tombes, } \\
\text { nettoyage } \\
\text { des tombes, } \\
\text { offrandes; réci- } \\
\text { tation des sūtra } \\
\text { par le moine } \\
\text { devant l'autel } \\
\text { domestique) }\end{array}$ & Higan & $\begin{array}{l}\text { Visite au } \\
\text { columbarium; } \\
\text { offrandes de } \\
\text { mochi aux } \\
\text { haricots rouges. } \\
\text { Idem au temple }\end{array}$ & Higan & $\begin{array}{l}\text { Nettoyage du } \\
\text { columbarium } \\
\text { collectif } \\
\text { (par sections). } \\
\text { Visite aux } \\
\text { tombes }\end{array}$ & Higan & $\begin{array}{l}\text { Visite au temple } \\
\text { et aux tombes }\end{array}$ & Higan & $\begin{array}{l}\text { Visite aux } \\
\text { tombes } \\
\text { (à Akama 赤間 } \\
\text { dans la ville } \\
\text { de Munakata } \\
\text { 宗像市) }\end{array}$ & & \\
\hline & & & & & & & & $\begin{array}{c}\text { Réunion générale } \\
\text { des sections. } \\
\text { Réunion générale } \\
\text { du quartier }\end{array}$ & $\begin{array}{c}\text { Vacances } \\
\text { de prin- } \\
\text { temps }\end{array}$ & $\begin{array}{c}\text { Rassemblement } \\
\text { des diplômes } \\
\text { (menjö yori 免状 } \\
\text { 寄り) }\end{array}$ & & $\begin{array}{l}\text { Réunion générale } \\
\text { des sections. } \\
\text { Réunion générale } \\
\text { du quartier }\end{array}$ & & $\begin{array}{l}\text { Excursion pour } \\
\text { admirer les cerisiers } \\
\text { en fleurs organisée } \\
\text { par le Salon des mères } \\
\text { élevant des enfants }\end{array}$ \\
\hline \multirow[t]{2}{*}{ Avril } & & & & $\begin{array}{c}\text { Arrivée des } \\
\text { pèlerins sur le } \\
\text { circuit du Nou- } \\
\text { veau Shikoku de } \\
\text { Sasaguri }\end{array}$ & & & & & & & dimanche & $\begin{array}{c}\text { Okomori du } \\
\text { dieu des Grains } \\
\text { Gokoku-jin }\end{array}$ & & \\
\hline & & & & & & & $\begin{array}{c}3 \\
\text { (Ancien } \\
\text { calen- } \\
\text { drier) }\end{array}$ & Fête des poupées & & & & & $\begin{array}{l}\text { Milieu } \\
\text { avril }\end{array}$ & $\begin{array}{l}\text { Réunion générale } \\
\text { du quartier }\end{array}$ \\
\hline
\end{tabular}




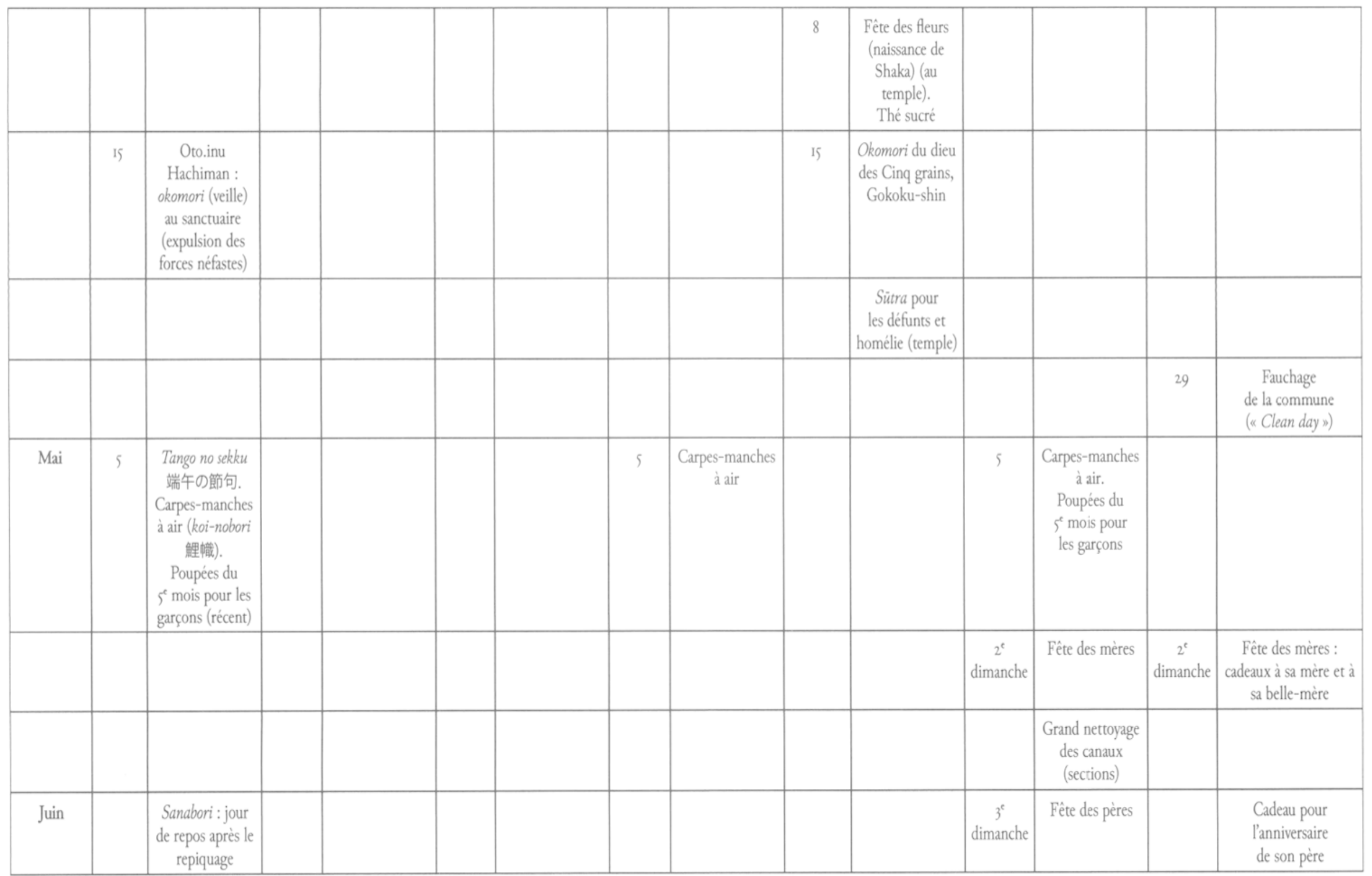




\begin{tabular}{|c|c|c|c|c|c|c|c|c|c|c|c|c|c|}
\hline & & & & & & & 20 & $\begin{array}{c}\text { Sanabori; } \\
\text { dobe-otoshi どべ } \\
\text { 落とし ("faire } \\
\text { tomber la boue } \\
\text { de ses bottes ", } \\
\text { pour signifier } \\
\text { que le repiquage } \\
\text { est fini) }\end{array}$ & & & & & $\begin{array}{l}\text { Chasse aux lucioles } \\
\text { (association } \\
\text { des parents } \\
\text { des écoles primaire } \\
\text { et secondaire) }\end{array}$ \\
\hline \multirow[t]{6}{*}{ Juillet } & & & & & & & & & & & $\begin{array}{c}\text { Okomori du } \\
\text { sanctuaire tuté- } \\
\text { laire Goryō-gū. } \\
\text { Purification pour } \\
\text { ceux qui sont à } \\
\text { un âge néfaste }\end{array}$ & & Fête de l'été (quartier) \\
\hline & & & & & & & & & & & $\begin{array}{c}\text { Grand nettoyage } \\
\text { (sections) }\end{array}$ & & \\
\hline & & & 6 & $\begin{array}{c}\text { Fête de } \\
\text { Gion 祇園祭: } \\
\text { portage des chars } \\
\text { et exercice de } \\
\text { portage des chars } \\
\text { (actuellement } \\
2^{e} \text { samedi du } \\
\text { mois). } \\
\text { Danse du lion }\end{array}$ & & & & & & & $\begin{array}{l}\text { Sumō sur la } \\
\text { berge de la } \\
\text { rivière }\end{array}$ & & \\
\hline & 7 & $\begin{array}{l}\text { Tanabata: } \\
\text { fête des étoiles } \\
\text { (récent) }\end{array}$ & & & 7 & $\begin{array}{l}\text { Tanabata. } \\
\text { Nettoyage des } \\
\text { tombes }\end{array}$ & 7 & $\begin{array}{l}\text { Tanabata. } \\
\text { Fête des jeux de } \\
\text { Wada (Maison } \\
\text { citoyenne) }\end{array}$ & & & & 7 & $\begin{array}{l}\text { Tanabata (Salon des } \\
\text { mères élevant des } \\
\text { enfants) }\end{array}$ \\
\hline & & & & $\begin{array}{l}\text { Sumō au sanc- } \\
\text { tuaire Taiso de } \\
\text { Wakasugi }\end{array}$ & & & & & & & & & \\
\hline & & & & & & & & & 15 & $\begin{array}{l}\text { Okomori au sanc- } \\
\text { tuaire tutélaire } \\
\text { Goryō-gū }\end{array}$ & & & \\
\hline
\end{tabular}




\begin{tabular}{|c|c|c|c|c|c|c|c|c|c|}
\hline & & & & & & $?$ & $\begin{array}{l}\text { Sumō sur la } \\
\text { berge de la } \\
\text { rivière }\end{array}$ & & \\
\hline & & & & & & 17 & $\begin{array}{c}\text { Célébration } \\
\text { de Kannon } \\
\text { O-Kannon sama } \\
\text { (section) }\end{array}$ & & \\
\hline \multirow[t]{6}{*}{ Août } & & & & & $\begin{array}{l}\text { Nettoyage du } \\
\text { columbarium } \\
\text { collectif } \\
\text { (sections) }\end{array}$ & & & $\begin{array}{l}\text { Danse du bon: } \\
\text { fête de l'été } \\
\text { (sections et } \\
\text { quartier) }\end{array}$ & $\begin{array}{c}\text { Retour dans sa famille } \\
\text { uniquement lorsqu'il } \\
\text { y a eu un décès dans } \\
\text { l'année }\end{array}$ \\
\hline & & & & & & & & $\begin{array}{l}\text { Nettoyage } \\
\text { de l'autel } \\
\text { bouddhique } \\
\text { domestique }\end{array}$ & \\
\hline & & & & & & 6 & $\begin{array}{l}\text { Nettoyage des } \\
\text { tombes (cime- } \\
\text { tière communal) }\end{array}$ & & \\
\hline & 10 & $\begin{array}{l}\text { Segaki: offrande } \\
\text { aux âmes } \\
\text { abandonnées }\end{array}$ & Fête de l'été & & & & & & \\
\hline & & $\begin{array}{c}\text { Nettoyage des } \\
\text { tombes }\end{array}$ & Danse du lion & $\begin{array}{l}\text { Échange de } \\
\text { cadeaux du bon }\end{array}$ & & & & & \\
\hline & & & & & & 12 & $\begin{array}{c}\text { Offrandes de } \\
\text { boulettes de riz } \\
\text { (jusqu'au is), } \\
\text { de fruits, de } \\
\text { friandises sèches } \\
\text { (rakugan 落晟), } \\
\text { de riz pour les } \\
\text { âmes (sur l'autel } \\
\text { bouddhique } \\
\text { domestique) }\end{array}$ & & \\
\hline
\end{tabular}




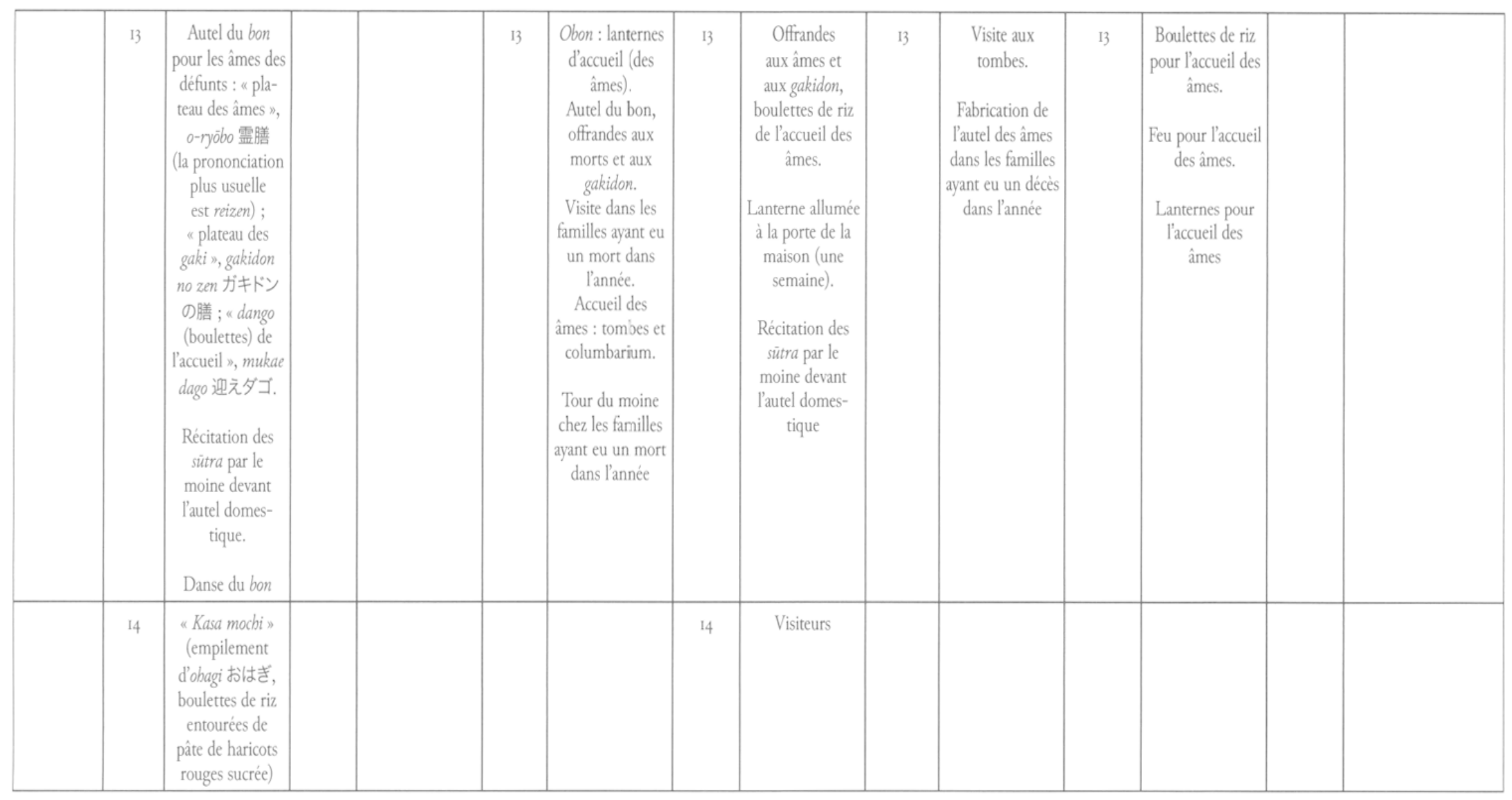




\begin{tabular}{|c|c|c|c|c|c|c|c|c|c|c|c|}
\hline & I5 & $\begin{array}{l}\text { Renvoi des âmes } \\
\text { «shörai okuri » } \\
\text { 精霊送り } \\
\text { (aux tombes, } \\
\text { à la rivière) }\end{array}$ & & & 15 & $\begin{array}{c}\text { Boulettes de riz } \\
\text { du renvoi des } \\
\text { âmes. } \\
\text { Tour des } \\
6 \text { maisons de la } \\
\text { famille A. par } \\
\text { les } 6 \text { maittres de } \\
\text { maison. } \\
\text { Tir à la corde } \\
\text { du bon et mise } \\
\text { de la corde à la } \\
\text { rivière. } \\
\text { Renvoi des âmes } \\
\text { au columbarium } \\
\text { avec de l'encens } \\
\text { allumé }\end{array}$ & & & 15 & $\begin{array}{l}\text { Offrandes aux } \\
\text { gaki qui sont } \\
\text { récupéreies par le } \\
\text { parc de Sasaguri. } \\
\text { Boulettes de riz } \\
\text { pour le renvoi } \\
\text { des àmes }\end{array}$ & \\
\hline & $16-18$ & $\begin{array}{l}\text { Boulettes de riz } \\
\text { («shiro dago») }\end{array}$ & & & & & & & & & \\
\hline \multirow[t]{2}{*}{ Septembre } & $\begin{array}{l}\text { Higan } \\
\text { (équi- } \\
\text { noxe } \\
\text { d'au- } \\
\text { tomne) }\end{array}$ & $\begin{array}{l}\text { Visite aux } \\
\text { tombes, } \\
\text { nettoyage } \\
\text { des tombes, } \\
\text { offrandes }\end{array}$ & & & & $\begin{array}{l}\text { Réunion en } \\
\text { l'honneur des } \\
\text { Anciens du } \\
\text { quartier }\end{array}$ & Higan & $\begin{array}{l}\text { Visite au temple } \\
\text { et aux tombes }\end{array}$ & & $\begin{array}{l}\text { Grande fête du } \\
\text { sport. } \\
\text { Réunion en } \\
\text { l'honneur des } \\
\text { Anciens du } \\
\text { quartier }\end{array}$ & \\
\hline & & & 15 & $\begin{array}{c}\text { Puisage de } \\
\text { l'eau (quartier) } \\
\text { au sanctuaire } \\
\text { Hakozaki 管崎宮 } \\
\text { à Fukuoka }\end{array}$ & & & & & & & \\
\hline \multirow[t]{3}{*}{ Octobre } & & & & & & $\begin{array}{c}\text { Concours de } \\
\text { base-ball }\end{array}$ & & & & & Halloween (quartier) \\
\hline & & & & & & & 9 & $\begin{array}{l}\text { Okuncbi (au } \\
\text { Goryō-gū) }\end{array}$ & & & \\
\hline & & & & & & & & $\begin{array}{l}\text { Sütra pour } \\
\text { les défunts } \\
\text { (au temple) }\end{array}$ & & & \\
\hline
\end{tabular}




\begin{tabular}{|c|c|c|c|c|c|c|c|c|c|c|}
\hline & 17 & $\begin{array}{c}\text { Okuncbi (fête des } \\
\text { moissons) sanc- } \\
\text { tuaire d'Oto.inu } \\
\text { Hachiman (danse } \\
\text { du lion ; sur } \\
\text { l'autel des dieux : } \\
\text { mochi à la pâte de } \\
\text { haricots rouges) }\end{array}$ & & & 17 & $\begin{array}{l}\text { Okuncbi par le } \\
\text { responsable du } \\
\text { miyaza 宮座 } \\
\text { (groupe chargé } \\
\text { des services aux } \\
\text { sanctuaires) }\end{array}$ & & & & \\
\hline \multirow[t]{3}{*}{ Novembre } & 12 & $\begin{array}{c}\text { Fête de Yakushi } \\
\text { (Grand feu) }\end{array}$ & & & & & 15 & $\begin{array}{l}\text { Rite des enfants } \\
\text { de Sept, Cinq, } \\
\text { Trois (ans) } \\
\text { (disparu) }\end{array}$ & & \\
\hline & & & & & 28 & $\begin{array}{l}\text { Ojüya お十夜 } \\
\text { "dix soirs » } \\
\text { (récitation du } \\
\text { nenbutsu le soir, } \\
\text { jusqu'au 30) }\end{array}$ & & & & $\begin{array}{c}\text { Préparatifs pour les } \\
\text { illuminations }\end{array}$ \\
\hline & & & & & $\begin{array}{c}\text { Fin du } \\
\text { mois }\end{array}$ & $\begin{array}{c}\text { Réunion de } \\
\text { l'amicale (Mino- } \\
\text { ru-kai) }\end{array}$ & & & $\begin{array}{l}\text { Écriture des } \\
\text { cartes de vœux }\end{array}$ & $\begin{array}{c}\text { Écriture des cartes } \\
\text { de vœeux }\end{array}$ \\
\hline \multirow[t]{3}{*}{ Décembre } & & $\begin{array}{l}\text { Rite pour la } \\
\text { maison (yagitō) } \\
\text { Fête des étoiles } \\
\text { (boshi matsuri } \\
\quad \text { 星祭) }\end{array}$ & & & & & $\begin{array}{l}\text { Milieu } \\
\text { du mois }\end{array}$ & $\begin{array}{c}\text { Distribution } \\
\text { des amulettes } \\
\text { (o-fuda お札) de } \\
\text { protection du } \\
\text { Goryō-gū par le } \\
\text { représentant des } \\
\text { ujiko }\end{array}$ & & \\
\hline & & & & & & & & $\begin{array}{c}\text { Höon-kōo 報恩講, } \\
\text { réunion de } \\
\text { gratitude (au } \\
\text { temple) : } \\
\text { célébration en } \\
\text { l'honneur de } \\
\text { Shinran 親䉆, } \\
\text { fondateur de } \\
\text { Jödo Shin-shū } \\
\end{array}$ & & \\
\hline & 24 & $\begin{array}{l}\text { Christmas } \\
\text { (récent) }\end{array}$ & 24 & $\begin{array}{c}\text { Christmas } \\
\text { (enfants) (récent) }\end{array}$ & & & & & Christmas & Christmas \\
\hline
\end{tabular}


总

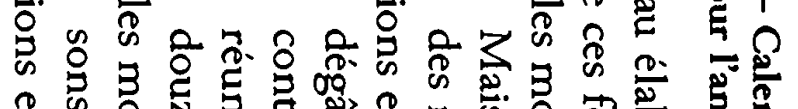
劳

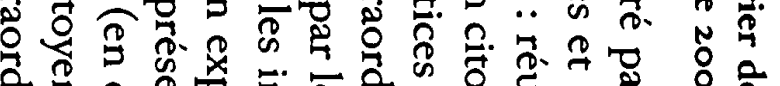

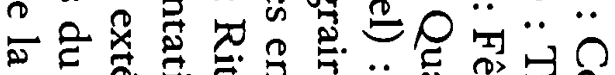

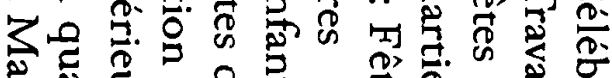

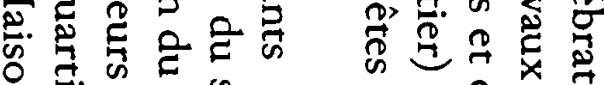

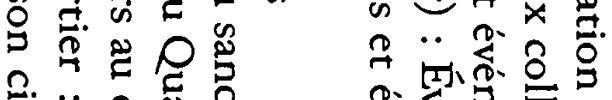

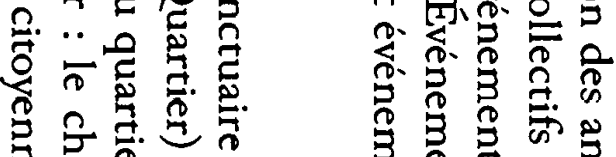

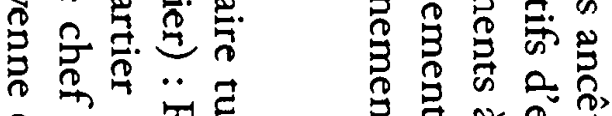

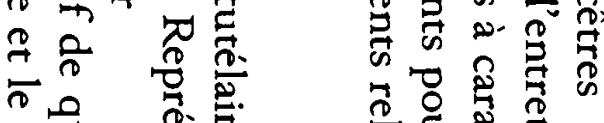

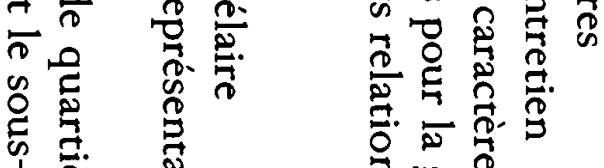
क.

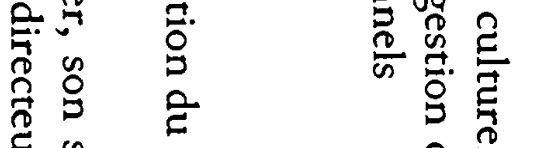
ริ) 娄 蛋

5)

$\div \overline{0}$

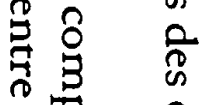
这蓠蓠

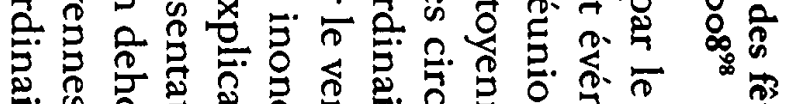

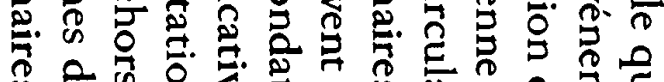

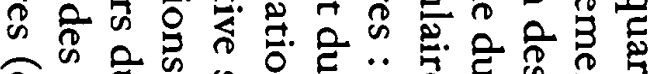

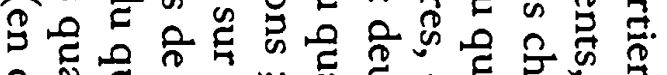

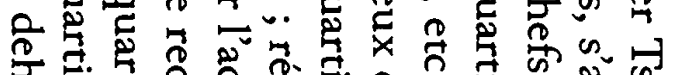

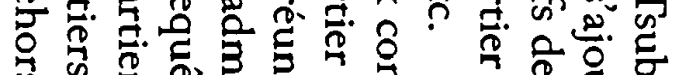

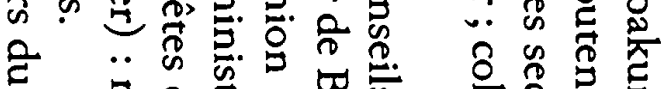
कर 20 必

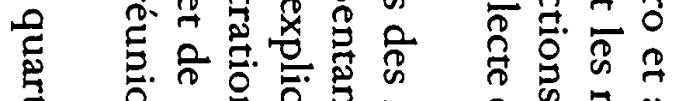
त.

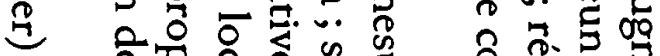
$\therefore$ के

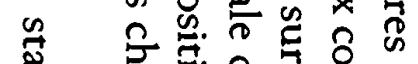

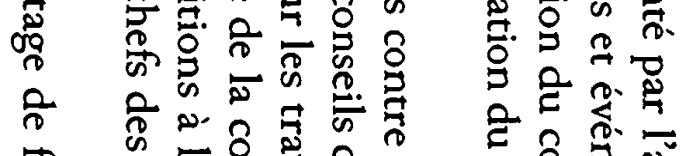

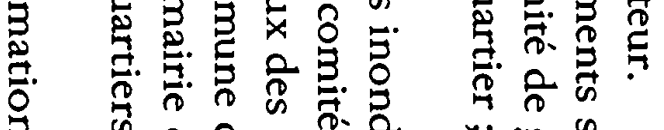
के की के ठी

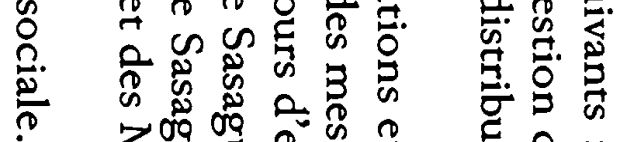

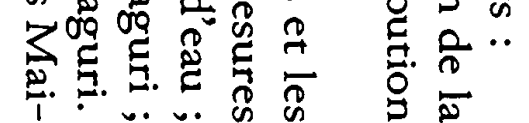

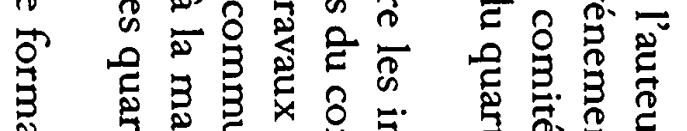




\begin{tabular}{|c|c|c|c|c|c|}
\hline $11 / 04$ & $\begin{array}{c}\text { Réunions des nou- } \\
\text { veaux responsables } \\
\text { de sections }\end{array}$ & GQ & $\begin{array}{l}\text { Maison } \\
\text { citoyenne }\end{array}$ & Quartier & $\begin{array}{l}\text { Responsables du quartier, } \\
\text { membres des sections }\end{array}$ \\
\hline $12 / 04$ & $\begin{array}{c}\text { Okomori (veille) du } \\
\text { dieu des Cinq grains } \\
\text { (Gokoku-shin) }\end{array}$ & $\mathrm{RA}$ & $\begin{array}{l}\text { Devant la } \\
\text { stèle du } \\
\text { Goku-shin }\end{array}$ & Quartier & $\begin{array}{c}\text { Responsables du quartier, } \\
\text { les habitants }\end{array}$ \\
\hline $15 / 04$ & $\begin{array}{c}\text { Fête de printemps } \\
\text { du sanctuaire tuté- } \\
\text { laire Goryō-gū }\end{array}$ & $\mathrm{U}$ & $\begin{array}{l}\text { Enceinte du } \\
\text { sanctuaire }\end{array}$ & Quartier & $\begin{array}{l}\text { Représentants de la } \\
\text { communauté du sanc- } \\
\text { tuaire, responsables du } \\
\text { quartier }\end{array}$ \\
\hline $09 / 05$ & $\mathrm{I}^{\mathrm{er}}$ « salon-vitalité » & $\mathrm{R}$ & $\begin{array}{c}\text { Maison } \\
\text { citoyenne }\end{array}$ & Quartier & $\begin{array}{c}\text { Les personnes âgées } \\
\text { du quartier }\end{array}$ \\
\hline $14 / 05$ & $\begin{array}{l}\text { Réunion de travail } \\
\text { collectif pour les } \\
\text { responsables du } \\
\text { quartier }\end{array}$ & RQ & $\begin{array}{l}\text { Kuri.eito } \\
(\text { (Create ») } \\
\text { Sasaguri }\end{array}$ & $\begin{array}{l}\text { Commune de } \\
\text { Sasaguri }\end{array}$ & $\begin{array}{l}\text { Directeurs des Maisons } \\
\text { citoyennes des quartiers }\end{array}$ \\
\hline $24 / 05$ & $\begin{array}{l}\text { Fête du sport du } \\
\text { collège }\end{array}$ & RQ & $\begin{array}{c}\text { Collège de } \\
\text { Sasaguri Nord }\end{array}$ & Collège & Responsables du quartier \\
\hline $28 / 05$ & $\begin{array}{l}\text { Vérification des } \\
\text { liaisons radio de } \\
\text { prévention contre } \\
\text { les aléas naturels }\end{array}$ & $\mathrm{E}$ & $\begin{array}{l}\text { Maison } \\
\text { citoyenne }\end{array}$ & Quartier & Responsables du quartier \\
\hline $31 / 05$ & $\begin{array}{l}\text { Grand nettoyage } \\
\text { des canaux et } \\
\text { rigoles du quartier }\end{array}$ & $\mathrm{E}$ & $\begin{array}{c}\text { Dans tout le } \\
\text { quartier }\end{array}$ & Quartier & $\begin{array}{c}\text { Responsables du quartier, } \\
\text { les habitants }\end{array}$ \\
\hline $06 / 06$ & $2^{\mathrm{c}}$ « salon-vitalité » & $\mathrm{R}$ & $\begin{array}{l}\text { Maison } \\
\text { citoyenne }\end{array}$ & Quartier & $\begin{array}{c}\text { Les personnes âgées } \\
\text { du quartier }\end{array}$ \\
\hline $07 / 06$ & Tournoi de softball & $\mathrm{C}$ & $\begin{array}{c}\text { Collège de } \\
\text { Sasaguri Nord }\end{array}$ & $\begin{array}{l}\text { Maison } \\
\text { citoyenne }\end{array}$ & $\begin{array}{c}\text { Responsables du quartier, } \\
6 \text { équipes }\end{array}$ \\
\hline $28 / 06$ & $\begin{array}{l}\text { Grand rassem- } \\
\text { blement pour } \\
\text { le maniement } \\
\text { des pompes des } \\
\text { sapeurs-pompiers }\end{array}$ & $\mathrm{E}$ & $\begin{array}{l}\text { Caserne } \\
\text { centrale des } \\
\text { sapeurs- } \\
\text { pompiers de } \\
\text { Kasuya }\end{array}$ & $\begin{array}{l}\text { Sapeurs-pom- } \\
\text { piers }\end{array}$ & Responsables du quartier \\
\hline $05 / 07$ & $\begin{array}{c}\text { Sumō sur la berge } \\
\text { de la rivière }\end{array}$ & RE & $\begin{array}{c}\text { Place de la } \\
\text { Santé }\end{array}$ & $\begin{array}{l}\text { Comité édu- } \\
\text { catif }\end{array}$ & $\begin{array}{l}\text { Responsables du quartier, } \\
\text { les habitants du quartier }\end{array}$ \\
\hline $12 / 07$ & $\begin{array}{l}\text { Okomori du sanc- } \\
\text { tuaire Goryō-gū }\end{array}$ & $\mathrm{U}$ & $\begin{array}{l}\text { Enceinte du } \\
\text { sanctuaire }\end{array}$ & Quartier & Les habitants du quartier \\
\hline $12 / 07$ & $\begin{array}{l}\text { Comité exécutif } \\
\text { pour la fête de l'été }\end{array}$ & GQ & $\begin{array}{l}\text { Maison } \\
\text { citoyenne }\end{array}$ & $\begin{array}{l}\text { Maison } \\
\text { citoyenne }\end{array}$ & $\begin{array}{l}\text { Responsables du quar- } \\
\text { tier, le comité éducatif }\end{array}$ \\
\hline $13 / 07$ & $3^{\mathrm{e}}$ « salon-vitalité » & $\mathrm{R}$ & $\begin{array}{l}\text { Maison } \\
\text { citoyenne }\end{array}$ & Quartier & $\begin{array}{l}\text { Les personnes âgées du } \\
\text { quartier }\end{array}$ \\
\hline
\end{tabular}




\begin{tabular}{|c|c|c|c|c|c|}
\hline $19 / 07$ & $\begin{array}{c}\text { Grand nettoyage } \\
\text { de l'été }\end{array}$ & $\mathrm{E}$ & $\begin{array}{l}\text { Maison } \\
\text { citoyenne, } \\
\text { salle de } \\
\text { réunion }\end{array}$ & Quartier & $\begin{array}{l}\text { Responsables du quartier, } \\
\text { les habitants du quartier }\end{array}$ \\
\hline $25 / 07$ & $\begin{array}{l}\text { Répétitions pour } \\
\text { la fête de l'été et } \\
\text { les danses }\end{array}$ & GQ & $\begin{array}{l}\text { Maison } \\
\text { citoyenne }\end{array}$ & $\begin{array}{l}\text { Maison } \\
\text { citoyenne }\end{array}$ & $\begin{array}{l}\text { Responsables du quartier, } \\
\text { les habitants du quartier }\end{array}$ \\
\hline $01 / 08$ & $\begin{array}{l}\text { Fête de l'été } \\
\text { du quartier } \\
\text { (danse du bon) }\end{array}$ & $A, R$ & $\begin{array}{l}\text { Place devant } \\
\text { la Maison } \\
\text { citoyenne }\end{array}$ & $\begin{array}{l}\text { Quartier, } \\
\text { Maison } \\
\text { citoyenne }\end{array}$ & $\begin{array}{l}\text { Responsables du quartier, } \\
\text { le comité éducatif, les } \\
\text { habitants du quartier } \\
\text { ( } 550 \text { personnes) }\end{array}$ \\
\hline $07 / 08$ & $4^{\mathrm{e}}$ « salon-vitalité » & $\mathrm{R}$ & $\begin{array}{l}\text { Maison } \\
\text { citoyenne }\end{array}$ & Quartier & $\begin{array}{l}\text { Les personnes âgées } \\
\text { du quartier }\end{array}$ \\
\hline $10 / 08$ & $\begin{array}{l}\text { Visites aux familles } \\
\text { ayant eu un décès } \\
\text { dans l'année }\end{array}$ & $A, R$ & II foyers & $\begin{array}{l}\text { Maisons } \\
\text { célébrant le } \mathrm{I}^{\mathrm{er}} \\
\text { bon (après le } \\
\text { décès) }\end{array}$ & $\begin{array}{c}\text { Les } 3 \text { responsables } \\
\text { du quartier, le directeur } \\
\text { de la Maison citoyenne }\end{array}$ \\
\hline $05 / 09$ & $\begin{array}{l}\text { Comité pour la fête } \\
\text { en l'honneur des } \\
\text { personnes âgées }\end{array}$ & GQ & $\begin{array}{l}\text { Maison } \\
\text { citoyenne }\end{array}$ & $\begin{array}{l}\text { Comité, } \\
\text { quartier }\end{array}$ & $\begin{array}{l}\text { Les } 3 \text { responsables du } \\
\text { quartier, le directeur de } \\
\text { la Maison citoyenne, } \\
\text { les chefs de sections, } \\
\text { photographes }\end{array}$ \\
\hline $07 / 09$ & $5^{\mathrm{e}}$ " salon-vitalité » & $\mathrm{R}$ & $\begin{array}{l}\text { Maison } \\
\text { citoyenne }\end{array}$ & Quartier & $\begin{array}{c}\text { Les personnes âgées } \\
\text { du quartier }\end{array}$ \\
\hline $13 / 09$ & $\begin{array}{l}\text { Grand tournoi } \\
\text { de golf }\end{array}$ & RQ & $\begin{array}{l}\text { Collège de } \\
\text { Sasaguri } \\
\text { Nord }\end{array}$ & $\begin{array}{l}\text { Maison } \\
\text { citoyenne }\end{array}$ & $\begin{array}{l}\text { Responsables du quartier, } \\
\text { I84 concurrents, } \\
65 \text { supporters }\end{array}$ \\
\hline $17 / 09$ & \begin{tabular}{|c} 
Réunion explicative \\
sur la télévision \\
digitale
\end{tabular} & $\mathrm{E}$ & $\begin{array}{l}\text { Maison } \\
\text { citoyenne }\end{array}$ & Quartier & $\begin{array}{l}\text { Responsables du quartier, } \\
\text { les habitants du quartier }\end{array}$ \\
\hline $19 / 09$ & $\begin{array}{c}\text { Fête en l'honneur } \\
\text { des personnes } \\
\text { âgées de Tsubakuro }\end{array}$ & $\mathrm{R}$ & $\begin{array}{l}\text { Parc Fukusei } \\
\text { 福生園 }\end{array}$ & Quartier & $\begin{array}{c}\text { Responsables du quartier, } \\
63 \text { personnes âgées du } \\
\text { quartier }\end{array}$ \\
\hline $04 / 10$ & $\begin{array}{l}\text { Fête du sport de } \\
\text { l'école primaire }\end{array}$ & RQ & $\begin{array}{l}\text { École primaire } \\
\text { de Seto-Nord }\end{array}$ & École primaire & Responsables du quartier \\
\hline $\mathrm{II} / \mathrm{IO}$ & $\begin{array}{l}\text { Grand tournoi } \\
\text { communal de sumō } \\
\text { d'automne }\end{array}$ & RQ & $\begin{array}{l}\text { Sanctuaire } \\
\text { Suwa }\end{array}$ & $\begin{array}{l}\text { Club de sumō } \\
\text { de Sasaguri }\end{array}$ & $\begin{array}{l}\text { Comité éducatif, } \\
\text { concurrents }\end{array}$ \\
\hline $15 / 10$ & $6^{\mathrm{e}}$ «salon-vitalité » & $\mathrm{R}$ & $\begin{array}{l}\text { Maison } \\
\text { citoyenne }\end{array}$ & Quartier & $\begin{array}{c}\text { Les personnes âgées du } \\
\text { quartier }\end{array}$ \\
\hline $17 / 10$ & $\begin{array}{c}\text { Fête d'automne } \\
\text { du sanctuaire } \\
\text { Goryō-gū }\end{array}$ & $\mathrm{U}$ & $\begin{array}{l}\text { Enceinte du } \\
\text { sanctuaire }\end{array}$ & Quartier & $\begin{array}{c}\text { Représentants de la } \\
\text { communauté du sanc- } \\
\text { tuaire, les } 3 \text { responsables } \\
\text { du quartier }\end{array}$ \\
\hline
\end{tabular}




\begin{tabular}{|c|c|c|c|c|c|}
\hline $22 / 10$ & $\begin{array}{l}\text { Vérification des } \\
\text { liaisons radio de } \\
\text { prévention contre } \\
\text { les aléas naturels }\end{array}$ & $\mathrm{E}$ & $\begin{array}{l}\text { Maison } \\
\text { citoyenne }\end{array}$ & Quartier & Responsables du quartier \\
\hline $26 / 10$ & $\begin{array}{c}\text { Fête de la culture } \\
\text { de la commune de } \\
\text { Sasaguri }\end{array}$ & RQ & $\begin{array}{l}\text { Kuri.eito } \\
\text { Sasaguri }\end{array}$ & Commune & Représentants du quartier \\
\hline OI/II & $\begin{array}{l}\text { Sasa-olympic } \\
\text { (shuffleboard) }\end{array}$ & RQ & $\begin{array}{l}\text { Gymnase } \\
\text { commémo- } \\
\text { ratif }\end{array}$ & Commune & Concurrents \\
\hline O8/II & $\begin{array}{l}\text { Sapeurs-pompiers : } \\
\text { rassemblement } \\
\text { d'urgence }\end{array}$ & $\mathrm{E}$ & Lieu inconnu & $\begin{array}{l}\text { Sapeurs-pom- } \\
\text { piers }\end{array}$ & $\begin{array}{l}\text { Responsables du quartier, } \\
\text { sapeurs-pompiers }\end{array}$ \\
\hline $16 / 11$ & $\begin{array}{l}7^{\mathrm{e}} \text { « salon-vitalité } " \\
\text { (excursion en car) }\end{array}$ & $\mathrm{R}$ & $\begin{array}{l}\text { Maison } \\
\text { citoyenne }\end{array}$ & Quartier & $\begin{array}{c}\text { Les personnes âgées } \\
\text { du quartier }\end{array}$ \\
\hline $2 I / I I$ & $\begin{array}{l}\text { Stage de la succur- } \\
\text { sale de Tsubakuro } \\
\text { pour la promotion } \\
\text { de l'éducation saine } \\
\text { des adolescents et } \\
\text { des enfants }\end{array}$ & GQ & $\begin{array}{l}\text { Maison } \\
\text { citoyenne }\end{array}$ & Quartier & Responsables du quartier \\
\hline $28 / 11$ & $\begin{array}{c}\text { Réunion commune } \\
\text { du comité consul- } \\
\text { tatif et du comité } \\
\text { de sélection }\end{array}$ & GQ & $\begin{array}{l}\text { Maison } \\
\text { citoyenne }\end{array}$ & Quartier & $\begin{array}{l}\text { Responsables du quartier, } \\
\text { membres des comités }\end{array}$ \\
\hline $13 / 12$ & $\begin{array}{c}\text { Grand nettoyage } \\
\text { d'hiver }\end{array}$ & $\mathrm{E}$ & $\begin{array}{l}\text { Maison } \\
\text { citoyenne, } \\
\text { salle de } \\
\text { réunion }\end{array}$ & Quartier & $\begin{array}{l}\text { Responsables du quartier, } \\
\text { les habitants du quartier }\end{array}$ \\
\hline $13 / 12$ & $\begin{array}{l}\text { Stage de la succur- } \\
\text { sale de l'école de } \\
\text { Seto-Nord pour } \\
\text { la promotion de } \\
\text { l'éducation saine } \\
\text { des adolescents et } \\
\text { des enfants }\end{array}$ & RQ & $\begin{array}{l}\text { Kuri.eito } \\
\text { Sasaguri }\end{array}$ & $\begin{array}{l}\text { Quartier } \\
\text { Wada: } \\
\text { responsable } \\
\text { de l'année }\end{array}$ & $\begin{array}{l}\text { Directeurs des Maisons } \\
\text { citoyennes du quartier } \\
\text { de l'école de Seto-Nord }\end{array}$ \\
\hline $18 / 12$ & $\begin{array}{l}8^{\mathrm{e}} \text { « salon-vitalité » } \\
\text { (réunion de Noël) }\end{array}$ & $\mathrm{R}$ & $\begin{array}{l}\text { Maison } \\
\text { citoyenne }\end{array}$ & Quartier & $\begin{array}{l}\text { Les personnes âgées } \\
\text { du quartier }\end{array}$ \\
\hline $20 / 12$ & $\begin{array}{l}\text { Préparatifs } \\
\text { pour le hokkengyō } \\
\text { (grand feu rituel } \\
\text { du Nouvel An) }\end{array}$ & GQ & $\begin{array}{l}\text { Place de la } \\
\text { Santé }\end{array}$ & $\begin{array}{l}\text { Maison } \\
\text { citoyenne }\end{array}$ & Responsables du quartier \\
\hline
\end{tabular}




\begin{tabular}{|c|c|c|c|c|c|}
\hline $31 / 12$ & $\begin{array}{l}\text { Préparatifs pour } \\
\text { les visites du } \\
\text { Premier de l'an } \\
\text { au sanctuaire } \\
\text { Goryō-gū }\end{array}$ & GQ & $\begin{array}{l}\text { Enceinte du } \\
\text { sanctuaire }\end{array}$ & $\begin{array}{l}\text { Représentants } \\
\text { de la com- } \\
\text { munauté du } \\
\text { sanctuaire, et } \\
\text { du quartier }\end{array}$ & $\begin{array}{c}\text { Représentants } \\
\text { de la communauté du } \\
\text { sanctuaire, responsables } \\
\text { du quartier }\end{array}$ \\
\hline OI/OI & $\begin{array}{l}\text { Pèlerinage du } \mathrm{I}^{\mathrm{er}} \mathrm{de} \\
\text { l'an au sanctuaire } \\
\text { Goryō-gū ; fête du } \\
\text { Nouvel An }\end{array}$ & $\mathrm{U}$ & $\begin{array}{l}\text { Enceinte du } \\
\text { sanctuaire }\end{array}$ & $\begin{array}{l}\text { Représentants } \\
\text { de la com- } \\
\text { munauté du } \\
\text { sanctuaire, et } \\
\text { du quartier } \\
\end{array}$ & $\begin{array}{c}\text { Représentants } \\
\text { de la communauté du } \\
\text { sanctuaire, responsables } \\
\text { du quartier, les habitants } \\
\text { du quartier }\end{array}$ \\
\hline Io/OI & $\begin{array}{l}\text { Cérémonie de } \mathrm{I}^{\mathrm{re}} \\
\text { sortie des sapeurs- } \\
\text { pompiers }\end{array}$ & $\mathrm{E}$ & $\begin{array}{l}\text { Caserne } \\
\text { centrale des } \\
\text { sapeurs- } \\
\text { pompiers de } \\
\text { Kasuya }\end{array}$ & $\begin{array}{l}\text { Direction } \\
\text { de la caserne } \\
\text { centrale } \\
\text { des sapeurs- } \\
\text { pompiers }\end{array}$ & $\begin{array}{l}\text { Responsables du quartier, } \\
\text { sapeurs-pompiers }\end{array}$ \\
\hline IO/OI & $\begin{array}{l}\text { Cérémonie de } \\
\text { l'arrivée à l'âge } \\
\text { adulte }\end{array}$ & RQ & $\begin{array}{l}\text { Kuri.eito } \\
\text { Sasaguri }\end{array}$ & Commune & $\begin{array}{c}\text { Responsables du quartier, } \\
\text { jeunes du quartier ayant } \\
\text { atteint la majorité }\end{array}$ \\
\hline IO/OI & $\begin{array}{l}\text { Hokkengyō (grand } \\
\text { feu rituel du Nou- } \\
\text { vel An) }\end{array}$ & $\mathrm{RE}$ & $\begin{array}{l}\text { Place de la } \\
\text { Santé }\end{array}$ & $\begin{array}{l}\text { Maison } \\
\text { citoyenne }\end{array}$ & $\begin{array}{l}\text { Responsables du quartier, } \\
\text { comité éducatif, } \\
\text { I20 habitants du quartier }\end{array}$ \\
\hline $17 / 01$ & $\begin{array}{l}\text { Grand tournoi com- } \\
\text { munal de karaoké }\end{array}$ & RQ & $\begin{array}{l}\text { Kuri.eito } \\
\text { Sasaguri }\end{array}$ & Commune & $\begin{array}{c}\text { Responsables du quartier, } \\
\text { volontaires }\end{array}$ \\
\hline $05 / 02$ & $9^{\mathrm{e}} \ll$ salon-vitalité $»$ & $\mathrm{R}$ & $\begin{array}{l}\text { Maison } \\
\text { citoyenne }\end{array}$ & & $\begin{array}{c}\text { Les personnes âgées } \\
\text { du quartier }\end{array}$ \\
\hline $05 / 03$ & $10^{\mathrm{e}}$ 《salon-vitalité » & $\mathrm{R}$ & $\begin{array}{l}\text { Maison } \\
\text { citoyenne }\end{array}$ & Quartier & $\begin{array}{l}\text { Les personnes âgées } \\
\text { du quartier }\end{array}$ \\
\hline $07 / 03$ & Comité consultatif & GQ & $\begin{array}{l}\text { Maison } \\
\text { citoyenne }\end{array}$ & & $\begin{array}{c}\text { Responsables du quartier, } \\
\text { membres du comité }\end{array}$ \\
\hline $07 / 03$ & $\begin{array}{l}\text { Sapeurs-pompiers : } \\
\text { rassemblement } \\
\text { d'urgence }\end{array}$ & $\mathrm{E}$ & & $\begin{array}{l}\text { Sapeurs-pom- } \\
\text { piers }\end{array}$ & $\begin{array}{c}\text { Responsables du quartier, } \\
\text { sapeurs-pompiers }\end{array}$ \\
\hline $14 / 03$ & $\begin{array}{l}\text { Contrôle de la } \\
\text { comptabilité (quar- } \\
\text { tier, sanctuaire, } \\
\text { Maison citoyenne) }\end{array}$ & GQ & $\begin{array}{l}\text { Maison } \\
\text { citoyenne }\end{array}$ & Quartier & $\begin{array}{c}\text { Représentants de la } \\
\text { communauté du } \\
\text { sanctuaire, responsables } \\
\text { du quartier }\end{array}$ \\
\hline $20 / 03$ & $\begin{array}{l}\text { Réunion exception- } \\
\text { nelle des chefs de } \\
\text { sections (préparatifs } \\
\text { des documents pour } \\
\text { la réunion annuelle) }\end{array}$ & GQ & $\begin{array}{l}\text { Maison } \\
\text { citoyenne }\end{array}$ & Quartier & $\begin{array}{l}\text { Responsables du quartier, } \\
\text { chefs de sections }\end{array}$ \\
\hline $28 / 03$ & $\begin{array}{l}\text { Réunion annuelle } \\
\text { du quartier }\end{array}$ & GQ & $\begin{array}{l}\text { Maison } \\
\text { citoyenne }\end{array}$ & Quartier & $\begin{array}{c}\text { Responsables du quartier, } \\
\text { chefs de sections, } \\
\text { habitants du quartier }\end{array}$ \\
\hline
\end{tabular}




\section{Résumé en japonais/日本語要旨}

変わり行くイエ並びに地域其同体の年中行事一一共同生活の場のウチとソト

家を取り巻くソトは、地域共同体(区、組)であり、篠栗町はこれらで糊成されている。この篠栗町の 事例をあげながら、場所、主催者、目的の3基準をもつて年中行事を分析し、家と地域共同体の継続・ 変化とウチとソトという時空、二重の力学を考える。また、新四国整場を有する篠栗町のソトからやっ てくる巡礼者の影響もある。家のウチで行う行事は「ケ」から「ハレ」に変換する装㯰の変化により、行 事主催者・行事目的の変化を促した。これらを考察することで現代家族の有りようが見えてくる。そこ には女性の関与が大きい。また、地域行事はイエごとに関わる集団の连いから、各イエの行事が多様 化している。中でも、家のウチに入って来る行事では、特に女性の負担が大きく、行事や集団の継承存 続の行方を女性が握っており、継承仔続への上夫を様々に行っている。 